Portland State University

PDXScholar

Spring 6-6-2019

\title{
Family Linked Workplace Resources and Contextual Factors as Important Predictors of Job and Individual Well-being for Employees and Families
}

Jacquelyn Marie Brady

Portland State University

Follow this and additional works at: https://pdxscholar.library.pdx.edu/open_access_etds

Part of the Psychology Commons

Let us know how access to this document benefits you.

\section{Recommended Citation}

Brady, Jacquelyn Marie, "Family Linked Workplace Resources and Contextual Factors as Important Predictors of Job and Individual Well-being for Employees and Families" (2019). Dissertations and Theses. Paper 5010.

https://doi.org/10.15760/etd.6886

This Dissertation is brought to you for free and open access. It has been accepted for inclusion in Dissertations and Theses by an authorized administrator of PDXScholar. Please contact us if we can make this document more accessible: pdxscholar@pdx.edu. 
Family Linked Workplace Resources and Contextual Factors as Important Predictors of Job and Individual Well-being for Employees and Families

by

Jacquelyn Marie Brady

A dissertation submitted in partial fulfillment of the requirements for the degree of

Doctor of Philosophy

in

Applied Psychology

Dissertation Committee:

Leslie Hammer, Chair

Todd E. Bodner

Cynthia D. Mohr

Jennifer K. Dimoff

Julia Goodman

Portland State University

2019 
(C) 2019 Jacquelyn Marie Brady 


\begin{abstract}
The inextricable ties between work and family have been extensively studied, however, with both societal and organizational change there is a continuing need for organizational research to elucidate the effects work can have on family, individual, and job well-being. Through three studies, this body of work demonstrates the role of supervisors, psychological contextual factors, and workplace work-family resources for improving employee and spouse family well-being and employee psychological and job well-being. This dissertation drew upon data from the Study for Employment Retention of Veterans (SERVe) and the Work-family Health Network (WFHN). Study 1 investigated the link between a supportive supervisor training and employee and spouse ratings of spouse and parent-child relationship quality at 3 and 9 months, while examining the moderating effects of baseline stress. Results revealed that the supportive supervisor training is associated with improved spouse reports of spousal relationship quality 3 months following the training. Additionally, results suggested that the training protects against employee and spouse declines in relationship quality under conditions of higher baseline employee stress. Study 2 examined the daily within and between-person link between work-to-family conflict (WFC) and affective well-being for employees and their spouses, with a focus on how daily family supportive supervisor behaviors (FSSB) can protect against WFC associated declines in mood. Findings from Study 2 revealed that daily WFC is related to declines in both employee and spouse mood at the within and betweenperson levels, however the associations between WFC and spouse mood are nuanced. Specifically, employee WFC was associated with spouse positive mood at the within-
\end{abstract}


person level, but with spouse negative mood at the between-person level. Furthermore, FSSB protected against daily within-person WFC associated declines in employee positive mood. Study 3 utilized a novel theoretical integration of COR theory and climate framework, multi-level methodology, and a time-lagged design in order to elucidate the relationships between supervisor work-family views, unit-level work-family resources (e.g., FSSB and schedule control), and individual well-being. Results revealed that positive supervisor views about flexible work arrangements (FWA) for employees was associated with higher unit levels of FSSB, and that unit level FSSB and schedule control were both strongly related to subsequent employee burnout. Additionally, supervisor FWA was indirectly associated with job-burnout via FSSB. These three studies drew upon multi-level, multi-time points, and multi-source data to further work-family literature and theory, and demonstrate the importance of work-family resources for protecting employees and their families from stress related resource loss. The unique contributions of this dissertation and future directions are discussed. 


\section{Acknowledgments}

I would like to take to express my deepest gratitude to my professional and personal support network. First, I am extremely fortunate to have the unequivocal support and guidance provided from my chair, Dr. Leslie Hammer. Dr. Leslie Hammer has guided me through a variety of personal and professional successes and challenges with strong unwavering support, while also providing a variety of opportunities to promote both my professional and personal growth and success. I would also like to thank my committee, who have truly been exemplary in their service. Each member has always made time to provide extremely helpful and important guidance and feedback throughout the development of each chapter included in this document. Further, each has served as both professional and personal sources of inspiration. Additionally, I would to thank those who helped to obtain and worked on the large-scale grants and project efforts for the Study for Employment and Retention of Veterans, and the Work-family Health Network. These project efforts, supported by researchers and research assistants, have supplied the accumulation of high-quality data utilized throughout this dissertation. I would also like to thank my colleagues and graduate student community for both the professional and personal support they have provided throughout my graduate school experience, for which I strongly believe has contributed to my success through the many challenges faced in graduate school. I would also like to thank my extended family and friends, who have been there since before I knew graduate school existed, I consider myself lucky to have you all. Finally I could never fully express how grateful I am for my immediate loved ones, my husband and my two children. I would not have the same level of 
determination, purpose, or unconditional love without them. For they have not only been a large source of my passion for this research, and my personal support, but they have also made me who I am. 
Table of Contents

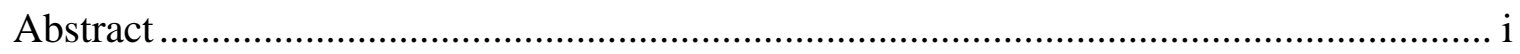

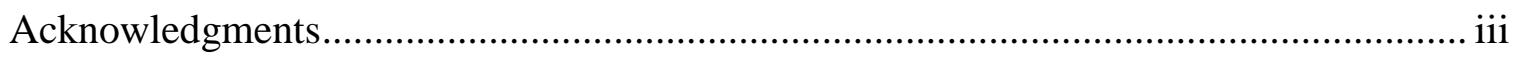

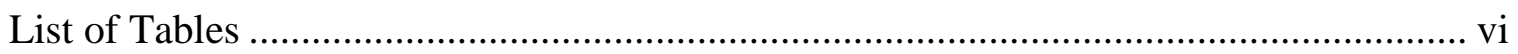

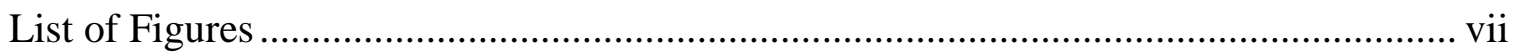

Chapter 1. Family Related Workplace Resources and Contextual Factors as Predictors of Job Outcomes and Well-being for Employees and Families. ..........................................

Chapter 2. Improving Spouse and Parent-child Relationship Quality via a Supportive

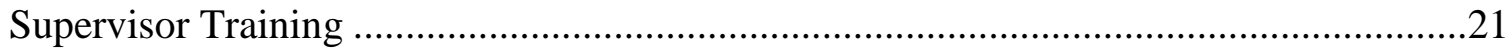

Chapter 3. Work-Family Conflict and Family-Supportive Supervisor Behaviors: Daily Affective Well-being Consequences for Couples.....................................................75

Chapter 4. A Multi-level Model of Supervisors Perceptions Shaping Unit Work-Family Resources and Subsequent Psychological and Job Well-being ....................................122

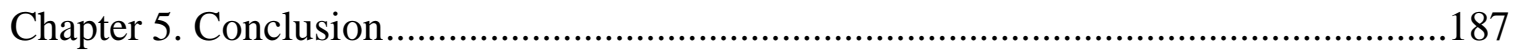

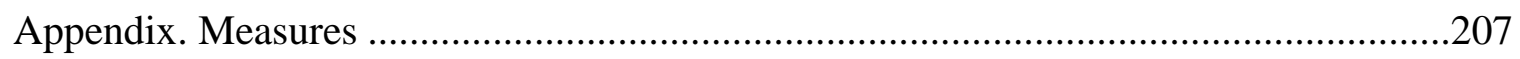




\section{List of Tables}

\section{Chapter 2 Tables}

Table 2.1. Employee and Spouse Demographic Characteristics ............................... 52

Table 2.2. Relationship Descriptive Statistics of Couples ........................................ 53

Table 2.3. Employee and Spouse Descriptive Statistics of Study Variables ................ 54

Table 2.4. Correlation Matrix of Study Variables ................................................... 55

Table 2.5. Main and Employee Stress Moderated Training Effects on Employee

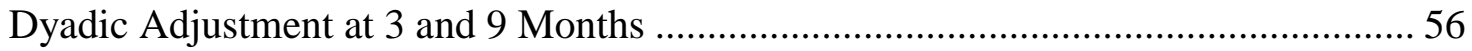

Table 2.6. Main and Employee Stress Moderated Training Effects on Spouse Dyadic

Adjustment at 3 and 9 Months

Table 2.7. Main and Employee Stress Moderated Training Effects on Employee

Positive Parenting at 3 and 9 Months .................................................................... 58

Table 2.8. Main and Stress Moderated Training Effects Spouse Positive Parenting at 3

and 9 Months.

Chapter 3 Tables

Table 3.1. Within and Between-person Means, Standard Deviations, and Correlations of Study Variables. 108

Table 3.2. General Linear Mixed Model Results for Daily Employee Positive and

Negative Mood

Table 3.3. General Linear Mixed Model Results for Daily Spouse Positive and

Negative Mood

Table 3.4. Summary of Hypothesis Test Results

Chapter 4 Tables

Table 4.1. Sample Demographics and Descriptive Characteristics 164

Table 4.2. Descriptive Statistics, Scale Reliability, and Correlations of Study Variables

Table 4.3. Unit-level Resource Variable Means, Standard Deviations, ICCs and F-test.

Table 4.4. Main Effects of Supervisor Views on Unit-level Resources.

Table 4.5. Main Effects of Unit-level Resources on Employee Well-being 
List of Figures

\section{Chapter 2 Figures}

Figure 2.1. Study conceptual model.

Figure 2.2. Study for Employment Retention of Veterans (SERVe) design.

Figure 2.3. Baseline employee stress moderated training effect on employee dyadic adjustment at 9-months.

Figure 2.4. Baseline employee stress moderated training effect on spouse dyadic adjustment at 9 -months.

Figure 2.5. Baseline employee stress moderated training effect on spouse positive parenting at 9 -months.

\section{Chapter 3 Figures}

Figure 3.1. Study conceptual model.

Figure 3.2. Moderating effect of family supportive supervisor behaviors (FSSB) on the association between work-to-family conflict (WTFC) and employee positive mood.

\section{Chapter 4 Figures}

Figure 4.1. Study conceptual model where each relationship is hypothesized with a single predictor.

Figure 4.2. Unstandardized effects observed from main effects, single predictor hypotheses (hypothesis 1 - 4), and analyses.

Figure 4.3. Unstandardized path statistics from MSEM mediation path analysis of supervisor perceptions of workplace climate for family sacrifices, unit-level family supportive supervisor behaviors, and individual job burnout and psychological distress.

Figure 4.4. Unstandardized path statistics from MSEM mediation path analysis of supervisor views toward flexible work arrangements, unit-level family supportive supervisor behaviors and individual job burnout and psychological distress.

Figure 4.5. Unstandardized path statistics from MSEM mediation path analysis of supervisor perceptions of workplace climate for family sacrifices, unit-level family supportive supervisor behaviors and individual job burnout and psychological distress.

Figure 4.6. Unstandardized path statistics from MSEM mediation path analysis of supervisor views toward flexible work arrangements (FWA), unit-level family schedule control (SC), and individual job burnout and psychological distress. 
Chapter 1. Family Related Workplace Resources and Contextual Factors as Predictors of Job Outcomes and Well-being for Employees and Families.

The work-family interface is the broad study of the interplay between one's work and home lives. A general goal of work-family researchers is to understand how factors from each domain interact to promote or hinder employee well-being and functioning. The effects of these interactions can be within domain, such as workload influencing job performance, or cross-domain, such as workload influencing marital satisfaction (Amstad, Meier, Fasel, Elfering, \& Semner, 2011). That is, work and family factors can "spill-over," to impact individuals in the alternate domain (Pleck, 1995). Several workfamily constructs have been examined, and these constructs can generally be sorted into two over-arching phenomena: work-family conflict (WFC; Netemeyer, Boles, \& McMurrian, 1996) and work-family enrichment (WFE; Greenhaus \& Powell, 2006). WFC is a type of inter-role conflict that includes both work-to-family conflict (WTFC) and family-to-work conflict (FTWC), in which one's work and family demands are incompatible (Kahn, 1996), and therefore interfere with one's ability to meet needs and demands in the alternate domain (Netemeyer et al., 1996). Broadly, both types of WFC are linked to a host of negative outcomes. For example, the extent to which individuals feel that work interferes with their family is associated with reduced job and individual well-being (e.g. job burnout and psychological strain; Amstad et al., 2011).

In terms of WFE, researchers have argued that serving multiple roles can promote well-being because of the additive effects from high quality experiences in each domain (Barnett \& Hyde, 2001; Perry Jenkins, Repetti, \& Crouter, 2000). Thus, the WFE 
perspective focuses on the pathway from work and family experiences that improve the quality of life in the alternate domain, and includes both work-to-family enrichment (WTFE) and family-to-work enrichment (FTWE; Greenhaus \& Powell, 2006). From this perspective, we depart from the traditional idea that one's work serves primarily as a negative force on family, and move to a view in which workplace factors can serve as a potential source of resources to help promote functioning in one's family. Both WFC and WFE have received meta-analytic support of their role in impacting well-being (Amstad et al., 2011; McNall, Nicklin, \& Masuda, 2010), and there is general consensus that individuals can experience both conflict and enrichment (e.g. Greenhaus \& Powell, 2006)

In addition to cross-domain spillover described above, crossover effects also occur. Crossover, unlike spillover, is a cross individual and domain effect, whereby stress experienced by an individual at work can cross over and produce contagious reactions in close others, such as their spouse (Bolger, DeLongis, Kessler, \& Wethington, 1989). Although crossover was originally defined as a process occurring when job stress or psychological strain experienced by one person affects the level of strain of another person in the same social environment (Bolger et al., 1989), it has been extended to include positive crossover resulting from positive experiences (Westman, 2001). An individual's home and work are intimate pieces of their life, and established spillover and crossover effects further demonstrate the way in which work and home are inextricably intertwined. For instance, mounting evidence suggests that an individual's work-life can impact their mood and subsequent behaviors towards their family (Repetti \& Wang, 2017). Considering that behaviors towards one's spouse can lead to changes in spousal 
views of their relationship (van Steenbergen, Kluwer, \& Karney, 2014), and that spousal relationships are also important for understanding job outcomes (e.g. spousal commitment influences partner turnover intentions in their work; Ferguson et al., 2016), there is reason to further understand the far-reaching effects of work factors on spouse outcomes.

Resources are central to promoting positive well-being among employees and their families. According to COR theory, resources are defined as objects, personal characteristics, conditions, or energies that are valued by the individual or that serve as a means for attainment of major goals or universal values such as family and well-being (Hobfoll, 1989; Hobfoll, Halbesleben, Neveu, \& Westman, 2018). Resources that can help individuals meet their goal attainment in the work-family literature are similar to those that tend to be beneficial for meeting employee needs generally, such as schedule control and supervisor support. However, resources that are specifically targeted towards family needs may be most meaningful and therefore deserve specific attention. For instance, when workplaces and supervisors are perceived as providing family-specific support (Kossek et al., 2011) or as providing a general family friendly environment (Mesmer-Magnus \& Viswevaran, 2006), employees will feel they have more resources to draw upon, and therefore experience reduced WFC and improved well-being.

\section{Statement of Purpose}

The purpose of this dissertation was to further understand a) the distal effects of workplace resources on employees' proximal job outcomes, and b) the capacity of resources to spillover and subsequently crossover to employee and family well-being 
outcomes. In the following three studies of this dissertation, I focused on supervisors as facilitators of important resources for individuals' well-being and family needs, in three different contexts and types of well-being outcomes, and I sought to help answer the following questions:

1) Can a supportive supervisor training reach beyond a focal employee to their spouse and improve both employee and spousal reports of spousal and parentchild relationship quality? Further, in a test of COR theory, are resource gains more meaningful when employees are more highly resource depleted?

2) Are daily employee reports of WFC associated both positive and negative mood among employees and their spouses, and can receiving family supportive supervisor behaviors (FSSB) on days with higher WFC counteract the negative effects of WFC on affective well-being for an employee and their spouse?

3) Do supervisor views of workplace family policy and family policy usage play a role in shaping aggregate unit-level perceptions of work-family resources as reported by their employees? Further, can these aggregate unit-level perceptions of work-family resources predict individual level job outcomes and employee well-being?

\section{Summary}

In order to answer the above research questions, this dissertation drew heavily upon Conservation of Resources (COR; Hobfoll, 1989) theory to explain the linkage of the role of workplace resources, such as work-family resources, to important employee and spouse well-being outcomes. Below, I discuss COR theory in more detail, highlight 
relevant constructs, broadly address how work stressors draw away from employee resources, and how the addition of resources can help to counteract resource depletion, and thus, promote positive well-being for employees and their families.

\section{COR Theory to Spillover and Crossover}

The central focus of COR theory is that individuals seek to obtain, maintain, and protect resources, and inability to do so results in stress. Resources are defined as objects, personal characteristics, conditions, or energies that are valued and promote major goal attainment (e.g. obtaining a more senior position at work, financially caring for one's family). According to COR theory, resources that promote well-being, family, work, and other universally valued resources will be more meaningful in predicting general phenomena (Hobfoll et al., 2018). Additionally, COR theory poses several principles, tenets, and corollaries which are discussed in further detail in applicable chapters within this dissertation. Generally, the role of resources in the workplace has been consistent with COR theory, that resources have positive effects on employee well-being (Halbesleben, Neveu, Paustian-Underdahl, \& Westman, 2014). Additionally, COR theory aids in understanding the role of work spillover to home, how work experiences can crossover to influence spouses, and how dyadic experiences can be shared (Hobfoll et al., 2018). Recent qualitative work has further elucidated the process by which this occurs. First, a work event is experienced by an employee. Second, the impact of the event is experienced by the employee. Third, this impact is transferred from the employee to the employee's partner, who subsequently experiences an impact on well-being. Fourth and finally, dyadic crossover can be observed (Brough, Muller, \& Westman, 2018). 


\section{Employee Stress}

Decades of research has shown the important effects that stress has on health (Thoits, 2010). According to COR theory, stress can be defined as "a reaction to the environment in which there is actual or perceived threat of resource loss, resource loss, or a lack of resource gain following resource investment" (Hobfoll, 1989). Indeed, work is consistently cited by the American Psychological Association as a leading source of stress (APA; 2017). Work-life stress as a specific type of work stress has been further classified as a health hazard because of its deleterious effects on employee health and health behaviors (Hammer \& Sauter, 2013). While there are various reasons stress arises from work, the most detrimental effects of stress will be seen as loss spirals. A corollary of COR theory (Hobfoll, 1989), is that resource loss begets more resource loss because individuals have fewer resources to draw upon with each blow to resources, which increases the rate and momentum of loss spirals (Hobfoll et al., 2018). Work that draws upon resources of an employee, without providing sufficient gain, will therefore leave employees stressed, and subsequently, employees may enter loss spirals if they do not have sufficient resource replenishment outside of work.

Consistent with COR and crossover perspectives described above (Hobfoll et al., 2018), the impact of resource loss on individuals can also impact their close others (e.g. WFC can impact spouse WFC; Bakker, Demerouti, \& Dollard, 2009). For example, if one's workplaces generally draw on employee resources without sufficiently providing resource gains, employees will go home with less resources to invest in their families. In research examining the effect of workplace stress on employees in their home lives, 
scholars have demonstrated that individuals who have work stress come home and display more anger and withdrawal towards their family (for brief review see Repetti \& Wang, 2017). Findings such as these support the major COR principle of desperation, that when individuals are in a state of resource loss, they enter a state of defensiveness and potential aggression in order to protect remaining resources (Hobfoll et al., 2018). Those remaining resources may be personal resources, or they may be the family itself. For instance, Repetti and Wang (2017) have suggested that it may be nuanced, in that withdrawal occurs to protect one's family from the effects of stress on the individual. However, in withdrawing from one's family, individuals are removing resources from their spouses and/or children, leaving family members with less resources as well, which can promote poor outcomes among family members and relationships. The ill-effects of work-stress can also crossover via traditional perspectives on crossover (shared dyadic stress; Westman, 2001). Taken together, it is fairly unsurprising that studies have demonstrated that one's workplace can facilitate resource related losses not only for employees, but also for their spouses (e.g. Bakker, et al., 2009).

\section{The Role of Resources}

On the other side of the spectrum of employee stress and work-life resource loss is the role of resource gain in the workplace. Several sources of resource replenishment are available to help offset work-place drains on resources (Halblesleben et al., 2014; Hobfoll \& Shirom, 2001). For example, work generally draws upon individual time resources, leaving employees with less time, and therefore resources, to invest in their personal lives. However, this loss can be offset when the organization provides resources 
such as objects (e.g. money, flexible work arrangements, FSSB) to their employees, so employees can re-invest resources into their personal lives. COR theory has two relevant principles to mention here. First, resource gain is less salient than resource loss. That is, the impact of resource gain will not produce as substantial effects as resource loss. However, to qualify this, COR also proposes the gain paradox principle, which suggests that resource gains are more salient to employees when they are experiencing resource loss (Hobfoll, 1989). For example, when employees are feeling highly stressed, as is likely the case when experiencing high WFC, resources gain will be more salient and valuable. As a result, employees will be more likely to recover from resource loss, and less likely to enter a loss spiral. Further, they may be able to initiate a gain spiral where newly obtained resources can be put to use cultivating additional resources. Research by Hammer, Kossek, Anger, Bodner, Zimmerman (2011) has demonstrated support for the gain paradox principle in their finding that for individuals with high WFC, resources in the form of family supportive supervisor behaviors (FSSB) promoted positive employee outcomes (e.g. psychological and physical health). Finally, resource gain has also been demonstrated to improve outcomes for family (e.g. workplace training can prevent against affective declines in children; Lawson, et al., 2016), and workplace resources can also crossover to spouses (e.g. performance self-esteem between spouses; Neff, Sonnentag, Niessen, \& Unger, 2012).

\section{Summary}

In summary, much is known about the work-family interface including the role of work stressors and work resources in shaping employee outcomes and well-being, which 
is highly informed by COR theory. In recent decades researchers have become much more interested in the way one's work impacts spouses, as well. Because of the bidirectional effects of work on family and family on work (Amstad et al., 2011; Ferguson et al, 2016), workplaces ought to be concerned with the impact of organizational factors on employees' family lives. Although a great deal of research has been conducted on the interplay of the work and home domains, there remains several gaps in the literature that I sought to help address with the following three studies.

\section{Study 1}

There is substantial evidence in the work-family literature that work can impact marital satisfaction (Amstad, et al., 2011), and spouse marital satisfaction (van Steenbergen, Kluwer, \& Karney, 2014). In addition, researchers have demonstrated that a FSSB training can promote employee well-being, particularly when they have higher WFC (Hammer et al., 2011), and that such training can increase the time parents spend with children (Davis et al., 2014), as well as children's sleep (McHale et al., 2015), and affect (Lawson et al., 2016). However, there remains several unanswered questions. For instance, to my knowledge there is no known research examining the implications of a family supportive supervisor training on employee and spouse relationship quality, despite that such trainings aim to support meeting work and family needs. Further, it is unknown whether COR theory may help to uncover when such training effects may occur. For instance, mapping the training onto specific COR principles, such as the gain paradox principle (e.g. resources are more salient in the face of resource loss), can help shed light on when such training effects on family outcomes are more likely to be 
observed. Based on tenants of COR theory (Hobfoll, 1989), I hypothesized that the impacts of a supportive supervisor training would improve spouse and parent-child relationship quality for employees, and based on evidence of spillover and crossover (Westman, 2001), it would also lead to improved spouse reports of relationship quality. In addition, based on the resource gain paradox principal of COR theory (Hobfoll, 1989), I examined whether the training effects were more prominent (moderated) when employees reported higher levels of baseline stress. Thus, the goal of Study 1 was to extend knowledge of the distal effects of a supportive supervisor training to include both employees' and their spouses' long-term marital and parent-child relationship quality.

\section{Study 2}

While the first study investigated the effects of a supportive supervisor training on longer-term, and more distal relationship outcomes, there still exists a need to uncover the day-to-day effects of WFC on employees and spouses. Specifically, uncovering these day-to-day effects may help to establish potential mechanisms leading to long-term family relationship outcomes associated with day-to-day work-life stress and resources. Positivity towards one spouse has been shown to mediate the relationship between WFE and marital satisfaction, and withdrawal mediates the relationship between WFC and marital satisfaction (van Steenbergen et al., 2014), suggesting that behavioral cues of affective well-being are important considerations in understanding the role of work on employees family relationships. However, the immediate implications of work-life stress on positive and negative mood among both employees and their spouses have yet to be established, despite the strong link between WFC and employee negative mood (e.g. 
Almeida et al., 2016). Researchers have established that exertion work has on employees can also crossover daily to affect spouses. However, most research examines how poor outcomes crossover (e.g. burnout to spouse burnout; Bakker \& Demerouti, 2009), while less research examines the role of a stressor experienced by the employee (e.g. employee WFC) on other spouse outcomes (e.g., marital satisfaction). Further, given the role of FSSB in improving long-term outcomes for employees with higher levels of WFC (Hammer et al., 2011), it is important to uncover the mechanisms, or whether this may be developing on a day-to-day level via primary affective responses. Therefore, in Study 2, I examined the association of daily WFC as a resource depleting stressor, that in line with COR (Hobfoll, 1989), with daily employee and spouse reports of affective well-being (i.e., mood). I also examined the role of $\mathrm{FSSB}$, a resource poised to replenish employees who have higher WFC, as a resource to protect against affective resource loss for both employees and spouses.

\section{Study 3}

The workplace climate literature has demonstrated both the importance of supervisors in establishing and shaping climate (Zohar \& Luria, 2005) as well as the role of climate on employee outcomes (Christian, Bradley, Wallace, \& Burke, 2009;

Nahrgang, Morgeson, \& Hofmann, 2010). In the work-family literature, it is known that individual perceptions of a positive work-family climate can serve as a resource for promoting positive employee outcomes. However, less research in the work-family sphere examines unit-level perceptions (consistent with the definition of climate) as promotional of positive employee outcomes, largely because attitudes on work-family 
policies vary substantially (Perrigino, Dunford, \& Wilson, 2018), rendering it difficult to establish agreement within units (Hammer et al., 2015). However, researchers have recently demonstrated that FSSB does emerge as a shared resource within units (Hill, Matthews, \& Walsh, 2016) that is associated with work outcomes. Thus, adopting a perspective of a climate for resources may help to further clarify the role of work-family resources on employee outcomes. Additionally, despite evidence that supervisor workfamily experiences produce contagious effects in employees (Hill et al., 2016), there is no known work that has established the predictors of shared unit level resources, namely, supervisor views towards flexible work arrangements or supervisor perceptions of organizational culture for making family sacrifices. Thus, in study 3 , I examined the role of supervisor views surrounding family-specific support (i.e., flexible work arrangements and organizational work-family climate) and their associations with unit-level perceptions of work-family supportive resources (e.g. SC and FSSB), and the mediating role these resources play in predicting employee psychological and job well-being. In line with COR (Hobfoll, 1989), I argue that if supervisors see flexible work arrangements as resource depleting, they are less likely to allocate these resources, and to this end, employees will experience poorer unit level perceptions of resources and thus individual and job well-being. Thus, to the extent that supervisors view flexible work arrangements positively and perceive a positive organizational climate supportive of balancing workfamily needs, employee work-units will perceive a climate of high resources for meeting both work and family demands, and subsequently experience improved well-being.

\section{Conclusion}


Through three studies, my overarching goal of this dissertation was to help further understanding of the role of resources, and specifically supervisors as facilitators of work-family resources, for promoting employee and spousal well-being. This dissertation draws on three sources of data to answer three research questions, and draws broadly on COR theory (Hobfoll, 1989) as a guiding framework. First, my co-authors and I examined whether a supportive supervisor training can reach to and beyond a focal employee, to their spouse, to improve both employee and spouse reports of spouse and parent-child relationship quality. Further, this study investigated whether the supportive supervisor training was more influential for employees who report more general stress, as a test of a COR theory principle. Second, my co-authors and I examined whether daily employee reports of WTFC are associated with both positive and negative mood among employees and their spouses, and whether perceptions of FSSB on days with higher WFC counteract the negative effects of WFC on affective well-being for employees and their spouses. Finally, in Study 3, I took a novel approach towards understanding work-family resources by examining them from a shared perspective. Additionally, I examined the role of supervisor views toward workplace family climate and flexible work arrangements as shaping unit-level work-family resources. Finally, I tested whether these aggregate unit-level perceptions of work-family resources predict individual job and employee well-being. Thus, these three studies further understandings of 1) supportive supervisor training effects on important home-domain relationship quality outcomes for both employees and their spouses, 2) day-level influences of WTFC and FSSB on daily 
mood for employees and spouses, and 3) the influence of supervisor views and unit-level work-family resources on the well-being of employees. 


\section{References}

Allen, T. D., Herst, D. E., Bruck, C. S., \& Sutton, M. (2000). Consequences associated with work-to-family conflict: A review and agenda for future research. Journal of Occupational Health Psychology, 5(2), 278-308.

Almeida, D. M., Davis, K. D., Lee, S., Lawson, K. M., Walter, K. N., \& Moen, P. (2016). Supervisor support buffers daily psychological and physiological reactivity to work-to-family conflict. Journal of Marriage and Family, 78(1), 165-179.

American Psychological Association. (2017). Annual Stress in America Press Release.

Amstad, F. T., Meier, L. L., Fasel, U., Elfering, A., \& Semmer, N. K. (2011). A Metaanalysis of work-family conflict and various outcomes with a special emphasis on cross-domain versus matching-domain relations. Journal of Occupational Health Psychology, 16(2), 151-169.

Bakker, A. B. (2009). The crossover of burnout and its relation to partner health. Stress and Health: Journal of the International Society for the Investigation of Stress, 25(4), 343-353.

Bakker, A. B., Demerouti, E., \& Dollard, M. F. (2008). How job demands affect partners' experience of exhaustion: integrating work-family conflict and crossover theory. Journal of Applied Psychology, 93(4), 901-911.

Barnett, R. C., \& Hyde, J. S. (2001). Women, men, work, and family: An expansionist theory. American Psychologist, 56(10), 781-796.

Bolger, N., DeLongis, A., Kessler, R. C., \& Schilling, E. A. (1989). Effects of daily stress on negative mood. Journal of Personality and Social Psychology, 57(5), 808-818. 
Bolger, N., DeLongis, A., Kessler, R. C., \& Wethington, E. (1989). The contagion of stress across multiple roles. Journal of Marriage and the Family, 175-183.

Brough, P., Muller, W., \& Westman, M. (2018). Work, stress, and relationships: The crossover process model. Australian Journal of Psychology, 70, 341-349.

Christian, M. S., Bradley, J. C., Wallace, J. C., \& Burke, M. J. (2009). Workplace safety: a meta-analysis of the roles of person and situation factors. Journal of Applied Psychology, 94(5), 1103-1127.

Davis, K. D., Lawson, K., Almeida, D. M., Kelly, E., King, R. B., Hammer, L. Casper, L., Okechukwu, C., \& Hanson, G., \& McHale, S. M. (2015). Parents' daily time with their children: A workplace intervention. Pediatrics, 135(5), 875-882.

Demerouti, E., Bakker, A. B., \& Schaufeli, W. B. (2005). Spillover and crossover of exhaustion and life satisfaction among dual-earner parents. Journal of Vocational Behavior, 67(2), 266-289.

Ferguson, M., Carlson, D., Boswell, W., Whitten, D., Butts, M. M., \& Kacmar, K. M. (2016). Tethered to work: A family systems approach linking mobile device use to turnover intentions. Journal of Applied Psychology, 101(4), 520-534.

Ferguson, M., Carlson, D., Kacmar, K. M., \& Halbesleben, J. R. (2016). The supportive spouse at work: Does being work-linked help? Journal of Occupational Health Psychology, 21(1), 37-51.

Greenhaus, J. H., \& Powell, G. N. (2006). When work and family are allies: A theory of work-family enrichment. Academy of Management Review, 31(1), 72-92. 
Halbesleben, J. R., Neveu, J. P., Paustian-Underdahl, S. C., \& Westman, M. (2014). Getting to the "COR" understanding the role of resources in conservation of resources theory. Journal of Management, 40(5), 1334-1364.

Hammer, L. B., Cullen, J. C., Neal, M. B., Sinclair, R. R., \& Shafiro, M. V. (2005). The longitudinal effects of work-family conflict and positive spillover on depressive symptoms among dual-earner couples. Journal of Occupational Health Psychology, 10(2), 138-154.

Hammer, L. B., Kossek, E. E., Anger, W. K., Bodner, T., \& Zimmerman, K. L. (2011). Clarifying work-family intervention processes: The roles of work-family conflict and family-supportive supervisor behaviors. Journal of Applied Psychology, 96(1), 134-150.

Hammer, L. B., \& Sauter, S. (2013). Total worker health and work-life stress. Journal of Occupational and Environmental Medicine, 55, S25-S29.

Hobfoll, S. E. (1989). Conservation of resources: A new attempt at conceptualizing stress. American Psychologist, 44(3), 513-524.

Hobfoll, S. E., Halbesleben, J., Neveu, J. P., \& Westman, M. (2018). Conservation of resources in the organizational context: The reality of resources and their consequences. Annual Review of Organizational Psychology and Organizational Behavior, 5, 103-128.

Hobfoll, S. E., \& Shirom, A. (2001). Conservation of resources theory: Applications to stress and management in the workplace. In R. T. Golembiewski (Ed.), Handbook of Organizational Behavior (pp. 57-80). New York, NY, US: Marcel Dekker. 
Kossek, E. E., Pichler, S., Bodner, T., \& Hammer, L. B. (2011). Workplace social support and work-family conflict: A meta-analysis clarifying the influence of general and work-family-specific supervisor and organizational support. Personnel Psychology, 64(2), 289-313.

Lawson, K. M., Davis, K. D., McHale, S. M., Almeida, D. M., Kelly, E. L., \& King, R. B. (2016). Effects of workplace intervention on affective well-being in employees' children. Developmental Psychology, 52(5), 772-777.

McHale, S. M., Lawson, K. M., Davis, K. D., Casper, L., Kelly, E. L., \& Buxton, O. (2015). Effects of a workplace intervention on sleep in employees' children. Journal of Adolescent Health, 56(6), 672-677.

McNall, L. A., Nicklin, J. M., \& Masuda, A. D. (2010). A meta-analytic review of the consequences associated with work-family enrichment. Journal of Business and Psychology, 25(3), 381-396.

Mesmer-Magnus, J. R., \& Viswesvaran, C. (2006). How family-friendly work environments affect work/family conflict: A meta-analytic examination. Journal of Labor Research, 27(4), 555-574.

Neff A, Sonnentag S, Niessen C, Unger D. 2012. What's mine is yours: the crossover of day-specific self esteem. Journal of Vocational Behavior, 81(3), 385-394.

Nahrgang, J. D., Morgeson, F. P., \& Hofmann, D. A. (2011). Safety at work: a metaanalytic investigation of the link between job demands, job resources, burnout, engagement, and safety outcomes. Journal of Applied Psychology, 96(1), 71-95. 
Netemeyer, R. G., Boles, J. S., \& McMurrian, R. (1996). Development and validation of work-family conflict and family-work conflict scales. Journal of Applied Psychology, 81(4), 400-410.

Perrigino, M. B., Dunford, B. B., \& Wilson, K. S. (2018). Work-Family Backlash: The "Dark Side” of Work-Life Balance (WLB) Policies. Academy of Management Annals, 12(2), 600-630.

Perry-Jenkins, M., Repetti, R. L., \& Crouter, A. C. (2000). Work and family in the 1990s. Journal of Marriage and Family, 62(4), 981-998.

Pleck, J. H. (1995). Work roles, family roles and well-being: Current conceptual perspectives. In G. L. Bowen \& J. E Pittman (Eds.), The work and family interface: Toward a contextual effects perspective (pp. 17-22). Minneapolis, MN: National Council on Family Relations

Repetti, R. L. (1989). Effects of daily workload on subsequent behavior during marital interaction: The roles of social withdrawal and spouse support. Journal of Personality and Social Psychology, 57(4), 651-659.

Repetti, R. L., \& Wood, J. (1997). Effects of daily stress at work on mothers' interactions with preschoolers. Journal of Family Psychology, 11(1), 90-108.

Repetti, R., \& Wang, S. W. (2017). Effects of job stress on family relationships. Current Opinion in Psychology, 13, 15-18.

Thoits, P. A. (2010). Stress and health: Major findings and policy implications. Journal of Health and Social Behavior, 51(1_suppl), S41-S53. 
van Steenbergen, E. F., Kluwer, E. S., \& Karney, B. R. (2014). Work-family enrichment, work-family conflict, and marital satisfaction: A dyadic analysis. Journal of Occupational Health Psychology, 19(2), 182-194.

Westman, M. (2001). Stress and strain crossover. Human Relations, 54(6), 717-751.

Westman, M., \& Etzion, D. L. (2005). The crossover of work-family conflict from one spouse to the other. Journal of Applied Social Psychology, 35(9), 1936-1957.

Zohar, D., \& Luria, G. (2005). A multilevel model of safety climate: cross-level relationships between organization and group-level climates. Journal of Applied Psychology, 90(4), 616-628 
Chapter 2. Improving Spouse and Parent-child Relationship Quality via a Supportive Supervisor Training

Jacquelyn M. Brady ${ }^{1}$, Leslie B. Hammer ${ }^{1,2}$, Cynthia D. Mohr ${ }^{1}$, \& Todd E. Bodner ${ }^{1}$

\section{1: Portland State University}

2: Oregon Health and Science University

\section{Author Note}

Jacquelyn M. Brady, Department of Psychology, Portland State University. Leslie B. Hammer, Department of Psychology, Portland State University and Oregon Institute of Occupational Health Sciences, Oregon Health \& Science University. Cynthia D. Mohr, Department of Psychology, Todd Bodner, Department of Psychology, Portland State University. The U.S. Army Medical Research Acquisition Activity, 820 Chandler Street, Fort Detrick MD 21702-5014 is the awarding and administering acquisition office. This work was supported by the Office of the Assistant Secretary of Defense for Health Affairs, through the USAMRMC Broad Agency Announcement under Award W81XWH13-2-0020. Opinions, interpretations, conclusions and recommendations are those of the authors and are not necessarily endorsed by the Department of Defense. Portions of this research were supported by the Grant \# T03OH008435 awarded to Portland State University, funded by the Centers for Disease Control and Prevention, National Institute for Occupational Safety and Health. Its contents are solely the responsibility of the authors and do not necessarily represent the official views of NIOSH, CDC or HHS. 
Correspondence concerning this article should be addressed to Jacquelyn M.

Brady, Department of Psychology, Portland State University, 1721 SW Broadway St., Portland, OR 97207. Contact: bradja@ohsu.edu. 


\begin{abstract}
Both spillover and crossover research have demonstrated a clear link between home and work domains, such that one's work life impacts one's home life and vice versa. While supportive supervisor trainings have been shown to improve employee work and health outcomes, no known research exists examining the impact of a supportive supervisor training on spouse and parental relationship quality for both employees and spouses. In the current study, we draw on Conservation of Resources (COR) theory as a framework to guide our understanding of how a supportive supervisor training affects spouse and parent-child relationship quality for 250 employees (recently separated military veterans) and their matched spouses. Using a randomized controlled trial design, we found that training supervisors to be supportive of veterans in the workplace lead to significant positive crossover effects by promoting improved spouse ratings of spouse relationship quality 3-months following the training. Additionally, employee baseline level of stress was a significant moderator of 9-month spouse and parent-child relationship quality for both the employee (spillover) and their spouse (training crossover). Specifically, when employees had higher levels of baseline stress, the training was effective at promoting improved relationship quality at 9-months following the training. We discuss the theoretical and practical contributions of the current work, while considering the limitations and gaps where future research can help shed light on our understanding of the impact of supportive supervisor training on families.
\end{abstract}


Improving Spouse and Parent-child Relationship Quality via a Supportive Supervisor Training

People hold multiple social roles (e.g. colleague, employee, parent, spouse, and supervisor) that fluctuate in terms of salience and are vital for overall well-being (Cohen, 2004; Thoits, 1991; Umberson \& Montez, 2010), with marital relationships being the strongest predictors of general well-being and mortality (Bolger, DeLongis, Kessler, \& Wethington, 1989; Holt-Lunstad, Smith, \& Layton, 2010; Myers, 2001). This is due in part to the role of the marital/partnered relationship in reducing stress (Cohen, 2004). Poor relationship quality negatively influences individual well-being (e.g. Cohen, 2004), as well as the well-being of one's family unit (e.g., romantic partner, children). Positive familial relationships are often a resource for support (Ingersoll-Dayton, Neal, \& Hammer, 2001; Silverstein, Conroy, Wang, Giarrusso, \& Bengtson, 2002). Unfortunately, work, which is often cited as one of the leading sources of stress for individuals (American Psychological Association, 2017), can drain resources and lead to spouse and parent-child relationships marked by withdrawal and anger (e.g. Repetti, 1989; Repetti \& Wood, 1997; Story \& Repetti, 2006). Given the tremendous importance of these relationships for health and well-being, and the prevalence of workplace stressors, it is vital to understand the role that one's workplace has on these familial relationships.

The workplace influences individuals through two primary processes, spillover and crossover. Spillover is a bi-directional, intra-individual, cross-domain effect (Westman, 2001), and has been well supported in the literature. For example, job stress 
can result in employee reductions of family satisfaction and increases in work-family conflict (WFC), which are then associated with lower levels of job satisfaction (Ford, Heinen, \& Langkamer, 2007). Additionally, WFC is associated with reduced life and marital satisfaction for employees (Amstad, Meier, Fasel, Elfering, \& Semmer, 2011). Crossover effects refer to an inter-individual process by which a stressor or strain experienced by one person affects another person in a similar manner (Westman, 2001). Work stress influences the way employees interact with their spouse and children (e.g. withdrawal; Repetti, 1989; Repetti \& Wood, 1997), and therefore it is no surprise that work-related outcomes crossover to impact family members. Crossover has been well supported in the literature; for example employee burnout leads to partner burnout (Bakker, Demerouti, \& Dollard, 2008; Bakker, Demerouti, \& Schaufeli, 2005), employee WFC influences spousal relationship satisfaction (van Steenbergen, Kluwer, \& Karney, 2014), long employee work hours lead to higher stress and lower relationship quality for spouses (Shafer, Kelly, Buxton, \& Berkman, 2017), and work-family focused trainings lead to positive child outcomes such as increased positive affect, better sleep quality, longer sleep duration, and increased time spent with parent (Davis et al., 2015; Lawson, Davis, McHale, Hammer, \& Buxton, 2014; McHale et al., 2015). Crossover between romantic partners may occur more so than with others (e.g. friends) because of the intimate nature of spousal relationships and higher frequency of social interactions, and it occurs through various mechanisms (e.g. contagious reactions, when one partner is less satisfied it results in reduced satisfaction for the other; Westman, Vinokur, Hamilton, \& Roziner, 2004). 
Researchers have primarily focused on negative spillover and crossover effects (Bolger et al., 1989; Bolger, DeLongis, Kessler, \& Schilling 1989), but positive spillover effects also occur (Greenhaus \& Powell, 2006). For example, Butler, Grzywacz, Bass, and Linney (2005) found that higher levels of control in the workplace were indirectly associated with increases in positive mood spillover. Spillover has also been examined in terms of relationship quality, for example job satisfaction is linked to marital satisfaction and vice versa through positive affect (Heller \& Watson, 2005). Thus, one's work can also serve as a resource, which may lead to more positive outcomes with an employees' family. Supervisors are an important piece in this puzzle, as a body of research has demonstrated that supervisors are key targets to improving employee well-being (Kelloway \& Barling, 2010), and supportive supervisor trainings can improve employee outcomes (Hammer, Kossek, Anger, Bodner\& Zimmerman, 2011). The work-life literature has led to significant advancements in the understanding of the intertwined nature of work and home, however there remains several gaps in the literature.

First, there is no known research that examines the impact of a supportive supervisor training on long-term employee-spouse and parent-child relationship quality, despite evidence such trainings improve employee well-being (Hammer et al., 2011). Second, despite evidence of crossover, there is no known research examining the effectiveness of a supportive supervisor training on spouse reports of spouse and parentchild relationship quality. Third, researchers have argued that individuals who are stressed are more sensitive to changes and respond disproportionately to both stressors and resources in the environment (more negatively and positively; Belsky \& Pluess, 
2009), yet researchers have not examined the impact of stress on supportive supervisor training effectiveness. Fourth, calls have been made for more research on underserved populations (Colella, Hebl, \& King 2017), such as military veterans who have been understudied. To address these gaps, we draw on the Conservation of Resources Theory (COR; Hobfoll, 1989; 2002) as a framework to guide the investigation of the effects of a workplace, resource-based, family supportive supervisor training.

\section{Conservation of Resources (COR) Theory}

COR theory is founded on the principal that individuals seek out, maintain, and protect their resources (Hobfoll, 1989; 2002). Within COR theory, resources are defined as objects, personal characteristics, or conditions (e.g. autonomy and social support) that positively contribute to individuals' well-being. COR theory proposes two broad processes: gain and loss spirals. Gain spirals occur when an individual gains new resources, which leads to the acquisition of additional resources. For instance, a promotion and raise (i.e., an increase in monetary resources) would allow an individual to purchase a new house, and enjoy a higher socio-economic status, which allows them to gain more resources. Alternatively, when resources are lost or threatened, a stress reaction occurs. This stress reaction can invoke a loss spiral that occurs when there is insufficient resource replenishment relative to expended resources, and therefore individuals have fewer resources to invest, resulting in even fewer gains. For example, job loss may produce additional negative outcomes beyond lost monetary resources, such as suffering from lower self-esteem or depression, leaving few resources to reinvest and break a loss spiral. Due to its conceptualization of resources as being those that help 
support universally shared values such as well-being and family (Hobfoll, Halbesleben, Neveu, \& Westman, 2018), as well as acknowledgement that factors from one domain influence other aspects of one's life, COR theory is particularly well-suited to help explain the relationships between the work-family interface and health and well-being outcomes.

\section{Military Veteran Employee Context}

COR theory is useful for understanding the military veteran employee context. Veteran employees face unique challenges during reintegration into the workplace that require psychological resources (e.g. reconciling employment identity with military identity; Rumann \& Hamrick, 2010). Thus, their employment context may be important for understanding how to improve veteran health and well-being, by creating an environment where resources can be replenished. Military service also impacts military couples' marriages (Karney \& Crown, 2007), as relocation and deployment serve as a drain on both members of a military couple, and military couples go through many transitions (including transitions to work) that can impact their health, well-being, and their relationships (Wan, Hammer, \& Haverly, 2018). Although, military couples are not more likely than civilian couples to divorce when they are matched on key demographic qualities (Karney, Loughran, \& Pollard, 2012), the marital relationship for veterans is key to their well-being. As such, a veteran's workplace can either serve as a resource that helps promote positive well-being, or as a stressor that can initiate loss spirals that trickle down to affect their family. Thus, research focusing on the impact of work on relationship quality is important to both military and civilian couples. 


\section{Family Relationship Quality}

Family relationships are vital for well-being and health for each member of a family unit. For example, Holt-Lunstad, Birmingham, and Jones (2008) demonstrated that improved marital quality is linked to lower blood pressure, decreased stress, and decreased depression, as well as higher life satisfaction. In a daily study, Arpin, Starkey, Mohr, Greenhalgh, and Hammer (2019) demonstrated that positive relationship functioning is linked to improved sleep for employees and their partners. For children, parent-child relationship quality is an important predictor of child outcomes (Coyne, Burchill, \& Stiles, 1991), as researchers tend to find aspects of parenting, such as poor and inconsistent discipline and harsh punishment, lead to poor child outcomes (e.g., behavioral problems, externalizing problems; Dadds, 1995). Positive parenting behavioral trainings, however, were shown to significantly improve long-term child outcomes (Sanders, Markie-Dadds, Tully, \& Bor, 2000). Thus, positive perceptions of spouse and parent-child relationship quality are both important for maintaining health and well-being.

Dyadic adjustment is one measure of spouse relationship quality, and is frequently cited as one of the most utilized indicators. Because long-term relationship quality is complex, researchers have argued that it is best measured in a way that demonstrates a process (e.g. Spainer, 1976). Dyadic adjustment as a tool has been shown to consistently be an effective relationship quality indicator (e.g. see meta-analysis by Graham, Liu, \& Jeziorski, 2006), that can point to relationship distress, and even predict divorce (Crane, Busby, \& Larson, 1991). Parent-child relationship quality was assessed with a measure of 
positive parenting techniques, a frequently used indicator of parent-child relationship quality. Parent-child relationship quality has been inconsistently defined in the literature, but broadly, researchers include aspects of parenting such as poor and inconsistent discipline, harsh punishment and lack of rewarding behaviors, which are linked to child behavioral and externalization problems (Dadds, 1995). However, when parents have more positive interactions with their children, there are often improvements in child outcomes. For instance, researchers have found that positive parenting behavioral trainings significantly improve child outcomes long-term (Sanders et al., 2000). Due to the link between positive parenting and long-term improved child outcomes, the current study utilizes a measure of positive parenting as an indicator of parent-child relationship quality.

Yet there are several challenges to maintaining positive relationship quality for both spouses and parent-child dyads, as doing so requires resource investments that are threatened by stressors. Marriage maintenance behaviors such as assurances, positivity, and sharing tasks are important for relationship quality outcomes (e.g. love, liking, commitment, and satisfaction; Stafford \& Canary, 1991; for meta-analytic review see Ogolsky \& Bowers, 2012), and maintenance behaviors require resources (Hobfoll, 2002). Both stress and stressors, negatively impact relationship quality (Doss, Rhoades, Stanley, Markman, 2009; Karney \& Bradbury, 1995). For example, work stress leads to higher incidences of anger and withdrawal behaviors towards children and spouses (Repetti, 1989; Repetti \& Wood, 1997; Story \& Repetti, 2006). Stressful life events, poor mood, and marital conflict all create challenges for improving parental behaviors towards 
children (Webster-Stratton \& Hammond, 1990). These findings can be explained by COR theory, when spouses and parents are drained of resources due to outside stressors (e.g. work), there may be fewer resources for them to draw upon in order to interact positively with each other and their children, hence leading to reduced relationship quality.

\section{Trainings to Increase Supervisor Support for Employees}

Family supportive supervisor behavior (FSSB) workplace trainings have been shown to improve employee job outcomes, well-being, sleep, and work-family conflict (e.g. Crain et al., 2014; Crain \& Stevens, 2018; Hammer et al., 2011; Hammer et al., 2016; Kelly et al., 2014; Kossek, Pichler, Bodner, \& Hammer., 2011; O’Driscoll et al., 2003), and several reviews have indicated there are additional beneficial effects resulting from FSSB trainings (Kossek, Odle-Dusseau, \& Hammer, 2018; Kossek, Hammer, Kelly, \& Moen, 2015). Recently, the FSSB training was customized to teach supervisors how to better support returning employees to the workplace. The Veteran Supportive Supervisor Training (VSST) was evaluated in a randomized controlled trial and demonstrated to have beneficial effects on employee health and well-being outcomes (Hammer, Wan, Brockwood, Bodner, \& Mohr, 2019). The VSST maintains principles of the FSSB training, such as family supportiveness, while adding veteran employee specific components, which are more thoroughly described in the method section of this manuscript. In line with COR theory, trainings for supervisors aimed at increasing employee resources should lead to gain spirals, because supervisors provide additional resources to employees. Employees can then steadily reinvest those resources into their health, children, and marriage, and therefore improve their relationships. Based on the 
body of research demonstrating spillover and crossover effects, the role of resources in relationships, and the corollary of COR (Hobfoll, 1989) that suggests resource gains lead to more resource gains, we expect that the VSST will have beneficial effects on spouse and parent-child relationship quality for both employees and their spouses. See Figure 2.1 for the full hypothesized model.

Hypothesis 1: The VSST will improve employee reports of spouse relationship quality for employees in the training group.

Hypothesis 2: The VSST will improve spouse reports of spouse relationship quality for spouses of employees in the training group.

Hypothesis 3: The VSST will improve employee parent-child relationship quality for employees in the training group.

Hypothesis 4: The VSST will improve spouse parent-child relationship quality for spouses of employees in the training group.

\section{Moderating Effects of Stress}

General stress is defined as the degree to which an individual considers their life to be unpredictable, uncontrollable, and overloaded (Cohen, Kamarck, and Mermelstein, 1983). According to Hobfoll's COR theory (1989), stress is the resulting state of being resource depleted (Hobfoll, 1989). Stress is a fundamental predictor of individual health and well-being outcomes (e.g., Cohen, 2004). For instance, when individuals are experiencing more stress in their relationships at home, they are more likely to suffer from poor immune functioning, depression, and loneliness (Cohen, 2004; Kiecolt-Glaser \& Glaser, 1981; Kiecolt-Glaser, et al., 1987), as well negative family-to-work spillover 
(Grzywacz \& Marks, 2000). In addition to the effects of stress on an individual, stress can crossover to close others, such as one's partner or family (Westman, 2001). Further, stress can lead to greater levels of partner, exhaustion, (Demerouti, Bakker, \& Shaufelli, 2005), and non-work outcomes, such as reduced life satisfaction (Demerouti et al., 2005).

Individuals who are stressed are more sensitive to changes and respond disproportionately to both stressors and enrichers in the environment. That is, stressed individuals responses to both positive and negative environmental changes tend to be more pronounced (Belsky \& Pluess, 2009). This is in line with COR, which suggests greater saliency of resource gain (Hobfoll, 1989) in the face of resource loss. Considering that stress poses a threat to relationship quality, previous findings that supervisor trainings may be most beneficial for those who need them (i.e., have higher work-family conflict; Hammer et al., 2011), and COR theory (Hobfoll, 1989) corollary that additional resources will be more salient to those individuals in a state of resource loss, we argue that training supervisors to be more supportive of employees in the workplace will provide greater benefits to employees who are under higher levels of stress compared to lower stress. Taken a step further, because the spouses of employees who are stressed will now experience a spouse who has gained resources, they too will reap greater benefits of the training.

Hypothesis 5: Stress will moderate the effectiveness of the VSST, such that employees with higher, compared to lower, stress at baseline will have improved spouse relationship quality. 
Hypothesis 6: Stress will moderate the effectiveness of the VSST, such that spouses of employees with higher, compared to lower, stress at baseline will have improved spouse relationship quality.

Hypothesis 7: Stress will moderate the effectiveness of the VSST, such that employees with higher, compared to lower, stress at baseline will have improved parent-child relationship quality.

Hypothesis 8: Stress will moderate the effectiveness of the VSST, such that spouses of employees with higher, compared to lower, stress at baseline will have improved parent-child relationship quality.

\section{Methods}

\section{Study Overview and Procedure}

The current study utilizes data from a randomized controlled trial (RCT) of a supportive supervisor training, and was funded by the Department of Defense. See Hammer, Wan, Brockwood, Mohr, and Carlson, (2017) for a detailed description of the baseline characteristics of study participants, and see Hammer et al., (2019) for a detailed description of the training design, although both are presented here with some brevity. All protocols and methods were approved by independent review boards for the institutions involved in the study.

Thirty-five organizations were recruited to participate in the study to evaluate the effectiveness of a supervisor training designed to increase support for employees who have, or are, transitioning into the civilian workforce. Seven additional organizations participated, but were not randomized because they did not have any participating 
employees $(m=6)$ or any participating supervisors $(m=1)$. Organizations were randomized after baseline data collection (Bodner \& Bliese, 2018), with 16 randomized into the training condition and 19 randomized into the waitlist control. Informed consent was obtained from participants prior to baseline data collection. Following baseline data collection, but prior to 3- and 9-month data collection, supervisors in the training group received the VSST (training description provided below). See Figure 2.2 for study design.

\section{Recruitment}

Organization recruitment took place through numerous outlets, including but not limited to: veteran employment events, contacting industries known to have a high proportion of Employees (e.g., first responders, security firms), and contact with the State Senate committee for Veterans' Affairs Representatives. Once participating organizations had been recruited $(n=35)$ the research team sent 2 emails to employees within the organization. The first was an email announcing the organization's participation in the study and an outline of general procedures. The second was aimed at identifying and recruiting eligible veteran employees (see eligibility criteria below), and provided a link to a screener survey. In the screener survey, we asked participants if they were married or partnered and gave them the opportunity to provide their spouse/partner's email to potentially participate in the spouse survey. We also we gave participants information about the spouse/partner portion to share with their significant other themselves. Spouses who were identified were followed-up with by the research team to invite them and to participate in the study (see eligibility and participants sections below). 


\section{Eligibility}

Employees completed a brief online screener survey to determine their eligibility and to gather contact information. Employee participants had to: 1) work at a participating organization for at least 20 hours per week, and 2) have served in the U.S. military in any branch (including National Guard and Reserves) any time after December 31, 2001 (i.e., post 9/11 era). Participants received surveys via email, completed their survey during non-work hours, and received a \$25 gift card for the completion of surveys at each time-period. If employees were eligible and indicated they had a partner that met eligibility criteria (e.g. together for $\geq 6$ months, cohabitating, and in agreement they were still together at each time point), we contacted the partners to see if they would like to participate. Upon confirming their intentions to participate and re-confirming eligibility, participants completed a survey containing demographic information, and a larger study questionnaire. An email message detailing the process and containing the survey link was also sent to the partners of the employee. Both the employee and their partner completed the same survey items used in this study.

\section{Participants}

This study focuses on training effects based on the intent-to-treat model, which means we examined differences between participants in the 16 organizations assigned to the training condition $(n=275,55.3 \%)$ and participants in the 19 organizations assigned to the control condition ( $n=222,44.7 \%)$. Of the 497 employees who completed the baseline survey, $83.5 \%(n=415)$ continued employment at the same organization and completed the 3-month follow-up survey; $72.6 \%(n=361)$ for the 9-month follow-up 
survey. Of the 497 employees who completed the baseline survey, $n=395$ met eligibility criteria to for spousal inclusion. We were able to recruit a total of $n=260$ matched spouses for baseline survey data collection. We subsequently removed couples from the current study if the primary employee member of the couple was a supervisor who completed the training $(n=8)$, or left their place of employment prior to completing the baseline survey $(n=2)$, leaving a total of $n=250(96 \%)$ matched couples completing baseline data. Of the 250 matched couples at baseline, 179 matched partners completed the 3-month follow up (72\%), however, 1 couple indicated they were no longer together, leaving a sample of $n=178(71 \%)$ for the 3-month wave of data. At 9-months, $n=158$ (63\%) matched couples participated, however, $n=4$ indicated separation, leaving a total of $n=154(62 \%)$ for the 9-month wave of data collection. Thus our final sample of matched couples for each time point were $n=250,178$, and 154 for baseline, 3 -months and 9-months respectively.

\section{Supervisor Training}

The VSST (Hammer et al., 2019) was created by drawing from the Family Supportive Supervisor Training (FSST) developed by Hammer and colleagues (2011). The VSST was a modified version of the FSST which also included training supervisors on how to be supportive of veterans in the workplace. The types of support targeted in the training include emotional support (e.g. providing emotional resources to employees), instrumental support (e.g., providing useful tools to veteran employees to help navigate their unique challenges), role modeling (e.g., demonstrating effective healthy behaviors), win-win management (e.g., describing the benefits of caring for employees and their 
families' well-being for both employees and the organization). Additionally, four types of performance support were included (e.g., measurement and direction, feedback and coaching, providing resources, and health protection) in order to target supportive supervision that focuses on task accomplishment.

The VSST is a computer-based training that takes approximately 1-hour to complete. Once the modules of the VSST were completed by supervisors, they were provided tools for goal setting and behavior tracking, an effective method to improve transfer of training (Olson et al., 2015; Salas et al., 2012). Finally, supervisors were provided additional brief modules described as "Above and Beyond," which included topics such as military leave and participation in a moderated message board about important topics in the training. See Hammer et al., (2019) for a more detailed overview of the training.

\section{Measures}

Demographics and family characteristics. The sample at baseline consisted of 250 matched couples. Of the 250 baseline couples, 137 included an employee who had a supervisor who was randomized into the training group. Eighty-nine percent of the couples were married, $80 \%$ identified as parents, and $70 \%$ had a child living in the home. Employees were primarily white (83\%) and male (89\%), with an average age of 38 (SD= 9.17), and their partners were primarily white (78\%) and female (89\%), with an average age of $35(S D=9.06)$, who worked full time $(49 \%)$ or were a stay at home parent $(29 \%)$ while the rest were unemployed or worked part-time (22\%). Full sample characteristics can be seen in Table 2.1, and relationship and parenting characteristics in Table 2.2 
Employee perceived stress. Four items from the perceived stress scale (Cohen et al., 1983) were used to measure employee baseline stress over the past 30 days $(\alpha=.76)$. Participants responded to the items (e.g. in the last month, how often have you felt that you were unable to control the important things in your life?) on a 1 (never) - 5 (very often) scale. Responses were assessed at baseline and averaged to create a composite score, where higher scores indicate greater baseline stress $(\alpha=.77)$.

Dependent variables were measured at baseline, 3-months, and 9-months. Baseline values of the dependent variables were used as control variables in the analyses (see analysis strategy below). All dependent variables were assessed for both employees and spouses.

Spouse relationship quality. Spouse relationship quality was assessed with the short form Dyadic Adjustment (DAS-7; Hunsley et al. 1995). The DAS-7 has been shown to be a reliable and valid measure of the longer version (Hunsley et al. 1995, 2001), and includes 3 sub-scales which should not be separated in order to maintain consistency (Graham, et al., 2006): dyadic agreement, dyadic cohesion, and overall dyadic satisfaction. Dyadic agreement and cohesion items are rated on a scale of 1 (always disagree/never) - 6 (always agree/more often), and contain three items each. Satisfaction is rated on a scale of 0 (extremely unhappy) - 6 (perfect) and contains one item (e.g. please select the place on the scale that best describes the degree of happiness, all things considered, of your relationship). Responses to items were averaged for each partner and at each time point to create composite scores. Reliability for employee DAS scores were $\alpha=.87, .86$, and .85 for baseline, 3-months, and 9-months respectively. For 
partners, reliability estimates for DAS were $\alpha=.84, .87$, and .85 at baseline, 3 -months, and 9-months respectively.

Parent-child relationship quality. Parent-child relationship quality was assessed via a positive parenting measure. Positive parenting is measured with three items (e.g., "you compliment your child after he/she has done something well") developed by Elgar, Waschbusch, Dadds, and Sigvaldason, (2007). Employees and partners responded to each item on a 1 (never) - 5 (always) scale. Items were averaged to create a composite score, where higher scores indicate greater positive parenting. Reliability for employee positive parenting scores were $\alpha=.92, .95$, and .95 for baseline, 3 -months, and 9-months respectively. For partners, reliability estimates for positive parenting were $\alpha=.89, .91$, and .95 at baseline, 3-months, and 9-months respectively.

\section{Analysis Strategy}

Participants were assigned to the training (intent-to-treat) condition if the organization that they worked in was part of the training group (condition $=1$ ).

Participants were assigned to the control condition if the organization they worked in was part of the waitlist control group (condition $=0$ ). Descriptive analyses were run in SPSS v25. Baseline predictors and control variables were grand mean centered, and subsequent analyses were run as multi-level mixed models in Mplus, version 8 (Muthén \& Muthén, 2017) in order to nest employees within their organizations. All analyses accounted for baseline levels of the outcome variables, nesting of employees in organizations with random effects for our intent-to-treat approach, following ANCOVA recommendations (Bodner \& Bliese, 2018). Training effects were evaluated at 3- and 9-months in separate 
models in order to use all available data for the respective outcome in each wave (Bodner \& Bliese, 2018). This strategy was used for each focal outcome.

\section{Results}

\section{Descriptive Analyses of Study Variables}

Table 2.3 displays the means and standard deviations of the study variables for employees and spouses in the training and control group at each time point. The number of veteran and spouse observations for their respective dyadic adjustment ratings at baseline were $(n=246,249)$, at 3-months $(n=177,177)$, and 9-months $(n=154,154)$. The number of observations for veterans and spouses respective positive parenting ratings at baseline were $(n=116,109)$, at 3-months $(n=80,74)$, and 9-months $(n=67$, 63). The smaller number of observations for positive parenting reflects the lower number of parents who completed all three waves of data collection, as parents were a subsample of the couples included in the analyses. Additionally we estimated correlations between study variables for both employees and spouses in Table 2.4, with spouses on the bottom half. Dyadic adjustment and positive parenting were generally not highly related to each other; however the magnitude of their respective correlations was relatively high, suggesting different facets of family relationship quality were being measured.

Additionally, the correlation between employees' ratings of dyadic adjustment, as well as their spouses, were quite strong, suggesting significant agreement among each partner in the couple. Finally, note that our interclass correlations ranged from (.002 - .030), for all of our mixed models, indicating very little variation dependent on organization identification. 


\section{Supervisor Training Effects on Spouse Relationship Quality}

Spousal relationship quality. For employees there were no main effects of the training on 3- or 9-month spousal relationship quality (Hypothesis 1; see Table 2.5). For spouses there was a main effect of the training on 3-month spousal relationship quality ( $b$ $\left.=.12, S E=.05, p=.03, r^{2}=.91\right)$, however there was no evidence of main training effects on 9-month spouse relationship quality (see Table 2.6). These findings lend partial support for Hypothesis 2, that spouses of employees in the training group would have improved dyadic adjustment following the training.

Parent-child relationship quality. There were no main effects of the training on parent-child relationship quality for either employees (see Table 2.7) or spouses (see Table 2.8) at 3 or 9 months (Hypotheses 3 and 4), and thus the hypotheses that the training would have a direct effect on employee and spouse parent-child relationship quality were not supported.

\section{Baseline Employee Stress as a Moderator}

To test the moderating role of employee stress on employee and spouse outcomes we calculated an interaction term where baseline stress was entered into the model as a control variable.

Moderated spousal relationship quality. There were no moderated effects of stress on 3-month dyadic adjustment for employees or spouses (see Tables 2.5 and 2.6). However, we did find evidence that the VSST protected against lower levels of dyadic adjustment at 9-months for employees $(b=.19, S E=.09, p=.029$; see Figure 2.3) and spouses ( $b=.15, S E=.07, p=.03$; see Figure 2.4) when the employee had higher 
baseline levels of stress, suggesting partial support for Hypothesis 5 and 6 (see Tables 2.5 and 2.6). Nine months following the training, employees in the VSST condition tended to report higher levels of dyadic adjustment, and this was more pronounced when they had higher levels of baseline stress, suggesting the training promoted positive perceptions of relationship quality for employees, particularly when they had higher levels of baseline stress. For spouses, dyadic adjustment reports looked similar to employees when employees had low levels of baseline stress. However, when employees had higher levels of stress, spouses of employees in the VSST group reported higher levels of dyadic adjustment. These findings are consistent with our Hypothesis that the VSST supports positive relationship quality for employees and spouses of employees who report higher levels of baseline stress.

Moderated parent-child relationship quality. There were no moderated effects of baseline stress on either employee or spouse positive parenting at 3 months (see Table 2.7 and 2.8). However, we did find evidence that the training improved positive parenting for spouses $(b=.28, S E=.10, p=.003$; see Figure 2.5 and Table 2.8) when employees had higher levels of baseline stress. Although non-significant, we also found a marginal VSST effects on improved positive parenting for employees $(b=.21, S E=.11, p=.06$; see Table 2.7) at 9 months when they had higher levels of baseline stress in a similar pattern to those of their spouses. The pattern of these findings suggest that for employees and spouses of employees in the training group, the VSST provides some protection against reductions in positive parenting particularly when employees are highly stressed at baseline. 


\section{Discussion}

Although there was no evidence of direct training effects on focal employee and spouse parent-child relationship quality, we found significant crossover effects, such that the training improved spouse ratings of dyadic adjustment 3-months following the training when compared to the control group. Thus, based on an RCT, the results of this study demonstrated the training effects cross over from employees to improve spouse reports of spousal relationship quality at 3 months. This finding is important given that spouses were not directly exposed to the supportive supervisor who received the training, yet their perceptions of their spousal relationship were positively influenced by the training, even when employees were not. In addition to these crossover effects, we found that for employees with higher stress, the VSST improves not only their own reports of spouse and parent-child relationship quality, but also their spouse's reports of spouse and parent-child relationship quality 9-months following the training.

Thus, the findings from this study make several contributions to the literature. First, we answered the call from Collela and colleagues (2017) for more research on underserved populations such as veterans. Second, our findings make theoretical contributions by providing a greater understanding of spillover and crossover effects, in that they can be improved by providing training to supervisors, and by identifying general stress as an important consideration in determining the effectiveness of family supportive trainings. Finally, given that employee's well-being is an important organizational consideration in the work-family interface (Hammer et al., 2011), and that WFC results in higher turnover intentions via spouses (Ferguson et al., 2016), our findings are 
particularly relevant. We have demonstrated that a supportive supervisor training is a practical and relevant tool for promoting employee well-being in ways that will benefit both one's organization as well as the employee and their family members' home life by showing it can foster improved relationship quality among family members.

\section{Theoretical Implications}

Our findings have several theoretical implications. First, our finding that a workplace supportive supervisor training impacts an individual's and their spouse's relationship quality, and spouse parent-child relationship quality represents important contributions to COR theory. This finding extends the applicability of COR Theory's gain spiral model (e.g. resource caravan; Hobfoll, 1989) to apply not only to individual's but more specifically to cross-partner effects. The findings also supported the notion that changes in spousal and child outcomes are related to supportive supervisor resources employees' receive. This suggests that a supportive supervisor training directed towards employees impacts spouse relationship quality by increasing employee resources that then cross over to the spouse. Further, when employees have higher levels of baseline stress, the training impacts spouse and parent-child relationship quality for both spouses and employees. This suggests that training supervisors to be supportive in tangible ways is vital for holistic employee well-being that spans across domains to measures of the quality of their family's relationships. Thus, we demonstrated that a supportive supervisor is most effective at improving spouse and parental relationship quality for both employees and their partners, when employees have higher levels of stress prior to the 
training. This finding is consistent with social support theory in that higher levels of stress represent a documented need that our training was able to address.

Second we contribute to COR theory demonstrating that increasing employee resources via a supportive supervisor training directly impacts their spouse's view of their relationship quality, suggesting that resources are salient enough to spouses, even when their employed partners show no significant improvements in dyadic adjustment following the training. As such, the supportive supervisor training utilized here demonstrates pronounced distal crossover power. Although partners experienced improvements in dyadic adjustment at 3 months, employees did not, and such improvements in dyadic adjustment did not persist to the 9-month follow-up. This may represent a complex relationship between our study variables that is yet to be established. For example, following the improved support from supervisors, employees may invest additional resources into the relationship, which improves partner perceptions of relationship quality. Yet, considering the intimate relationship with one's spouse and that this relationship requires maintenance behaviors (as previously discussed), the current training may not have provided enough resources to generally and consistently promote relationship-building maintenance behaviors into home life relationships. With initial investments into the relationship on the part of employees, spouses may have felt their relationship was improving. However, the amount or duration of additional resources invested into the relationship may not have been enough to elicit consistent additional resources on the part of both spouses, and therefore, significant changes in relationship quality were not generally observed. Additional research on resource allocation processes 
following such a training may help to further clarify this point. Thus, it is likely for employees with lower levels of stress, the training is not enough to promote steady increases in relationship quality over time. Per COR, resource gain is more salient in the face of resource loss (Hobfoll, 1989), and thus for less stressed employees, the salience of changes in resources from their supervisor was not enough to promote long-term relationship quality for them and their spouses.

\section{Practical Implications}

Findings from this study also make practical contributions. Scholars have recently described many different ways that work can impact military couples, including spouses. As we previously discussed, veterans and their spouses do not differ significantly from the general population in terms of divorce rates (Karney, et al, 2012), however, military spouses represent a vital source of support for veterans, as they deal with the challenges associated with military life, such as reintegration. Here we have demonstrated a method for improving spousal relationship quality, which may serve the couple to become more resilient to adversity. Further, we demonstrated that the value of family supportive supervisor trainings extends well beyond the focal employee and has positive effects on their families, particularly when the employee may be experiencing high levels of perceived stress. It is well documented that stress leads to poor workplace outcomes (e.g., turnover; Avey, Luthans, \& Jensen, 2009), and individual outcomes (e.g. health; Cohen, 2004; Goh, Pfeffer, \& Zenios, 2015), and that organizations have placed a heavier emphasis on reducing the costs associated with work-stress specifically (Le Fevre \& Kolt, 2006). In our study, we have described the critical elements supervisors should be 
trained on in order to improve their employees' well-being particularly when that employee has higher levels of general stress.

Although traditional workplace research has placed a relatively heavier emphasis on proximal work and individual outcomes, we demonstrated the value of such trainings for relationship quality among family members, including spouses of employees specifically. To our knowledge, no research exists demonstrating a supportive supervisor training can improve these spouse and parent-child relationship quality outcomes for employees and their spouses. Considering research that has demonstrated spouses' commitment to an employee's workplace is a stronger predictor of turnover than the employee's commitment (Ferguson et al., 2016), the importance of these outcomes could not be more paramount, both for the organization's and the family's well-being. If organizations foster environments that allow employees to maintain and improve home life relationships, employees and their families will be happier. We argue that these positive effects likely cycle back to create more positive workplace outcomes, a fruitful avenue for future research.

\section{Limitations and Future Research}

While this study makes several important contributions, there are some limitations and avenues for future research. COR theory, which has received a large body of support, suggests that the changes we have hypothesized occur due to the increase in resources available to the focal employees, and in turn their partners. However, we did not examine the perceived resource allocation process in terms of individual perceptions of resources. Specifically, we did not ask employees and partners whether they felt they were gaining 
additional resources from their supervisors, and therefore contributing more resources to their relationships. This process is implied in our theoretical framework, model (see Figure 2.1), analyses, and conclusions. Although Hobfoll and colleagues (2018) have maintained that individual perceptions are not key to understanding resource gains, losses, and allocations, gaining understanding of individual perceptions would answer an alternative and interesting conceptual question about how real or perceived gains and losses may interfere with the allocation of supportive supervisor resources. Future research should examine these processes to further clarify our understanding of how family supportive trainings initiate and maintain resource caravans.

Second, the moderated effects we observed were only at nine months and are likely the result of the dynamic, accumulative, and increasingly stable nature of long-term relationship quality (see Karney \& Bradbury, 1995 for a meta-analytic review). Given the complex and stable nature of relationships, it is not completely surprising that these relationships may take consistent and/or substantial investment from each partner to produce detectable changes in relationship quality. Such changes may be a challenging to achieve immediately following a supervisor training, particularly for individuals who are highly stressed. Those who are resource depleted are not necessarily accustomed to the new resources in which they receive, and may be more likely to act consistently with previous motivations of protecting resources rather than investing them (COR theory; Hobfoll, 1989). Further, those who are highly stressed may not immediately perceive changes in supervisor behaviors. Thus, the perceptions of highly stressed employees and their partners may take time to improve, and only improve once employees have reliably 
and consistently seen the increase in resources coming from their supervisors. Once employees are able to make the shift from protecting to investing, their relationship with their spouses and children may slowly reap the rewards of such investments. Although resource protection and investment is described in COR theory, steady changes in relationship quality may require substantial work, and thus steady resource investment to detect improvement, which is not explicitly conveyed in COR theory. Thus, future research should attempt to further clarify this process.

A final limitation is that our employee sample was primarily male, and spouse sample was primarily female. This should be considered when interpreting findings, as reviews have shown small but consistent gender differences in values that are thought to predict relationship quality (e.g. instrumental versus emotional support; Burleson, 2003). Future research should aim to determine whether the main effects we observed are due to gender differences or other factors. Although the sample characteristics may represent a limit on generalizability, it also reflects the reality of veterans as being predominately male, and the gendered nature of work in the United States. Thus, this research reflects a practical reality that should generalize well to specific more highly gendered occupations. Future research should assess these effects in more gender heterogeneous and/or predominately female-oriented occupations to understand if supervisor training effects are consistent across genders, or if the additional support provided to the predominatelymale employees was somehow more impactful for the predominately-female partners. In conclusion, it is important to be aware of the distal impact the workplace has on employee well-being, including the individuals in their family unit. The findings of 
this study contribution to the literature by extending COR theory to distal crossover effects of a supervisor training targeting employee needs to improve spouse relationship quality directly, the role of baseline stress in predicting training relationship quality effects, and we shed light on the temporal nature of such effects, while highlighting opportunities for future research. As such, we recommend organizations and scholars take a careful look at how their practices can enrich the lives of workers and their families. 
Table 2.1

\begin{tabular}{|c|c|c|c|}
\hline Employee & $\begin{array}{c}\text { Overall } \\
(N s=153-250) \\
\text { Mean }(\mathrm{SD}) / \%\end{array}$ & $\begin{array}{c}\text { Control } \\
(N s=112-113) \\
\mathrm{M}(\mathrm{SD}) / \%\end{array}$ & $\begin{array}{c}\text { Training } \\
(N s=133-137) \\
\text { Mean }(\mathrm{SD}) / \%\end{array}$ \\
\hline Age & $38.38(9.17)$ & $38.95(9.06)$ & $37.91(9.26)$ \\
\hline Male & $88.8 \%$ & $90.3 \%$ & $87.6 \%$ \\
\hline Ethnicity & -- & -- & -- \\
\hline American Indian/Alaskan Native & $1.6 \%$ & $0 \%$ & $2.9 \%$ \\
\hline Asian & $2.0 \%$ & $2.7 \%$ & $1.5 \%$ \\
\hline Black or African American & $.8 \%$ & $.9 \%$ & $.7 \%$ \\
\hline White & $82.8 \%$ & $85.8 \%$ & $80.3 \%$ \\
\hline Multiple/Other & $11.6 \%$ & $9.7 \%$ & $13.2 \%$ \\
\hline Education & -- & -- & -- \\
\hline High School Diploma/GED & $5.6 \%$ & $3.5 \%$ & $7.3 \%$ \\
\hline Some College & $25.6 \%$ & $28.3 \%$ & $23.4 \%$ \\
\hline College Degree/Certificate & $49.2 \%$ & $48.7 \%$ & $49.6 \%$ \\
\hline Graduate degree or in progress & $18.8 \%$ & $18.6 \%$ & $19 \%$ \\
\hline Employment & -- & -- & -- \\
\hline Hours per week & $42.26(6.33)$ & $42.46(7.05)$ & $42.10(5.68)$ \\
\hline Work Tenure in Years & $5.68(5.58)$ & $5.90(5.49)$ & $5.50(5.66)$ \\
\hline Spouse & $(N s=153-250)$ & $(N s=67-113)$ & $(N s=86-137)$ \\
\hline Age & $36.50(9.10)$ & $36.91(9.43)$ & $36.16(8.76)$ \\
\hline Female & $88.0 \%$ & $91.2 \%$ & $85.4 \%$ \\
\hline Ethnicity & -- & -- & -- \\
\hline American Indian/Alaskan Native & $.8 \%$ & $.9 \%$ & $.7 \%$ \\
\hline Asian & $4.8 \%$ & $3.5 \%$ & $5.8 \%$ \\
\hline Black or African American & $.8 \%$ & $0 \%$ & $1.5 \%$ \\
\hline White & $78.4 \%$ & $85 \%$ & $78.1 \%$ \\
\hline Multiple/Other & $13.6 \%$ & $8.9 \%$ & $10.9 \%$ \\
\hline Education & -- & -- & -- \\
\hline High School Diploma/GED & $7.2 \%$ & $7.1 \%$ & $7.5 \%$ \\
\hline Some College & $26.8 \%$ & $31 \%$ & $23.4 \%$ \\
\hline College Degree/Certificate & $46.8 \%$ & $46.9 \%$ & $46.7 \%$ \\
\hline Graduate degree or in progress & $16.4 \%$ & $13.3 \%$ & $19 \%$ \\
\hline Employment & -- & -- & -- \\
\hline Hours per week & $37.38(11.79)$ & $36.92(11.68)$ & $37.74(11.94)$ \\
\hline Full-time & $49.8 \%$ & $46 \%$ & $51.1 \%$ \\
\hline Stay at Home Parent & $29 \%$ & $29.2 \%$ & $29.2 \%$ \\
\hline Work Tenure in years & $4.72(5.32)$ & $5.10(5.76)$ & $4.46(4.97)$ \\
\hline
\end{tabular}

Employee and Spouse Demographic Characteristics

Note: Ns refer to number of observations for each descriptive variable dependent on the grouping variable (overall, control, or training) for the respective member of the couple (employee or spouse). 
Table 2.2

Relationship Descriptive Statistics of Couples

\begin{tabular}{lccc}
\hline \multicolumn{1}{c}{ Variable } & $\begin{array}{c}\text { Overall Dyad } \\
(N s=191-250) \\
\text { Mean (SD)/\% }\end{array}$ & $\begin{array}{c}\text { Dyad Control } \\
(N s=83-113) \\
\text { Mean (SD)/\% }\end{array}$ & $\begin{array}{c}\text { Dyad Training } \\
(N s=108-137) \\
\text { M (SD)/ } \%\end{array}$ \\
\hline $\begin{array}{l}\text { Relationship } \\
\text { Married }\end{array}$ & $89 \%$ & $92 \%$ & $86.9 \%$ \\
$\quad$ Committed Relationship & $11 \%$ & $8 \%$ & $13.1 \%$ \\
Parenting & & & \\
Has children & $80 \%$ & $77 \%$ & $82.5 \%$ \\
Has children living at home & $69.6 \%$ & $66.4 \%$ & $72.3 \%$ \\
Age of youngest child & $3.75(3.25)$ & $4.02(3.63)$ & $3.53(2.93)$ \\
\hline
\end{tabular}

Note: Ns refer to number of observations for each descriptive variable dependent on grouping variable (overall, control, or training). 
Table 2.3

Employee and Spouse Descriptive Statistics of Study Variables

\begin{tabular}{lccc}
\hline & Overall $M(S D) N$ & Control $M(S D) N$ & Training $M(S D) N$ \\
\hline Employee Stress & $2.33(.84) 250$ & $2.36(.88) 113$ & $2.30(.80) 137$ \\
Employee DAS & & & \\
Baseline & $4.36(.78), 246$ & $4.41(.82) 112$ & $4.31(.74) 134$ \\
3-month & $4.40(.77), 177$ & $4.45(.73) 82$ & $4.35(.81) 95$ \\
9-month & $4.36(.75), 154$ & $4.36(.67) 69$ & $4.37(.82) 85$ \\
Spouse DAS & & & \\
Baseline & $4.47(.76) 249$ & $4.50(.78) 113$ & $4.44(.74) 136$ \\
3-month & $4.40(.78) 177$ & $4.31(.84) 82$ & $4.47(.73) 95$ \\
9-month & $4.48(.75) 154$ & $4.44(.85) 69$ & $4.51(.66) 85$ \\
Employee PP & & & \\
Baseline & $4.26(.63) 116$ & $4.39(.61) 46$ & $4.17(.63) 70$ \\
3-month & $4.20(.66) 80$ & $4.31(.52) 32$ & $4.13(.73) 48$ \\
9-month & $4.20(.74) 67$ & $4.15(.86) 27$ & $4.23(.66) 40$ \\
Spouse PP & & & \\
Baseline & $4.42(.57) 109$ & $4.43(.55) 69$ & $4.40(.59) 63$ \\
3-month & $4.37(.60) 74$ & $4.23(.64) 46$ & $4.46(.55) 46$ \\
9-month & $4.43(.62) 63$ & $4.46(.59) 28$ & $4.42(.64) 39$ \\
\hline
\end{tabular}

Note: $M(S D)$ and $N$ refers to the mean, standard deviation and the number of observations for each outcome variable based on grouping variable (overall, control, training) at baseline, 3-month, and 9-month. DAS = Dyadic Adjustment, and PP = Positive Parenting) listed for the respective member of the couple (employee or spouse). 
Table 2.4

Correlation Matrix of Study Variables

\begin{tabular}{|c|c|c|c|c|c|c|c|c|c|c|c|c|c|}
\hline & 1 & 2 & 3 & 4 & 5 & 6 & 7 & 8 & 9 & 10 & 11 & 12 & 13 \\
\hline \multicolumn{14}{|l|}{$\begin{array}{l}\text { Baseline } \\
\text { Employee }\end{array}$} \\
\hline 1. Stress & .77 & & & & & & & & & & & & \\
\hline 2. DAS & $-.35^{* *}$ & .87 & & & & & & & & & & & \\
\hline 3. POSP & $-.19^{*}$ & $.29^{* *}$ & .92 & & & & & & & & & & \\
\hline \multicolumn{14}{|l|}{ 3-month } \\
\hline 4. DAS & $-.27^{* *}$ & $.66^{* *}$ & .19 & .86 & & & & & & & & & \\
\hline 5. POSP & $-.27^{*}$ & $.26^{*}$ & $.54^{* *}$ & -.04 & .95 & & & & & & & & \\
\hline \multicolumn{14}{|l|}{ 9-month } \\
\hline 6. DAS & $-.20^{*}$ & $.63^{* *}$ & $.36^{* *}$ & $.52^{* *}$ & .26 & .85 & & & & & & & \\
\hline 7. POSP & -.10 & $.24^{*}$ & $.73^{* * *}$ & .14 & $.43^{* *}$ & .22 & .95 & & & & & & \\
\hline \multicolumn{14}{|l|}{ Baseline } \\
\hline 8. DAS & $-.17^{* *}$ & $.47^{* *}$ & .15 & $.55^{* *}$ & .17 & .38 & -.10 & .84 & & & & & \\
\hline 9. POSP & .04 & .04 & $.22^{*}$ & .10 & .05 & .10 & .15 & .14 & .89 & & & & \\
\hline \multicolumn{14}{|l|}{ 3-month } \\
\hline 10. DAS & -.08 & $.44^{* *}$ & .14 & $.48^{* *}$ & .12 & $.34^{* * *}$ & .09 & $.78^{* *}$ & .18 & .87 & & & \\
\hline 11. POSP & .10 & .01 & .18 & $.29^{*}$ & .11 & .13 & $.38^{* *}$ & .04 & $.74^{* *}$ & .19 & .91 & & \\
\hline \multicolumn{14}{|l|}{ 9-month } \\
\hline 12. DAS & $-.20^{*}$ & $.51^{* *}$ & $.36^{* *}$ & $.48^{* *}$ & $.30^{*}$ & $.50^{* * *}$ & .15 & $.73^{* *}$ & .13 & $.74^{* *}$ & .06 & .85 & \\
\hline 13. POSP & -.05 & .03 & $.36^{* * *}$ & $.29^{*}$ & .21 & .16 & .23 & $.26^{*}$ & $.64^{* *}$ & $.44^{* *}$ & $.58^{* *}$ & $.26^{*}$ & .95 \\
\hline
\end{tabular}

Note: $* p<.05 . * * p<.01 . * * * p<.001$. DAS $=$ Dyadic Adjustment. POSP = Positive Parenting. Reliability coefficients are on the diagonal. Significance tests do not account for the nesting of the participants within organization 
Table 2.5

Main and Employee Stress Moderated Training Effects on Employee Dyadic Adjustment at 3 and 9 Months

\begin{tabular}{|c|c|c|c|c|c|c|c|c|}
\hline & \multicolumn{2}{|c|}{$\begin{array}{c}\text { Training Effect on } \\
\text { Employee DAS (3- } \\
\text { month) } \\
N=175\end{array}$} & \multicolumn{2}{|c|}{$\begin{array}{c}\text { Employee Stress } \\
\text { Moderated DAS (3- } \\
\text { month) } \\
N=175\end{array}$} & \multicolumn{2}{|c|}{$\begin{array}{c}\text { Training Effect on } \\
\text { Employee DAS (9- } \\
\text { month) } \\
N=152\end{array}$} & \multicolumn{2}{|c|}{$\begin{array}{c}\text { Employee Stress } \\
\text { Moderated DAS } \\
\text { (9-month) } \\
\quad N=152\end{array}$} \\
\hline & Est. & $95 \% \mathrm{CI}$ & Est. & $95 \%$ CI & Est. & $95 \% \mathrm{CI}$ & Est. & $95 \%$ CI \\
\hline Intercept & $4_{*}{ }^{*}{ }^{* *}$ & $(4.25,4.56)$ & $4.40^{* *}$ & $(.81,7.99)$ & $4.28^{* * *}$ & $(4.14,4.43)$ & $4.27^{* * *}$ & $(4.22,4.47)$ \\
\hline Training & -.04 & $(-.27, .18)$ & -.04 & $(-5.56,5.47)$ & .05 & $(-.19, .28)$ & .06 & $(.05, .32)$ \\
\hline Baseline DAS & $.72^{* * *}$ & $(.55, .89)$ & $.70^{* * *}$ & $(.45, .95)$ & $.71^{* * *}$ & $(.60, .82)$ & $.72^{* * *}$ & $(.69, .90)$ \\
\hline Employee Stress & ---- & --- & -.11 & $(-2.74,2.52)$ & ---- & --- & -.10 & $(-.24,-.01)$ \\
\hline Training*Emp Stress & ---- & ---- & .10 & $(-.57, .77)$ & ---- & ---- & $.19 *$ & $(.01-.28)$ \\
\hline Residual variance & $.33^{* * *}$ & $(.20, .45)$ & .33 & $(-1.98,2.63)$ & $.34^{* * *}$ & $(.21, .47)$ & $.24^{* * *}$ & $(.18, .31)$ \\
\hline Intercept variance & .003 & $(-.06, .07)$ & .00 & $(-3.16,3.16)$ & .00 & $(-.03, .04)$ & .00 & $(-.03, .02)$ \\
\hline Model $\mathrm{R}^{2}$ (within) & $.44^{* * *}$ & ---- & .45 & ---- & $.40^{* * *}$ & ---- & $.41^{* * *}$ & ---- \\
\hline Model $\mathrm{R}^{2}$ (between) & .13 & ---- & .23 & ---- & .20 & ---- & .26 & ---- \\
\hline
\end{tabular}

Note: $* p<.05 . * * p<.01 . * * * p<.001 . \uparrow<.10$. DAS = Dyadic Adjustment. DV = Dependent variable. Emp Stress = Employee baseline levels of stress. Models controlled for baseline levels of dependent variable. All estimates listed represent unstandardized values. All continuous predictors are grand-mean centered. 
Table 2.6

Main and Employee Stress Moderated Training Effects on Spouse Dyadic Adjustment at 3 and 9 Months

\begin{tabular}{|c|c|c|c|c|c|c|c|c|}
\hline \multirow[t]{2}{*}{$\begin{array}{l}\text { Outcome: Spouse } \\
\text { DAS }\end{array}$} & \multicolumn{2}{|c|}{$\begin{array}{c}\text { Training Effect on } \\
\text { Spouse DAS (3- } \\
\text { month) } \\
N=177\end{array}$} & \multicolumn{2}{|c|}{$\begin{array}{l}\text { Employee Stress } \\
\text { Moderated Spouse } \\
\text { DAS (3-month) } \\
\quad N=177\end{array}$} & \multicolumn{2}{|c|}{$\begin{array}{c}\text { Training Effect on } \\
\text { Spouse DAS (9-month) } \\
N=154\end{array}$} & \multicolumn{2}{|c|}{$\begin{array}{c}\text { Employee Stress } \\
\text { Moderated Spouse DAS } \\
\quad(9 \text {-month) } \\
N=154\end{array}$} \\
\hline & Est. & $95 \% \mathrm{CI}$ & Est. & $95 \% \mathrm{CI}$ & Est. & $95 \% \mathrm{CI}$ & Est. & $95 \% \mathrm{CI}$ \\
\hline Intercept & $4.32^{* * * *}$ & $(4.22,4.41)$ & $4.32^{* * * *}$ & $(4.22,4.47)$ & $4.34^{* * *}$ & $(4.19,4.50)$ & $4.34^{* * * *}$ & $(4.22,4.47)$ \\
\hline Training & $.12^{*}$ & $(.01, .22)$ & $.12^{*}$ & $(.05, .32)$ & $.19^{\dagger}$ & $(-.00, .39)$ & $.19^{* *}$ & $(.05, .32)$ \\
\hline Baseline DAS & $.85^{* * *}$ & $(.77 . .93)$ & $.86^{* * *}$ & $(.69, .90)$ & $.80^{* * *}$ & $(.70, .90)$ & $.79^{* * *}$ & $(.69, .90)$ \\
\hline Employee Stress & ---- & ---- & -.001 & $(-.24,-.01)$ & ---- & ---- & $-.12^{*}$ & $(-.24,-.01)$ \\
\hline $\begin{array}{l}\text { Training*Emp } \\
\text { Stress }\end{array}$ & ---- & ---- & .03 & $(.01-.28)$ & ---- & ---- & $.15^{* *}$ & $(.01-.28)$ \\
\hline Residual variance & $.24^{* * * *}$ & $(.16, .31)$ & $.24^{* *}$ & $(.18, .31)$ & $.25^{* * *}$ & $(.19, .31)$ & $.24^{* * * *}$ & $(.18, .31)$ \\
\hline Intercept variance & .00 & $(-.01, .01)$ & .00 & $(-.03, .02)$ & .00 & $(-.08, .08)$ & .00 & $(-.02, .02)$ \\
\hline Model $\mathrm{R}^{2}$ (within) & $.61^{* * *}$ & ---- & $.61^{* * *}$ & ---- & $.56^{* * *}$ & ---- & $.57^{* * *}$ & ---- \\
\hline Model R ${ }^{2}$ (between) & .91 & ---- & .91 & ---- & .88 & ---- & .95 & ---- \\
\hline
\end{tabular}

Note: $* p<.05 . * * p<.01 . * * * p<.001 . \dagger<.10$. DAS $=$ Dyadic Adjustment. DV = Dependent variable. Emp Stress $=$ Employee baseline levels of stress. Models controlled for baseline levels of dependent variable. All continuous predictors are grand-mean centered. 
Table 2.7

Main and Employee Stress Moderated Training Effects on Employee Positive Parenting at 3 and 9 Months

\begin{tabular}{|c|c|c|c|c|c|c|c|c|}
\hline \multirow[t]{2}{*}{$\begin{array}{l}\text { Outcome: Employee } \\
\text { Positive Parenting }\end{array}$} & \multicolumn{2}{|c|}{$\begin{array}{c}\text { Training Effect on } \\
\text { Employee Positive } \\
\text { Parenting (3-month) } \\
\quad N=72\end{array}$} & \multicolumn{2}{|c|}{$\begin{array}{c}\text { Employee Stress } \\
\text { Moderated Positive } \\
\text { Parenting (3-month) } \\
\quad N=72\end{array}$} & \multicolumn{2}{|c|}{$\begin{array}{c}\text { Training Effect on } \\
\text { Employee Positive } \\
\text { Parenting (9-month) } \\
\quad N=62\end{array}$} & \multicolumn{2}{|c|}{$\begin{array}{c}\text { Employee Stress } \\
\text { Moderated Positive } \\
\text { Parenting (9-month) } \\
N=62\end{array}$} \\
\hline & Est. & $95 \% \mathrm{CI}$ & Est. & $95 \% \mathrm{CI}$ & Est. & $95 \% \mathrm{CI}$ & Est. & $95 \% \mathrm{CI}$ \\
\hline Intercept & $4.23^{* * *}$ & $(4.04,4.41)$ & $4.21^{* * *}$ & $(4.04,4.37)$ & $4.14^{* * * *}$ & $(3.96,4.31)$ & $4.14^{* * *}$ & $(4.00,4.28)$ \\
\hline Training & -.11 & $(-.29, .08)$ & -.09 & $(-.25, .08)$ & .07 & $(-.08, .21)$ & .04 & $(-.11, .19)$ \\
\hline Baseline of DV & $.55^{* * *}$ & $(.40, .71)$ & $.53^{* * *}$ & $(.34, .72)$ & $.74^{* * * *}$ & $(.60, .88)$ & $.82^{* * *}$ & $(.69, .94)$ \\
\hline Employee Stress & ---- & ---- & -.13 & $(-.33, .08)$ & ---- & ---- & .06 & $(-.15, .26)$ \\
\hline Training*Emp Stress & ---- & ---- & .08 & $(-.22, .38)$ & ---- & ---- & $.21^{\dagger}$ & $(-.01, .43)$ \\
\hline Residual variance & $.29^{* * *}$ & $(.22, .36)$ & $.29^{* * *}$ & $(.21, .36)$ & $.18^{* * *}$ & $(.13, .23)$ & $.16^{* * *}$ & $(.12, .20)$ \\
\hline Intercept variance & .00 & $(-.05, .05)$ & .00 & $(-.04, .04)$ & .00 & $(-.05, .05)$ & .00 & $(-.01, .01)$ \\
\hline Model $\mathrm{R}^{2}$ (within) & $.29^{* * * *}$ & --- & $.30^{* * *}$ & --- & $.53^{* * *}$ & --- & $.60^{* * * *}$ & ---- \\
\hline Model $\mathrm{R}^{2}$ (between) & .72 & ---- & .67 & ---- & .75 & ---- & .66 & ---- \\
\hline
\end{tabular}

Note: $* p<.05 . * * p<.01 . * * * p<.001 . \dagger<.10 . \mathrm{DV}=$ Dependent variable. Emp Stress $=$ Employee baseline levels of stress.

Models controlled for baseline levels of outcome variable. All continuous predictors are grand-mean centered. 
Table 2.8

Main and Stress Moderated Training Effects Spouse Positive Parenting at 3 and 9 Months

\begin{tabular}{|c|c|c|c|c|c|c|c|c|}
\hline \multirow[t]{2}{*}{$\begin{array}{l}\text { Outcome: Spouse } \\
\text { Positive Parenting }\end{array}$} & \multicolumn{2}{|c|}{$\begin{array}{c}\text { Training Effect on } \\
\text { Spouse Positive } \\
\text { Parenting (3-month) } \\
N=69\end{array}$} & \multicolumn{2}{|c|}{$\begin{array}{c}\text { Employee Stress } \\
\text { Moderated Positive } \\
\text { Parenting (3-month) } \\
N=69\end{array}$} & \multicolumn{2}{|c|}{$\begin{array}{c}\text { Training Effect on } \\
\text { Spouse Positive } \\
\text { Parenting (9-month) } \\
N=58\end{array}$} & \multicolumn{2}{|c|}{$\begin{array}{c}\text { Employee Stress } \\
\text { Moderated Positive } \\
\text { Parenting (9-month) } \\
N=58\end{array}$} \\
\hline & Est. & $95 \% \mathrm{CI}$ & Est. & $95 \% \mathrm{CI}$ & Est. & $95 \% \mathrm{CI}$ & Est. & $95 \% \mathrm{CI}$ \\
\hline Intercept & $4.31 * * *$ & $(4.11,4.51)$ & $4.32 * * *$ & $\begin{array}{r}(4.13, \\
4.51)\end{array}$ & $4.36 * * *$ & $(4.15,4.57)$ & $4.33 * * *$ & $(4.20,4.47)$ \\
\hline Training & .07 & $(-.15, .30)$ & .06 & $(-.17, .29)$ & -.04 & $(-.30, .23)$ & -.02 & $(-.20, .17)$ \\
\hline Baseline of DV & $.76^{* * *}$ & $(.63, .90)$ & $.76 * * *$ & $(.63, .88)$ & $.72 * * *$ & $(.57, .86)$ & $.74 * * *$ & $(.58, .90)$ \\
\hline Employee Stress & ---- & ---- & .06 & $(-.16, .27)$ & ---- & ---- & $.22 * *$ & $(-.37,-.07)$ \\
\hline Training*Emp Stress & ---- & ---- & .01 & $(-.23, .24)$ & ---- & ---- & $.28 * *$ & $(.10, .27)$ \\
\hline Residual variance & $.15 * * *$ & $(.11, .18)$ & $.15^{* * *}$ & $(.11, .18)$ & $.21 * * *$ & $(.15, .27)$ & $.20 * * *$ & $(.13, .27)$ \\
\hline Intercept variance & .01 & $(-.03, .04)$ & .01 & $(-.03, .05)$ & .01 & $(-.04, .07)$ & .01 & $(-.08, .09)$ \\
\hline Model $\mathrm{R}^{2}$ (within) & $.56 * * *$ & ---- & $.57 * * *$ & ---- & $.42 * * *$ & ---- & $.45^{* * *}$ & ---- \\
\hline Model R ${ }^{2}$ (between) & .15 & ---- & .09 & ---- & .02 & ---- & .01 & ---- \\
\hline
\end{tabular}

Note: $* p<.05 . * * p<.01 . * * * p<.001 . \dagger<.10 . \mathrm{DV}=$ Dependent variable. Emp Stress = Employee baseline levels of stress. Models controlled for baseline levels of outcome variable. All continuous predictors are grand-mean centered. 


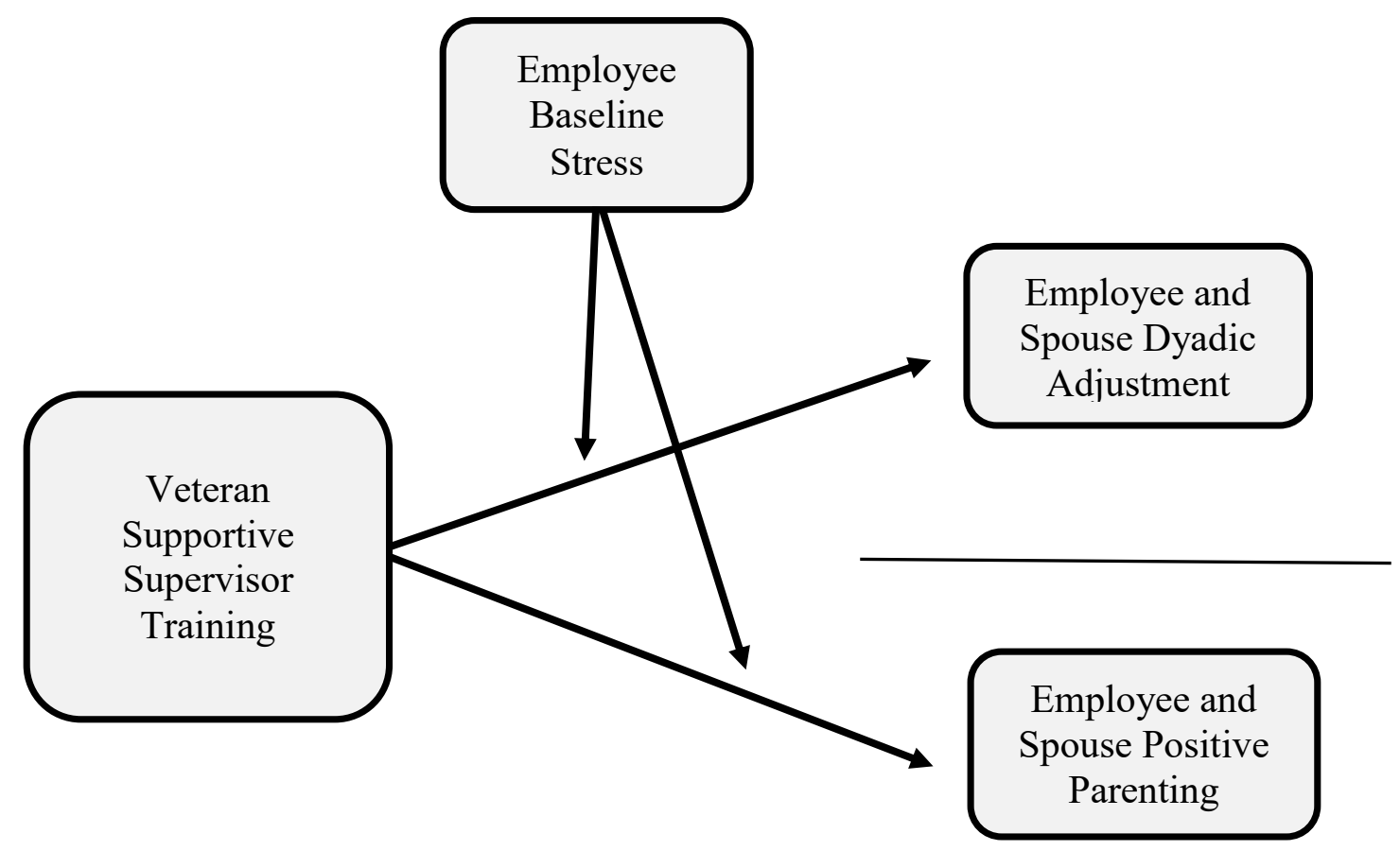

Figure 2.1. Study conceptual model. 


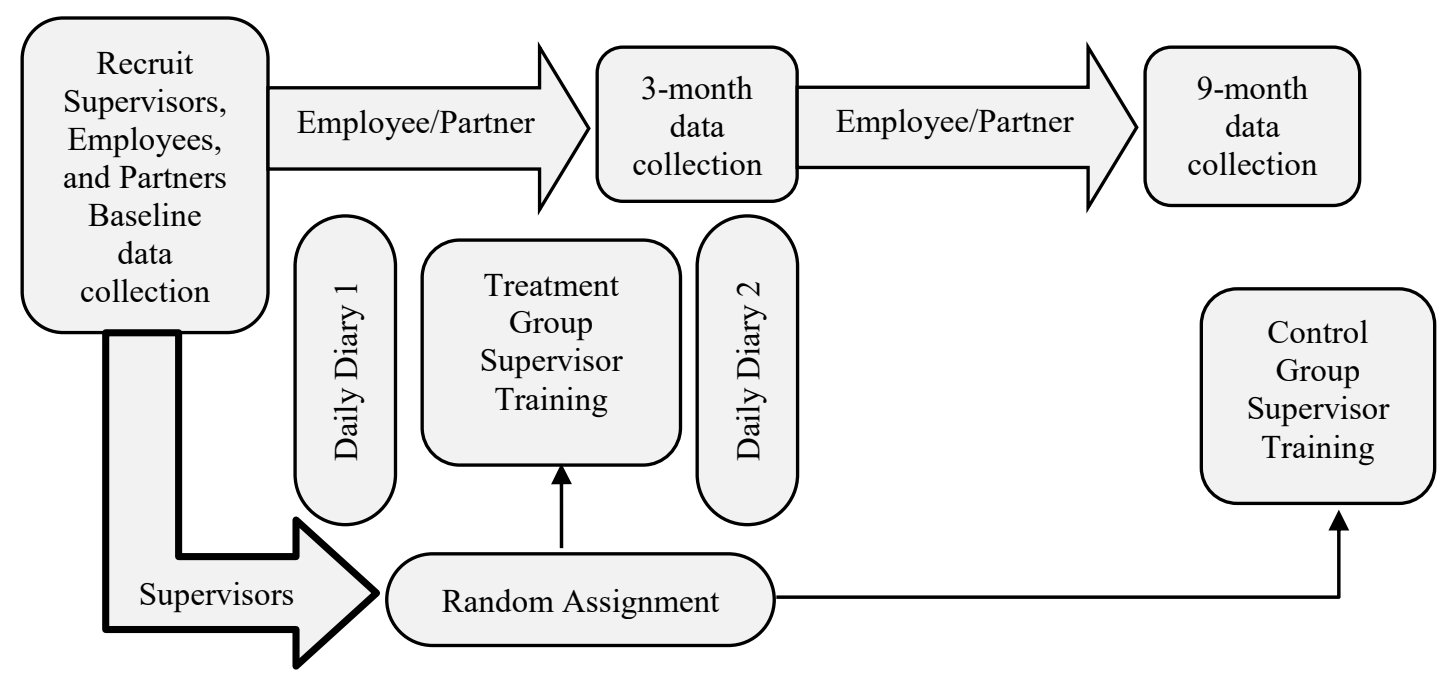

Figure 2.2. Study for Employment Retention of Veterans (SERVe) design. 


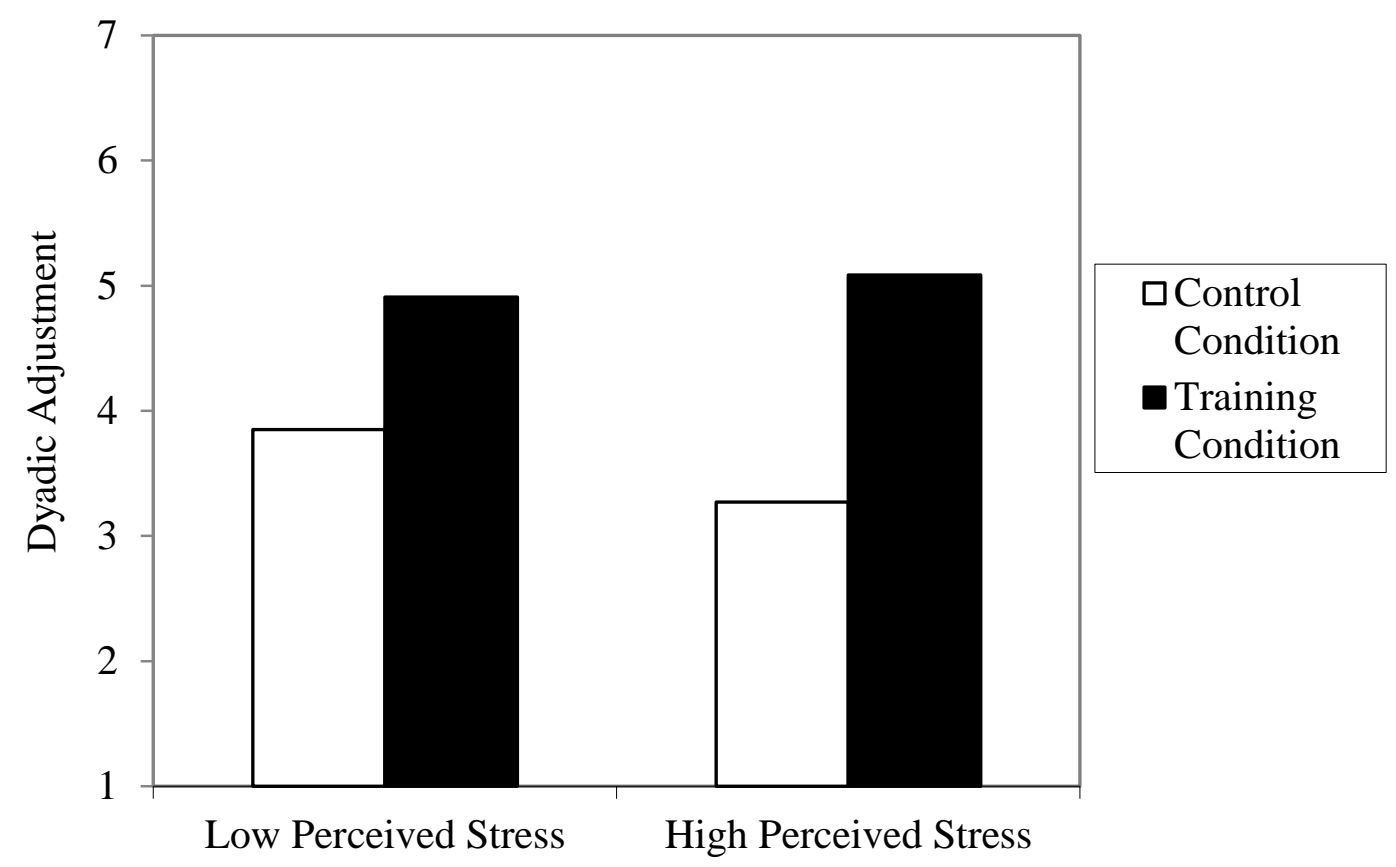

Figure 2.3. Baseline employee stress moderated training effect on employee dyadic adjustment at 9-months. 


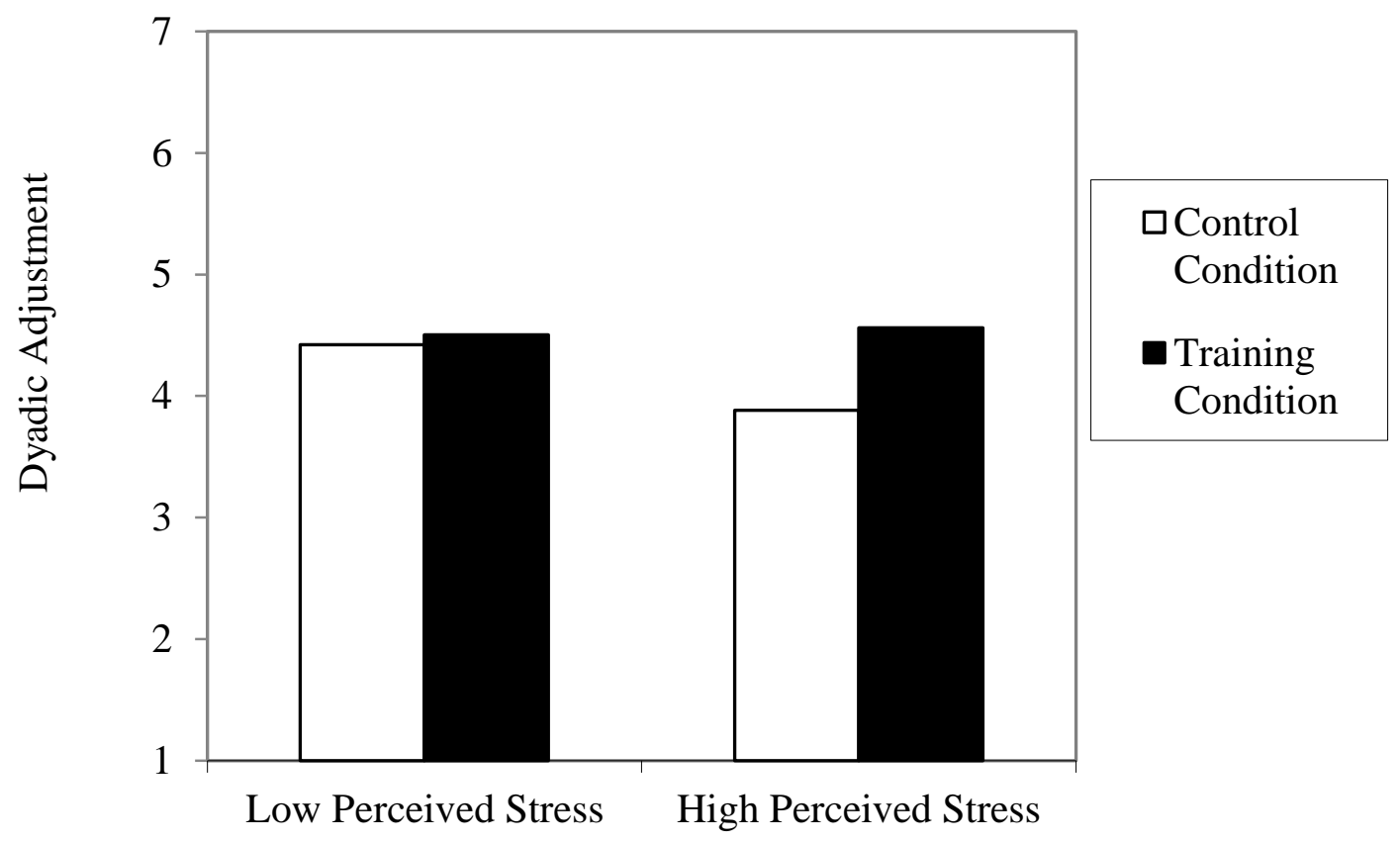

Figure 2.4. Baseline employee stress moderated training effect on spouse dyadic adjustment at 9-months. 


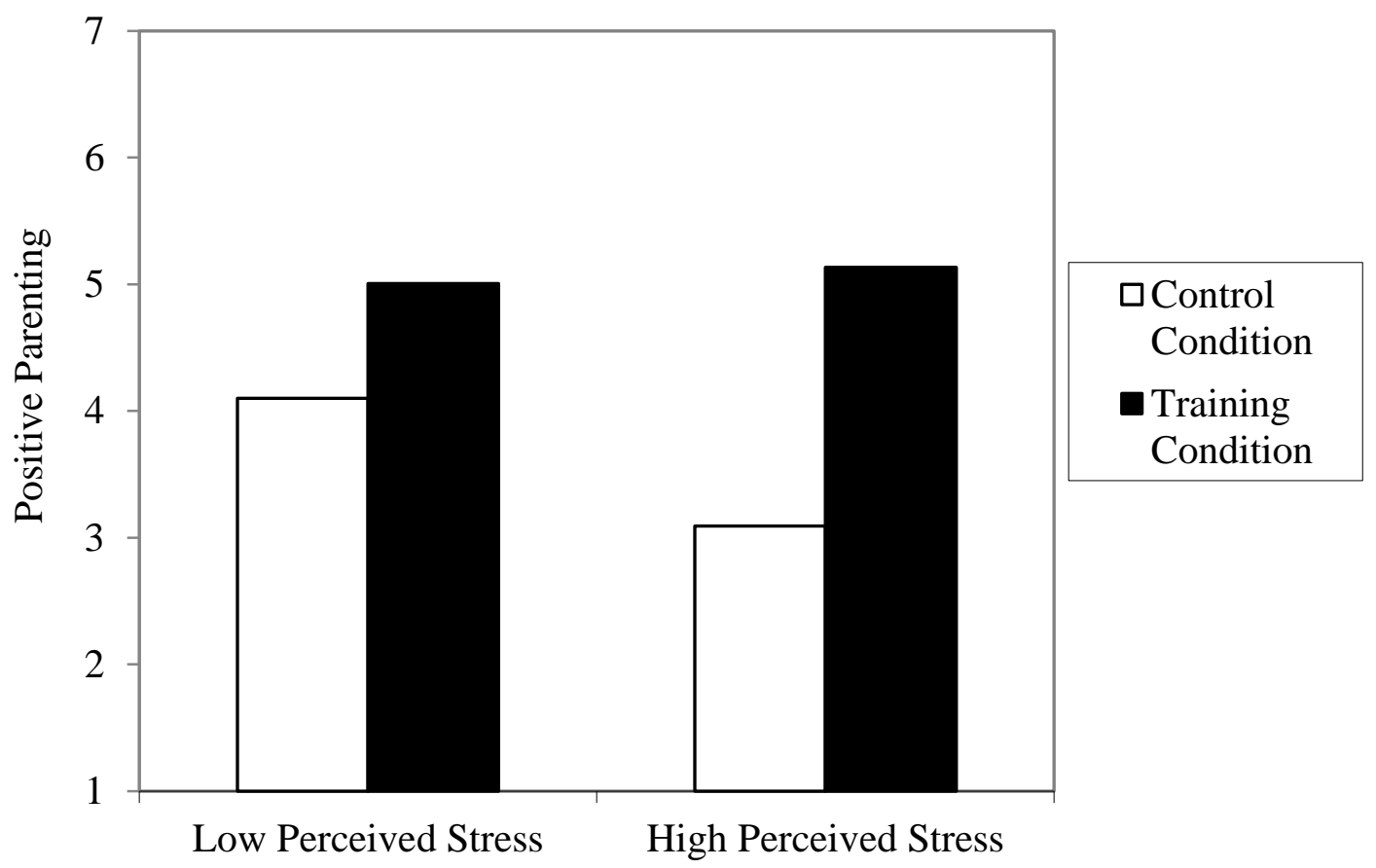

Figure 2.5. Baseline employee stress moderated training effect on spouse positive parenting at 9-months. 


\section{References}

American Psychological Association. (2017). Stress in America: The State of our Nation. https://www.apa.org/images/state-nation_tcm7-225609.pdf.

Amstad, F. T., Meier, L. L., Fasel, U., Elfering, A., \& Semmer, N. K. (2011). A Metaanalysis of work-family conflict and various outcomes with a special emphasis on cross-domain versus matching-domain relations. Journal of Occupational Health Psychology, 16(2), 151-169.

Arpin, S. N., Starkey, A., Mohr, C. D., Greenhalgh, A., \& Hammer, L. (2019). A well spent day brings happy sleep: Findings from a dyadic study of capitalization support, loneliness, and sleep outcomes. Journal of Family Psychology.

Avey, J. B., Luthans, F., \& Jensen, S. M. (2009). Psychological capital: A positive resource for combating employee stress and turnover. Human Resource Management, 48(5), 677-693.

Bakker, A. B., Demerouti, E., \& Dollard, M. F. (2008). How job demands affect partners' experience of exhaustion: integrating work-family conflict and crossover theory. Journal of Applied Psychology, 93(4), 901.

Bakker, A. B., Demerouti, E., \& Schaufeli, W. B. (2005). The crossover of burnout and work engagement among working couples. Human Relations, 58(5), 661-689.

Belsky, J., \& Pluess, M. (2009). Beyond diathesis stress: differential susceptibility to environmental influences. Psychological Bulletin, 135(6), 885-908. 
Bodner, T. E., \& Bliese, P. D. (2018). Detecting and differentiating the direction of change and intervention effects in randomized trials. Journal of Applied Psychology, 103(1), 37.

Bolger, N., DeLongis, A., Kessler, R. C., \& Schilling, E. A. (1989). Effects of daily stress on negative mood. Journal of Personality and Social Psychology, 57(5), 808.

Bolger, N., DeLongis, A., Kessler, R. C., \& Wethington, E. (1989). The contagion of stress across multiple roles. Journal of Marriage and the Family, 175-183.

Burleson, B. R. (2003). The experience and effects of emotional support: What the study of cultural and gender differences can tell us about close relationships, emotion, and interpersonal communication. Personal Relationships, 10(1), 1-23.

Butler, A., Grzywacz, J., Bass, B., \& Linney, K. (2005). Extending the demands-control model: A daily diary study of job characteristics, work-family conflict and workfamily facilitation. Journal of Occupational and Organizational Psychology, 78(2), 155-169.

Cohen, S. (2004). Social relationships and health. American Psychologist, 59(8), 676.

Cohen, S., Kamarck, T., \& Mermelstein, R. (1983). A global measure of perceived stress. Journal of Health and Social Behavior, 24(4), 385-396.

Colella, A., Hebl, M., \& King, E. (2017). One Hundred Years of Discrimination Research in Journal of Applied Psychology: A Sobering Synopsis. Journal of Applied Psychology, 102(3). 
Coyne, J. C., Burchill, S. A. L., \& Stiles, W. B. (1991). An interactional perspective on depression. Handbook of Social and Clinical Psychology: The Health Perspective, 162, 327-349.

Crain, T. L., Hammer, L. B., Bodner, T., Kossek, E. E., Moen, P., Lilienthal, R., \& Buxton, O. M. (2014). Work-family conflict, family-supportive supervisor behaviors (FSSB), and sleep outcomes. Journal of Occupational Health Psychology, 19(2), 155.

Crain, T. L., \& Stevens, S. C. (2018). Family-supportive supervisor behaviors: A review and recommendations for research and practice. Journal of Organizational Behavior, 39(7), 869-888.

Crane, D. R., Busby, D. M., \& Larson, J. H. (1991). A factor analysis of the Dyadic Adjustment Scale with distressed and nondistressed couples. American Journal of Family Therapy, 19, $60-66$.

Dadds, M. R. (1995). Families, children and the development of dysfunction (Vol. 32, pp. 73-83). Thousand Oaks, CA: Sage Publications Inc.

Davis, K. D., Lawson, K., Almeida, D. M., Kelly, E., King, R. B., Hammer, L. Casper, L., Okechukwu, C., \& Hanson, G., \& McHale, S. M. (2015). Parents' daily time with their children: A workplace intervention. Pediatrics, 135(5), 875-882.

Demerouti, E., Bakker, A. B., \& Schaufeli, W. B. (2005). Spillover and crossover of exhaustion and life satisfaction among dual-earner parents. Journal of Vocational Behavior, 67(2), 266-289. 
Doss, B. D., Rhoades, G. K., Stanley, S. M., \& Markman, H. J. (2009). Marital therapy, retreats, and books: The who, what, when, and why of relationship help-seeking. Journal of marital and family therapy, 35(1), 18-29.

Ferguson, M., Carlson, D., Boswell, W., Whitten, D., Butts, M. M., \& Kacmar, K. M. (2016). Tethered to work: A family systems approach linking mobile device use to turnover intentions. Journal of Applied Psychology, 101(4), 520.

Ford, M. T., Heinen, B. A., \& Langkamer, K. L. (2007). Work and family satisfaction and conflict: a meta-analysis of cross-domain relations. Journal of Applied Psychology, 92(1), 57.

Goh, J., Pfeffer, J., \& Zenios, S. A. (2015). The relationship between workplace stressors and mortality and health costs in the United States. Management Science, 62(2), 608-628.

Graham, J. M., Liu, Y. J., \& Jeziorski, J. L. (2006). The dyadic adjustment scale: A reliability generalization meta-analysis. Journal of Marriage and Family, 68(3), 701-717.

Greenhaus, J. H., \& Powell, G. N. (2006). When work and family are allies: A theory of work-family enrichment. Academy of Management Review, 31(1), 72-92.

Grzywacz, J. G., \& Marks, N. F. (2000). Reconceptualizing the work-family interface: An ecological perspective on the correlates of positive and negative spillover between work and family. Journal of Occupational Health Psychology, 5(1), 111.

Hammer, L. B., Johnson, R. C., Crain, T. L., Bodner, T. Kossek, E. E., Davis, K. D., Kelly, E. L., Berkman, L. F., Buxton, O. M., Karuntzos, G., \& Chosewood, L. 
C. (2016). Intervention Effects on safety compliance and citizenship behaviors: Evidence from the Work, Family, and Health Study. Journal of Applied Psychology, 101, p.190-208. doi: 10.1037/ap10000047.

Hammer, L. B., Kossek, E. E., Anger, W. K., Bodner, T., \& Zimmerman, K. L. (2011). Clarifying work-family intervention processes: The roles of work-family conflict and family-supportive supervisor behaviors. Journal of Applied Psychology, $96(1), 134$.

Hammer, L. B., Wan, W. H., Brockwood, K. J., Bodner, T., \& Mohr, C. D. (2019). Supervisor support training effects on veteran health and work outcomes in the civilian workplace. Journal of Applied Psychology, 104(1), 52-69.

Hammer, L. B., Wan, W. H., Brockwood, K. J., Mohr, C. D., \& Carlson, K. F. (2017). Military, work, and health characteristics of veterans and reservists from the Study for Employment Retention of Veterans (SERVe). Military Psychology. 29(6), 491-512.

Heller, D., \& Watson, D. (2005). The dynamic spillover of satisfaction between work and marriage: the role of time and mood. Journal of Applied Psychology, 90(6), 1273.

Hobfoll, S. E. (1989). Conservation of resources: A new attempt at conceptualizing stress. American Psychologist, 44(3), 513-524.

Hobfoll, S. E. (2002). Social and psychological resources and adaptation. Review of General Psychology, 6(4), 307-324.

Hobfoll, S. E., Halbesleben, J., Neveu, J. P., \& Westman, M. (2018). Conservation of resources in the organizational context: The reality of resources and their 
consequences. Annual Review of Organizational Psychology and Organizational Behavior, 5, 103-128.

Holt-Lunstad, J., Birmingham, W., \& Jones, B. Q. (2008). Is there something unique about marriage? The relative impact of marital status, relationship quality, and network social support on ambulatory blood pressure and mental health. Annals of Behavioral Medicine, 35(2), 239-244.

Holt-Lunstad, J., Smith, T. B., \& Layton, J. B. (2010). Social relationships and mortality risk: a meta-analytic review. PLoS medicine, 7(7).

Hunsley, J., Best, M., Lefebvre, M., \& Vito, D. (2001). The Seven-Item Short Form of the Dyadic Adjustment Scale: Further Evidence for Construct Validity. American Journal of Family Therapy, 29(4), 325-335. doi:10.1080/01926180152588734

Ingersoll-Dayton, B., Neal, M. B., \& Hammer, L. B. (2001). Aging parents helping adult children: The experience of the sandwiched generation. Family Relations, 50, 262-271.

Karney, B. R., \& Bradbury, T. N. (1995). The longitudinal course of marital quality and stability: A review of theory, methods, and research. Psychological Bulletin, $118(1), 3-34$.

Karney, B. R., \& Crown, J. S. (2007). Families under stress: An assessment of data, theory, and research on marriage and divorce in the military (Vol. 599). Rand Corporation. Santa Monica, CA. https://apps.dtic.mil/dtic/tr/fulltext/u2/a465553.pdf. 
Karney, B. R., Loughran, D. S., \& Pollard, M. S. (2012). Comparing marital status and divorce status in civilian and military populations. Journal of Family Issues, 33(12), 1572-1594.

Kelloway, E. K., \& Barling, J. (2010). Leadership development as an intervention in occupational health psychology. Work \& Stress, 24(3), 260-279.

Kelly, E. L., Moen, P., Oakes, J. M., Fan, W., Okechukwu, C., Davis, K. D., \& Mierzwa, F. (2014). Changing work and work-family conflict: Evidence from the work, family, and health network. American Sociological Review, 79(3), 485-516.

Kiecolt-Glaser, J. K., Fisher, L. D., Ogrocki, P., Stout, J. C., Speicher, C. E., \& Glaser, R. (1987). Marital quality, marital disruption, and immune function. Psychosomatic Medicine, 49(1), 13-34.

Kiecolt-Glaser, J. K., \& Glaser, R. (1981). Stress and immune function in humans. In Psychoneuroimmunology (pp. 849-867).

Kossek, E. E., Hammer, L. B., Kelly, E. L., \& Moen, P. (2014). Designing work, family $\&$ health organizational change initiatives. Organizational Dynamics, 43(1), 5363.

Kossek, E. E., Pichler, S., Bodner, T., \& Hammer, L. B. (2011). Workplace social support and work-family conflict: A meta-analysis clarifying the influence of general and work-family-specific supervisor and organizational support. Personnel Psychology, 64(2), 289-313. 
Lawson, K. M., Davis, K. D., McHale, S. M., Hammer, L. B., \& Buxton, O. M. (2014). Daily positive spillover and crossover from mothers' work to youth health. Journal of Family Psychology, 28(6), 897-907.

Le Fevre, M., \& Kolt, G. S. (2006). Eustress, distress and their interpretation in primary and secondary occupational stress management interventions: Which way first? Journal of Managerial Psychology, 21(6), 547-565.

McHale, S. M., Lawson, K. M., Davis, K. D., Casper, L., Kelly, E. L., \& Buxton, O. (2015). Effects of a workplace intervention on sleep in employees' children. Journal of Adolescent Health, 56(6), 672-677.

Muthén, L.K. and Muthén, B.O. (1998-2017). Mplus User’s Guide. Eighth Edition. Los Angeles, CA: Muthén \& Muthén

Myers, D. G. (2000). The funds, friends, and faith of happy people. American psychologist, 55(1), 56-67.

O'Driscoll, M. P., Poelmans, S., Spector, P. E., Kalliath, T., Allen, T. D., Cooper, C. L., \& Sanchez, J. I. (2003). Family-responsive interventions, perceived organizational and supervisor support, work-family conflict, and psychological strain. International Journal of Stress Management, 10(4), 326-344.

Ogolsky, B. G., \& Bowers, J. R. (2013). A meta-analytic review of relationship maintenance and its correlates. Journal of Social and Personal Relationships, $30(3), 343-367$. 
Repetti, R. L. (1989). Effects of daily workload on subsequent behavior during marital interaction: The roles of social withdrawal and spouse support. Journal of Personality and Social Psychology, 57(4), 651-659.

Repetti, R. L., \& Wood, J. (1997). Effects of daily stress at work on mothers' interactions with preschoolers. Journal of Family Psychology, 11(1), 90-108.

Rumann, C. B., \& Hamrick, F. A. (2010). Student veterans in transition: Re-enrolling after war zone deployments. The Journal of Higher Education, 81(4), 431-458.

Sanders, M. R., Markie-Dadds, C., Tully, L. A., \& Bor, W. (2000). The triple P-positive parenting program: a comparison of enhanced, standard, and self-directed behavioral family intervention for parents of children with early onset conduct problems. Journal of Consulting and Clinical Psychology, 68(4), 624-640.

Shafer, E. F., Kelly, E. L., Buxton, O. M., \& Berkman, L. F. (2017). Partners' overwork and individuals' well-being and experienced relationship quality. Community, Work \& Family, 21(4) 1-19.

Silverstein, M., Conroy, S. J., Wang, H., Giarrusso, R., \& Bengtson, V. L. (2002). Reciprocity in parent-child relations over the adult life course. The Journals of Gerontology Series B: Psychological Sciences and Social Sciences, 57(1), S3S13.

Spanier, G. B. (1976). Measuring dyadic adjustment: New scales for assessing the quality of marriage and similar dyads. Journal of Marriage and the Family, 38(1) 15-28. 
Stafford, L., \& Canary, D. J. (1991). Maintenance strategies and romantic relationship type, gender and relational characteristics. Journal of Social and Personal Relationships, 8(2), 217-242.

Story, L. B., \& Repetti, R. (2006). Daily occupational stressors and marital behavior. Journal of Family Psychology, 20(4), 690-700.

Thoits, P. A. (1991). On merging identity theory and stress research. Social Psychology Quarterly, 54, 101-112.

Umberson, D., \& Karas Montez, J. (2010). Social relationships and health: A flashpoint for health policy. Journal of Health and Social Behavior, 51(1_suppl), S54-S66.

van Steenbergen, E. F., Kluwer, E. S., \& Karney, B. R. (2014). Work-family enrichment, work-family conflict, and marital satisfaction: A dyadic analysis. Journal of Occupational Health Psychology, 19(2), 182.

Wan, W. H., Haverly, S. N., \& Hammer, L. B. (2018). Work, stress, and health of military couples across transitions. Occupational Stress and Well Being, 16, 6989. Emerald Publishing Limited.

Webster-Stratton, C., \& Hammond, M. (1990). Predictors of treatment outcome in parent training for families with conduct problem children. Behavior Therapy, 21(3), 319-337.

Westman, M. (2001). Stress and strain crossover. Human Relations, 54(6), 717-751.

Westman, M., Vinokur, A. D., Hamilton, V. L., \& Roziner, I. (2004). Crossover of marital dissatisfaction during military downsizing among Russian army officers and their spouses. Journal of Applied Psychology, 89(5), 769-779. 
Chapter 3. Work-Family Conflict and Family-Supportive Supervisor Behaviors: Daily Affective Well-being Consequences for Couples

Jacquelyn M. Brady ${ }^{1,2}$, Leslie B. Hammer ${ }^{1,2}$, Cynthia D. Mohr ${ }^{1}$, Todd E. Bodner ${ }^{1}$, Marjaana Sianoja ${ }^{2}$ and Wylie Wan $^{3}$

1. Portland State University

2. Oregon Health \& Science University

3. Northwest Regional Education Service District

Author Note

Jacquelyn M. Brady, Department of Psychology, Portland State University, and Oregon Institute of Occupational Health Sciences, Oregon Health \& Science University. Leslie B. Hammer, Department of Psychology, Portland State University, and Oregon Institute of Occupational Health Sciences, Oregon Health \& Science University. Cynthia D. Mohr, Department of Psychology, Portland State University. Todd E. Bodner, Department of Psychology, Portland State University. Marjaana Sianoja, Oregon Institute of Occupational Health Sciences, and Oregon Health \& Science University. Wylie Wan, Northwest Regional Education Service District. The U.S. Army Medical Research Acquisition Activity, 820 Chandler Street, Fort Detrick MD 21702-5014 is the awarding and administering acquisition office. This work was supported by the Office of the Assistant Secretary of Defense for Health Affairs, through the USAMRMC Broad Agency Announcement under Award W81XWH13-2-0020. Opinions, interpretations, conclusions and recommendations are those of the authors and are not necessarily endorsed by the Department of Defense. Portions of this research were supported by the Grant \# T03OH008435 awarded to Portland State University, funded by the Centers for Disease Control and Prevention, National Institute for Occupational Safety and Health. 
Its contents are solely the responsibility of the authors and do not necessarily represent the official views of NIOSH, CDC or HHS

Correspondence concerning this article should be addressed to Jacquelyn M.

Brady, Department of Psychology, Portland State University, 1721 SW Broadway St., Portland, OR 97207. Contact: bradja@ohsu.edu. 


\begin{abstract}
Previous studies have demonstrated that work-family conflict (WFC) is associated with declines in employee mood, and that the effects of WFC extend to relationship satisfaction at home via emotions. However, there is less research examining day-to-day resources that can prevent negative work-to-family conflict (WTFC) spillover to mood, nor is there any known research linking WTFC to daily spouse mood (crossover), despite recent calls to employ more longitudinal studies examining spillover and crossover. Through the lens of COR theory, the present study examines the daily associations of WTFC and employee and spouse positive and negative mood, as well as the role of family supportive supervisor behaviors (FSSB) as a resource to replenish WTFC-related affective resource loss. In addition, both within and between-person effects are examined at each step of the model. The current study utilizes a 32-day daily diary design and draws on a sample of employees and their spouse $(N=101)$. Findings generally support the hypotheses that daily employee WTFC is associated with both employee and spouse reports of positive and negative mood, however these effects are nuanced for spouses. In addition, FSSB protected against WTFC associated positive mood declines for employees, however there were no other moderating effects. We discuss the findings, implications, limitations, and avenues for future research.
\end{abstract}


Work-Family Conflict and Family-Supportive Supervisor Behaviors: Daily Affective Well-being Consequences for Couples

Work-life stress is a substantial health and safety hazard (Hammer \& Sauter, 2013). As the lines between work and home life are increasingly blurred, it is important to understand the effects of work-family conflict (WFC), a specific type of work-life stress (Aumann \& Galinsky, 2009). WFC is defined as "interrole conflict in which the role pressure from the work and family domains are mutually incompatible in some respect” (Greenhaus \& Beutell, 1985, p. 77), and can be further clarified as work-tofamily conflict (WTFC) or family-to-work-conflict (FTWC). WFC is associated with a wide range of negative work (e.g. job satisfaction), home (e.g., marital satisfaction), and individual outcomes (e.g., psychological distress; Allen, Herst, Bruck \& Sutton; 2000; Amstad, Meier, Fasel, Elfering, \& Semmer, 2011). Likewise, WFC is associated with spouse WFC (Hammer, Allen, \& Grigsby, 1997), and spouse resentment of a focal employee's work, and subsequent employee turnover intentions (Ferguson et al., 2016). Taken together, WFC is an important construct for consideration among organizations, individuals, and spouses. Although the body of WFC research is well established in many regards, there are several gaps in the extent literature.

The majority of WFC research has been based on cross-sectional studies. As noted by Almeida and colleagues, (2016), examining WFC as a static variable gives insight to general relationships between WFC and its correlates, but does not provide sufficient information about the effects of higher and lower levels of WFC compared to the general experience of WFC. Examining within-person effects are crucial to 
understanding the micro-processes by which WFC can spillover to impact employee outcomes (e.g. marital satisfaction, psychological distress; Amstad, et al, 2011). A number of diary studies have investigated spillover of WFC to positive or negative mood among employees (e.g., negative mood, Almeida, et al., 2016; discrete emotion spillover, Judge, Ilies, \& Scott; 2006; bi-directional emotion spillover, Williams \& Alliger, 1994; and positive and negative mood; Ilies et al., 2007). In addition to the intrapersonal effects of spillover, crossover, an interpersonal process when stress or strain of one person affects the strain in another person, can also occur. Despite evidence that WFC can crossover to influence spouse outcomes (e.g., marital satisfaction; van Steenbergen, Kluwer, \& Karney, 2014), extant diary research has focused on employee spillover or more distal crossover outcomes (e.g. positivity towards marriage; van Steenbergen et al., 2014; spousal support and subsequent relationship satisfaction, Bakker, Demerouti, \& Burke. 2009). Thus, a gap remains in understanding how employee WFC influences the more proximal crossover to spouse positive and negative mood using a daily diary methodology.

Although WFC is linked to poor outcomes, there exists a body of evidence suggesting that family supportive supervisor behaviors (FSSB) can promote positive outcomes and reduce the negative effects of WFC (for review see Crain \& Stevens, 2018; Hammer, Kossek, Yragui, Bodner, \& Hanson, 2009). Family-supportive supervisors exhibit behaviors that are supportive of employees' non-work lives and family responsibilities, and help employees to manage both work and non-work demands (Hammer et al., 2009). Almeida and colleagues (2016) showed that between-person 
general supervisor support moderates the within-person effect of WFC on negative mood. However they found no moderating effects on negative mood when examining matching level analyses (within-person WFC and general supervisor support), nor did they examine the moderating effects of FSSB. Additionally, Kossek et al., (2011) found that familyspecific support is more effective in terms of reducing individual perceptions of WFC than general supervisor support. Mirroring the large body of WFC research, the vast majority of research examining the link between FSSB and WFC has focused on their static relationship. Therefore, examining the role of FSSBs in protecting against the dayto-day effects of WFC is critical to understanding the underlying processes by which FSSBs improve employee outcomes.

Little is known about the pattern of findings when comparing between and withinperson effects of WFC. As evidenced by previous research in the work-family literature (Almeida et al., 2016; Shockley \& Allen, 2015), this gap is critical because the pattern of effects is not always consistent across levels (e.g. detecting within versus between, or between-person moderators on within-person effects). Utilizing a daily approach allows researchers to capture within and between-person effects. Such methods involve repeatedly capturing phenomena closer to actual occurrences over a period of time, and therefore researchers can examine within-person fluctuations while also obtaining more valid responses that are less subject to memory bias (Ohly, Sonnentagm Niessen \& Zapf, 2010). Furthermore, the within-person approach also allows for ruling out time invariant third variables (e.g., neuroticism) as alternative explanations for links between WFC and mood. As such, an additional gap in the literature is to compare previously unexplored 
relations between WFC and mood, as well as the moderating role of FSSBs for both employees and spouses at both the within and between-person levels.

The goals of the current study are to fill the above relevant gaps in the literature. Through the lens of COR theory (Hobfoll, 1989), we use a daily diary study to examine the effects of employee WFC on proximal affective outcomes for employees and spouses. By identifying daily mood associations with WFC, the current study provides insight to the pathways by which longer term outcomes, such as marital satisfaction, may occur (e.g. via positive, negative, or both affective pathways). Additionally, the current study aims to uncover the role of FSSB as a moderator of the negative effects of WFC on mood for employees and spouses. By examining the within-person-level, we hope to better capture the day-to-day dynamic processes in which FSSBs are thought to operate, such as counteracting the negative effects of daily WFC. Finally, we compare observed withinperson effects with between-person effects from aggregate daily diary reports. This strategy helps to untangle whether WFC and FSSB are better conceptualized from within or between-person perspectives.

\section{COR theory, Spillover, and Crossover}

COR theory (Hobfoll, 1989) indicates that individuals are motivated to obtain, maintain, and protect resources, and when resources are either lost or at risk of being lost, individuals experience stress and anxiety (Hobfoll, Halbesleben, Neveu, \& Westman, 2018). Subsequently, individuals enter a resource defensive state, where it is more difficult to obtain resources (e.g. resource loss begets resource loss; Hobfoll, 1989). This corollary of COR has been evident in the work-family literature, which shows work stress 
results in withdrawal and anger towards spouses and children (Repetti \& Wood, 1997). Thus, when individuals are in a state of resource loss, their partners may feel this loss either via empathy, or indirectly because their spouse has redirected their resources towards work and away from family, which leads to crossover. Westman (2001) further defined the crossover process to include positive crossover, and suggested it can occur through various mechanisms such as empathy, emotion contagion, and intervening variables (e.g. supervisor support). In the current study, we conceptualize WTFC crossover to shifts in spouse mood as a primary process. Because positive spouse relationships are important for health (for review see Kiecolt-Glaser \& Wilson, 2017), WTFC may drain resources and be a particularly powerful promoter of loss spirals for employees and spouses. However, COR theory also clarifies that when resource loss is present (e.g., WTFC), resource gain will be salient, and therefore reduce the negative effects of resource loss. Indeed, COR theory helps to explain the immediate results of resource loss within the spillover and crossover framework (Hobfoll et al., 2018). Here COR is utilized to understand how WTFC, as a stressor and drain on resources, impacts both employee and spouse mood, and how FSSB can help to prevent loss spirals and instead promote resource gains.

\section{Positive and Negative Mood}

Mood refers to a general sense of feeling good or bad, and is thus inherently broader than narrowly defined emotions (DeSteno, et al., 2013; Ekman, 1994; Rosenberg, 1998; Russell \& Feldman Barrett, 1999). Mood has been associated with health via direct physiological effects, as well as indirect effects by shaping behaviors and cognitions 
(DeSteno et al., 2013; Diener \& Chan, 2011). Therefore, mood is often conceptualized as a mediator to outcomes (e.g., negative mood mediates the relationship between surface acting and work withdrawal; Scott \& Barnes, 2011), and by itself as an indicator of subjective well-being (Diener \& Chan, 2011). Whereas the vast majority of early affective research focused on the poor outcomes that result from negative mood, there has been an upshift in focus on the role of positive mood for promoting positive outcomes (Fredrickson, 2001). The workplace literature has also been infused by the intrigue of the powerful effects of positive mood including increased productivity, creativity, flow, and income (Estrada, Isen, \& Young, 1994; Staw, Sutton, \& Pelled, 1995).

Whereas negative mood hinders one's ability to invest in resources because negative emotions narrow individuals' thoughts and abilities, positive mood allows individuals to broaden and build their resources (Fredrickson, 2001), it is often considered a link between resources and positive outcomes. Lyubomirsky, King, and Diener (2005) demonstrated that positive mood is associated with being able to utilize existing resources to gain more resources, which aligns with the concept from COR theory of resource gains leading to further resource gains (gain spirals; Hobfoll, 1989). Thus, whereas negative emotions may hinder resource gain, positive emotions may promote resource gain (Fredrickson, 2001). Since mood is a primary response to resource loss or gain, and represents an important well-being promoting outcome, it is important to further explore causes of both negative and positive mood stemming from the workfamily interface.

\section{WTFC and Employee Mood}


Until this point, WFC has been conceptualized generally as opposed to specifically (e.g., WTFC). We continue to do so, however, we also include more specific references to WTFC where noted. WTFC can spillover and impact individuals in their home life (e.g., family related stress; Amstad et al., 2011). In line with COR, experiencing resource loss draws individuals inward to a defensive state, leading them to feel poorly at home when resources have not been replenished. Cross-sectional, metaanalytic, and other empirical studies have shown that WTFC and general WFC is linked to individuals' physical and psychological well-being (van Hoof et al., 2005; GrantVallone \& Donaldson, 2001), including depression (Frone, Yardley, \& Markel, 1997; Hammer, Neal, Newsom, Brockwood, \& Colton, 2005), and relationship outcomes (e.g. marital satisfaction; Amstad et al., 2011). Previous research has demonstrated that WFC is also linked to mood. Both reduced positive and increased negative mood are associated with general WFC, and which is in turn related to job and psychological outcomes (e.g. job satisfaction and psychological distress; Kafetsios, 2007). In daily studies, higher levels of WTFC have been linked to higher levels of daily negative mood (Almeida et al., 2016). Further, correlations from a larger study by Ilies and colleagues (2007) has indicated the WTFC is associated with both higher levels of home negative mood and lower levels of home positive mood. We anticipate finding similar results as previous studies, and hypothesize (see Figure 1):

H1: Daily employee WTFC will be inversely associated with daily employee positive mood. 
H2: Daily WTFC will be positively associated with employee daily negative mood.

Insert Figure 1 about here

\section{WTFC and Spouse Mood}

Crossover effects from an individual to their spouse have been demonstrated.

High burnout, engagement, and WFC among individuals has been linked to high burnout, engagement, and WFC among spouses (Bakker, Demerouti, \& Schaufeli, 2005; Hammer et al., 1997). However, research has not investigated crossover of WTFC as a type of stress to spouse affective outcomes. Researchers have begun to focus on how changes in relationship satisfaction occur among dyads (e.g. Bakker et al., 2009; van Steenbergen et al., 2014), and there is mounting evidence that employee associated WFC is indirectly linked to spouse reports of marital satisfaction via spouse support (Bakker et al, 2009) and positivity towards marriage (van Steenbergen et al., 2014). However, these studies have either employed cross-sectional or time lagged-designs, or have not examined the immediate daily mood consequences for spouses of employees who have higher WFC. As such, they provide insight into how WFC may be expected to influence outcomes, but provide less evidence regarding the immediate and dynamic associations between WFC and crossover to spouses. Crossover theorists have maintained that crossover can occur through various mechanisms, including both empathy and emotion contagion (Westman, 2016). Therefore, when employees are exhibiting stress responses, their spouses are also 
likely to feel the immediate effects. Such effects are also in line with the COR theory tenet that resource depletion leads individuals to exhibit stress responses such as withdrawal (Hobfoll, 1989). Despite the above reviewed work, there is no known research examining the daily link between employee WTFC and spouse mood. Thus, it is hypothesized:

H3: Daily employee WTFC will be inversely associated with daily spousal positive mood.

H4: Daily employee WTFC will be positively associated with daily spousal negative mood.

\section{The Role of Family Supportive Supervisor Behaviors}

FSSB, which includes emotional support, instrumental support, role-modeling, and creative work-family management, are related to less negative and more positive spillover to one's home domain (Hammer et al., 2009). FSSB has been associated with a number of work (e.g., job satisfaction), and non-work outcomes (e.g., health; Crain \& Stevens, 2018), and is considered a workplace resource, when support is provided. Interventions promoting FSSB can increase time spent with children (Davis et al., 2015) and improve individual well-being and work outcomes, particularly when individuals have higher WFC (Hammer et al., 2011). WFC is associated most strongly with work stressors such as work role overload (Michel, Kotrba, Mitchelson, Clark, \& Baltes, 2011). Therefore, resources in the work domain, such as FSSB, may be key to stopping the spread of such stressors to one's home life. Meta-analytic evidence suggests that family- 
specific resources are more influential at reducing WFC compared to general workplace social support (Kossek et al., 2011).

Having a family supportive supervisor is also linked to lower daily stressors for employees. For instance, employee ratings of supervisors' family supportiveness buffers against the impact of daily work demands on daily WFC (Goh, Ilies, R \& Wilson, 2015). Almeida and colleagues (2016) found that general supervisor support moderates the effects of daily WFC on negative mood and physiological reactivity. However, there is no known research examining whether FSSB can buffer against the within-person daily effects of WFC. Considering that FSSB is thought to be more effective at improving well-being outcomes than general supervisor support, this link is particularly important. In line with COR, when employees with high WFC perceive FSSBs, they should also experience resource replenishment. As a result, negative affective spillover resulting from WFC will likely be reduced. On the other hand, given that resource gains can be particularly salient when in a state of resource depletion (Hobfoll, 1989), being afforded FSSBs when faced with WFC should elicit greater positive affective responses. Thus, it is hypothesized that:

H5: Positive daily FSSB experiences will buffer against daily WTFC associated declines in positive mood among employees.

H6: Positive daily FSSB experiences will buffer against daily WTFC associated increases in negative mood among employees.

\section{Moderating Role of FSSB for Spouses}


In addition to the proposed buffering effect of FSSB on the relation between WTFC and mood among employees, and in line with crossover perspectives (Westman, 2001), FSSB provided to employees should also limit the effects of employee WTFC on spouse mood because it is an intervening variable. Should employee mood improve as a result of daily FSSB, spouse mood should be expected to follow suit because the effect of the stressor of WTFC has been mitigated. In line with COR theory, if an employee's mood resources are less drained as a result of receiving higher FSSB on days with higher WTFC, they should then return home from work with a greater level of affective resources. In addition to lessening the impact of WTFC crossover to spouse mood, when employees experience WTFC but also FSSB, they may be able to better meet their timebased home needs, and less likely to exhibit the behaviors associated with work stress related resource loss when they get home (e.g. withdrawal and anger; see Repetti \& Wang, 2017). Taken together, it is hypothesized that:

H7: Positive daily FSSB experiences for employees will buffer against daily employee WTFC associated declines in spousal positive mood.

H8: Positive daily FSSB experiences for employees will buffer against daily employee WTFC associated increases in spousal negative mood.

\section{Within and Between-person Comparison}

In addition to evaluating the above hypotheses, we also compare the pattern of within and between-person effects for each hypothesis. In the current study, we expect within-person effects will explain the effects on individuals and their spouses' mood on days when an employee has more or less WTFC. Between-person effects will assess 
whether individuals with higher WTFC over the 32-day study period will experience different positive and negative mood compared to individuals with lower WTFC over the study period. Thus, the between-person analyses will assess the impact of more stable effects (e.g. having higher WTFC in general). Consistent with COR theory in that stressors promote resource loss, the patterns of within and between relationships should be similar. However, researchers have found that between and within-person comparisons can yield drastically different results. For example, Vancouver and Kendall (2006) found that although self-efficacy is associated with greater performance at the between-person level, but at the within-person level the opposite was true.

There has been some research examining the within and between-person effects of WFC. Shockley and Allen (2015) utilized an episodic approach to understanding within and between-person effects of work and family predictors on WFC decisions (e.g. work interferes with family, or family interferes with work). They found that withinpersons, hypotheses were generally supported, however between-person analyses revealed fewer significant results. Almeida and colleagues (2016) examined both within and between-person direct effects of WTFC to negative mood and found that when examining moderating effects of WTFC on negative mood, only within and betweenperson moderators were significant predictors of within-person effects. Due to the general lack of evidence comparing within and between-person differences in the effect of WFC on employee and spouse positive and negative mood, we pose this as a research question. 
Research Question: Are the patterns of between-person WTFC, FSSB, and positive and negative mood effects consistent with within-persons patterns?

\section{Methods}

\section{Participants}

The results presented are from daily diaries collected as part of the Study for Employment Retention of Veterans (SERVe), which was funded by the Department of Defense. SERVe was approved by the institutional review board and human subjects protection committees of two participating research institutions $(N=35)$. Participants who were employed at least part-time ( $<20$ hours per week) at an organization participating in the larger SERVe, who were also either (a) serving in the National Guard or Reserve components (NG/R) or (b) had recently separated (no earlier that December 31, 2001) from the US armed forces (e.g., veterans) were eligible to participate in the study. Participants from the larger SERVe were invited to complete surveys regarding their work, family, and health at baseline, 3 months, and 9 months. Additionally, eligible participants were invited to participate in a baseline and follow up daily diary study. Employees' civilian supervisors were invited to participate in a supervisor support training called the Veteran Supportive Supervisor Training (VSST) after the baseline data collection but prior to follow-ups. The current study is based on the baseline data collection. A total of 512 employees completed the baseline survey (see Hammer, Wan, Brockwood, Mohr, \& Carlson, 2017 for more information on SERVe). At baseline, 272 spouses completed the baseline surveys, among which 260 were matched to a participating employee. 
Daily Family Study (DFS). All 260 matched couples from the larger SERVe study were invited to participate in the DFS. Over 32 days, couples received email links to short surveys that asked about daily events at work and home, as well as their daily mood, interactions, and activities. Participants were sent the email links after their workday with a six-hour window to complete that day's survey. Spouses who did not work were sent links at the same time as the employee to capture the same time frame. Participants who worked regular daytime shifts completed daily diaries between $5 \mathrm{pm}$ and $11 \mathrm{pm}$, whereas those who had non-daytime shifts completed daily diaries between $5 \mathrm{am}$ and $11 \mathrm{am}$.

Overall, employees and spouses from 188 couples participated in baseline DFS data collection, among which 162 were matched couples $(62.3 \%$ of the 260 eligible couples). Next, we excluded three couples from the current analysis because the employee and spouse/partner completed the daily diary at different times of the day (e.g., employee completed the regular shift survey while the spouse/partner completed the shift work survey), leaving a sample of 159 matched couples (61\% of 260 eligible couples; $98 \%$ of matched couples). In order to be included in the within and between aggregated analyses, the employee needed to have responded to both predictors (WTFC and FSSB) in the daily diary at least 3 of the 32 days, which left us with a final sample of 111 matched couples ( $68.5 \%$ of matched DFS couples). Importantly, individuals were given the option to respond to each item on the FSSB scale as "I did not interact with my supervisor". Those who responded to any of the FSSB items as "I did not interact with my supervisor," rather than the 1 - 5 response scale described below, were dropped from 
the analyses due to data quality concerns about the measure anchor. A series of dropout analyses revealed that employees who responded on less than 3 days $(N=48)$ on WTFC or FSSB had higher WTFC $(M=2.15, S D=.81)$ and negative $\operatorname{mood}(M=1.29, S D=$ $.45)$, lower FSSB $(M=3.22, S D=.85)$ compared to the WTFC $(M=1.84, S D .69)$, negative $\operatorname{mood}(M=1.16, S D=.20)$ and $\operatorname{FSSB}(M=3.55, S D=.78)$ of those who responded on 3 or more days, $t(156)=2.47, p=.01, t(156)=2.65, p=.05$, and $t(142)=-$ $2.14, p=.03$, respectively. However there were no significant differences in employee positive mood $(\mathrm{p}=.87)$, spouse positive $\operatorname{mood}(p=.81)$, or spouse negative mood $(p=$ $.18)$.

\section{Descriptive Statistics}

Of the possible 32 days of participation, outcomes were reported by employees on average 26.10 days $($ Min. $=3$ days, Median $=29$ days, Max. $=32$ days $)$ and spouses on average 26.31 days $($ Min. $=1$ days, Median $=30$ days, Max. $=32$ days $)$. Among the employee's response days, $57.6 \%(M=15.04$ days) were reported as weekdays (Monday - Thursday) and 42.4\% ( $M=11.08$ days) were weekends (Friday - Sunday). Employees of the 111 dyads reported that they interacted with their supervisors on 982 occasions, and on average 8.85 days $(S D=4.75$, Min. $=3$ Median $=8$, Max $=22)$. Table 1 displays the descriptive statistics of the study variables across all employees and spouses on both week and weekend days.

\section{Demographic Statistics.}

On average, employees were middle-aged $(M=38.9$ years, $S D=9.2)$, collegeeducated $(68.6 \%)$ white $(92 \%)$ males $(89.3 \%)$ who worked at their organization for 5.65 
years $(S D=5.76$, range $=0.1-28.1$ years $)$, and 42.6 hours per week $(S D=6.34)$. Of the 111 employees, $92(82.8 \%)$ have separated from the military and $19(17.1 \%)$ were still active in the NG/R. Spouses were also generally middle-aged $(M=36.81$ years, $S D=$ 9.1), college-educated $(66.7 \%)$ white $(86 \%)$ females $(89.9 \%)$. Ninety-nine $(60 \%)$ of spouses indicated they were employed, have been employed at their current position for 5.69 years $(S D=5.92$, range $=0.1-27.6$ years $)$, and worked for 38.9 hours per week $(S D$ $=10.61)$. Twenty-one spouses $(13.2 \%)$ were in the military and none were actively serving. On a couple level, the sample was primarily married (92\%) for $M=12.48$ years $(S D=8.47)$, and 101 of the couples reported having at least 1 dependent child $(91 \%)$.

\section{Measures}

All scale scores are based on a mean of scale items. Day-level internal consistencies were computed for the measures below on 3 days representing the beginning (Day 3), middle (Day 18), and end (Day 32).

Daily Work-family Conflict. Employee's WFC was reported each day, and was assessed via a 5-item scale (Netemeyer, Boles, \& McMurrian, 1996) that asked employees about their WFC in the past 24 hours $(\alpha=.93, .98, .98)$. Employees responded to the following items on a $1=$ strongly disagree to $5=$ strongly agree scale: "The demands of my work interfered with my family or personal time", "my job produced strain that made it difficult to fulfill family duties." WFC was asked regardless of whether employees worked that day.

Daily Mood. Daily mood for both employees and spouses were measured using mood items adapted from the positive and negative mood schedule expanded (PANAS- 
X; Watson \& Clark, 1994), and mood circumplex model (Larsen \& Diener, 1992). Scale scores reflect participant average positive and negative mood "right now." Responses ranged from $1=$ not at all to $5=$ extremely. Positive mood was measured with 5 items, including happy, quiet relaxed, active. The positive and negative mood scale generally showed acceptable to good reliability on Day 3, 18, and 32. Employee positive mood scale reliability was $\alpha=.59, \alpha=.61$, and $\alpha=.69$ respectively, while spouse positive mood reliability was $\alpha=.76, \alpha=.63$, and $\alpha=.67$ respectively. Negative mood was measured with 6 items, including sad, angry, lonely, ashamed, guilty, and nervous. Employee negative mood scale reliability was $\alpha=.63, \alpha=.76$, and $\alpha=.71$ respectively, while spouse negative mood reliability was $\alpha=.82, \alpha=.67$, and $\alpha=.82$ respectively.

Daily FSSB. Supervisor support was captured with short form measure of familysupportive supervisor behaviors (FSSB-SF) scale, validated by Hammer, Kossek, Bodner, and Crain (2013). Daily FSSB responses were recorded on workdays with the following 4-items: "My supervisor made me feel comfortable talking to him/her about conflicts between work and non-work." Participants responded from a $1=$ strongly disagree to $5=$ strongly agree scale. This scale demonstrated good reliability $(\alpha=.84$, .98 , and .90). In total there were 982 days of reported FSSB.

Covariates. Due to the daily within-person focus of this paper, we determined that only time-variant covariates should be considered. However, we did perform an initial between-person correlation analyses, which revealed no significant correlations between gender, age, number of children, marital status, and spouse employment status with employee WFC or the mood outcomes. However, because weekends could 
potentially explain shifts in mood that are not necessarily related to WFC, we modeled this as a control variable in our analyses. Weekend was coded as $1=$ Friday - Sunday and $0=$ Monday through Thursday. Weekends made up approximately $42 \%$ of days included in the current study.

Analysis Strategy. We utilized a 2-level model with spouses linked to employees to test for within and between-person effects. The intraclass correlations (ICCs) at the organization level were very small (i.e., $<.0001)$. Therefore, we used two-level models to examine the within and between-person effects regardless of organization assignment, consistent with current research strategies examining daily within and between-person effects (e.g., Lee, McHale, Crouter, Kelly, Buxton. \& Almeida, 2017). For within-person effects, we person-mean centered our predictors. For between-person effects, we aggregated individual averages across employee participation days and grand-mean centered the aggregated predictors. We then estimated within and between-person correlations among the study variables (see Table 1 and 2). To assess our within-person hypotheses and comparison of between-person effects, we ran a series of multi-level models using the NLME library in R (Pinheiro \& Bates, 2000). Each model accounted for the observation day, as well as both within and between-person effects, while controlling for the effect of weekends on the outcomes. The independence of within-person errors was tested by including autocorrelation in the models. We assessed the hypotheses at different steps in the model. Model 1 was utilized to assess the intercept, while Model 2 assessed the main effects hypotheses that focused on the association between daily WFC and employee positive and negative mood (Hypothesis 1 and 2). The next step involved 
entering the FSSB variable to create our moderating term (Model 3). In our final models (Model 4) we entered our moderation term to assess whether FSSB moderated the effects of WFC on positive and negative mood for employees (Hypothesis 3 and 4; see Table 2 for employee models). We repeated these steps for spouses to test the main crossover effects model of WFC on spouse positive and negative mood (Hypotheses 5 and 6), and the moderating effect employee of FSSB on spouse positive and negative mood (Hypotheses 7 and 8; see Table 3 for spouse effects models).

\section{Results}

\section{Descriptive Statistics and Correlations}

Table 1 displays the means, standard deviations, and correlations of the betweenperson (aggregated) study variables. Generally, employees had low WTFC $(M=1.84, S D$ $=.68)$, and both employees and spouses had average positive $\operatorname{mood}\left(M_{\mathrm{e}}=2.49\right.$ and $M_{\mathrm{s}}=$ 2.54 on a $1-5$ scale $)$, and low negative $\operatorname{mood}\left(M_{\mathrm{e}}=1.16\right.$ and $M_{\mathrm{s}}=1.21$ on a $1-5$ scale $)$. Between-person correlations revealed that WFC and FSSB were negatively correlated ( $r$ $=-.20, p=.05)$. WFC was also related to lower employee positive $\operatorname{mood}(r=-.24, p=$ $.013)$, and more employee and spouse negative $\operatorname{mood}(r=.29, \mathrm{p}=.002$, and $r=.37, p<$ .001 , respectively). FSSB was marginally related to lower employee negative mood ( $r=$ $.16, p=.098$ ). Within-person correlations (see Table 1) revealed that employees' withinperson WFC was negatively associated with FSSB $\left(r_{e}=-.08, p=.012\right)$. WFC was also associated with lower levels of positive $\operatorname{mood}\left(r_{e}=-.07, p<.001\right.$ and $\left.r_{s}=-.06, p=.002\right)$ and higher levels of negative mood for employees $\left(r_{\mathrm{e}}=.08, p<.001\right.$, and $r_{s}=.04, p=$. 047). WFC was also negatively associated with weekends $\left(r_{e}=-.16, p<.001\right)$. 
Additionally, within-person FSSB was marginally related to lower employee negative $\operatorname{mood}\left(r_{e}=-.06, p=.059\right)$. Weekends were also related to more positive $\operatorname{mood}\left(r_{e}=.07, p\right.$ $<.001$ and $\left.r_{s}=.07, p=.001\right)$ and less negative mood for spouses $\left(r_{s}=-.05, p=.006\right)$. The within and between-person variances were calculated, and from those so were the intraclass correlations (ICCS). ICCs were .61, .37, .64, and .62 for employee positive and negative mood and spouse positive and negative mood respectively. Thus, the ICCs indicated there were both within and between sources of variance on each outcome.

\section{Employee WTFC and Mood Spillover}

Employee positive and negative mood. When assessing the association between WTFC and employee positive and negative mood at the within-person level we found support for Hypothesis 1 and 2. On days when employees had higher WTFC, they reported less positive mood $(b=-.04, S E=.01, p<.001)$ and more negative mood on that day $(b=.03, S E=.01, p<.001)$. These findings are consistent with COR theory and suggest that daily WTFC is significantly associated with day-to-day spillover to employee affective well-being at home (see Table 2, Model 2).

Employee crossover to spouse positive and negative mood. In support of Hypothesis 3, there was a significant association between employee WTFC and spouse positive mood at the within-person level $(b=-.04, S E=.01, p=.002)$. On days when employees had higher WTFC their spouses tended to report less positive mood. However there was no significant association between employee WTFC and spouse negative mood at the within-person level $(b=.01, S E=.01, p=.216)$. Therefore, Hypothesis 4 was not supported (see Table 3, Model 2). 
FSSB as moderator. In support of Hypothesis 5, daily FSSB was a significant moderator of the relationship between day-to-day WTFC and employee positive mood ( $b$ $=.15, S E=.03, p<.001)$. Specifically, FSSB protected against WTFC associated declines in positive mood. Positive mood was relatively similar under conditions of lower WTFC for employees reporting both higher $(M=2.53)$ and lower $(M=2.64)$ levels of FSSB. However, under conditions of higher WTFC and FSSB $(M=2.78)$ and higher WTFC and lower FSSB $(M=2.26)$, FSSB protected against employee WTFC associated declines in positive mood (see Figure 2 and Table 2, Model 4). There were no moderating within-person effects supporting the link between WTFC and negative mood $(b=.001$, S.E. $=02, p=.96$ ), and thus Hypothesis 6 was not supported. This suggests that daily FSSB may not be effective for replenishing daily WTFC related down shifts in negative mood.

FSSB as a crossover moderator. FSSB did not moderate the relationship between employee WTFC and spouse positive $(b=-.04, S E=.04, p=.36)$ or spouse negative mood $(b=-.0004, S E=.03, p=.99)$ at the within-person level (See Table 3, Model 4). Therefore, Hypothesis 7 and 8 were not supported. This suggests that FSSB may not serve to replenish spouse affective resource loss associated with higher employee daily WTFC.

\section{Between-person Effects}

Main between-person effects on employee mood. The between-person main effects of WTFC on employee mood followed similar patterns to the within-person dayto-day effects. There was a significant association between WTFC and lower employee 
positive $\operatorname{mood}(b=-.20, S E=.06, p<.001)$ and higher negative $\operatorname{mood}(b=.09, S E=.03$, $p=.001)$ at the between-person level.

Main between-person effects on spouse mood. The between-person effects of WTFC on spouse outcomes were more nuanced. Specifically, although there were observed within-person effects on spouse positive mood, there were no main betweenperson effects of employee WTFC on spouse positive $\operatorname{mood}(b=.09, S E=.08, p=.269)$. However, unlike the within-person findings, there was a significant relationship between employee WTFC and spouse negative mood $(b=.19, S E=.05, p<.001)$ at the betweenperson level.

Between-person FSSB. At the between-person level of analysis, there was no significant interaction between WTFC and FSSB on employee $(b=-.13$, S.E. $=.09, p=$ $.152)$ or spouse $(b=-.04$, S.E. $=.10, p=.682)$ positive mood. There were also not any significant moderating effects of FSSB on the link between employee WTFC and employee $(b=.06$, S.E. $=.03, p=.077)$ or spouse $(b=-.02, S . E .=.05, p=.724)$ negative mood. This suggests that between-persons FSSB is not necessarily enough to replenish resource loss associated with the wear-and-tear effects of WTFC. See Table 3.4 for a summary of findings.

\section{Discussion}

The current study utilized COR theory (Hobfoll, 1989), to expand on earlier research by examining daily direct and moderated associations between employees' WTFC and employees' and their spouses' positive and negative mood. The current study demonstrated the extent to which within and between-person comparisons can be made 
among these constructs with a 32-day daily diary study. Findings were generally in line with COR theory, and lend some support for daily spillover and crossover effects of WTFC. Specifically, replicating and extending existing research, we linked daily WTFC with less positive mood and more negative mood for employees. We also extended previous research by linking daily employee WTFC to less positive mood for spouses, and determined that there does not appear to be within-person effects of employee WTFC on spouse negative mood. For employees, FSSB moderated the effects on daily withinperson positive mood. That is, on days where employees had higher WTFC, experiencing greater levels of daily FSSB were important for protecting against declines in positive mood. However, there were no moderating effects on employee negative mood, nor were there significant moderating effects on spouse positive or negative mood.

\section{Between-person Findings}

Consistent evidence that the associations of WTFC and employee positive and negative mood were observed in the expected directions at both within and betweenperson levels of analyses, suggesting that WTFC has both day-to-day and wear-and-tear effects on positive and negative affective well-being for employees. The association between WTFC and spouse mood was more nuanced, suggesting that WTFC is associated with spouse day-to-day positive mood, but higher amounts of employee WTFC do not seem to erode spouse positive mood at the between-person level. The opposite occurred for spouse negative mood. That is, spouses of employees who had higher levels of WTFC overall reported higher levels of negative mood overall, but there were no significant within-person effects on spouse day-to-day negative mood. Finally, 
despite the within-person support for the buffering effect of FSSB between WTFC and employee positive mood, there were no significant moderating between-person effects of FSSB on any of the outcomes.

\section{Research and Theory Contributions}

This study extends previous research on the day-to-day spillover effects of specific WTFC on employee negative mood to employee positive mood. While positive and negative mood represent emotional resources, they have been known to represent two distinct pathways (Diener \& Emmons, 1984; Fredrickson, 2001). Findings support COR theory and suggest that WTFC spillover is associated with employee affective resource loss via both pathways, and both within and between-persons (day-to-day and wear-andtear effects). A second contribution is the finding of the association of employee WTFC and spouse day-to-day mood. Together the crossover findings suggest that within-person shifts in positive mood are sensitive to day-to-day changes in stressors, whereas day-today shifts in negative mood are more likely impacted by other stressors. Mapping on to affective pathways, these findings may also suggest that declines in positive mood are more easily recovered from and malleable, whereas down-shifts in negative mood may require more stable shifts in stressors and resources to recover from. In considering COR and crossover frameworks these findings suggest employee WTFC as a resource-draining stressor is differentially associated with day-to-day changes in spouse positive and negative affective personal resources, and that these resources should be further clarified.

In addition, the current study adds to understanding of the interaction of WTFC and FSSB and spillover on a daily basis. While FSSB promotes reductions in WTFC 
associated positive mood resource loss for employees, there were no effects on negative mood, nor were there any between-person effects. Together, this suggests the mechanisms which underlie the positive effects of FSSB on work and non-work outcomes (e.g. Crain \& Stevens, 2018) may be primarily due to their immediate effects on employee positive affective pathways. In regards to the lack of spillover effects on employee negative mood, the current findings may be reflective of the above observation that negative mood may represent a more resource depleted state that requires consistent shifts in resources and stressors in order to recover from losses. Still, the finding that FSSB does not moderate the relationship between day-to-day WTFC and negative mood is counter to findings from Almeida et al. (2016). Specifically Almeida et al. (2016) found that the WTFC and negative mood link is moderated by general supervisor support. Given that meta-analytic evidences suggests that family-specific support is more powerful in reducing WFC (Kossek et al., 2011), these inconsistent findings are relatively surprising and suggest a need for future research to uncover why general support may be an effective moderator of the relationship but not FSSB.

Finally, FSSB did not directly crossover to replenish spouse affective resource loss. The lack of direct crossover effects of FSSB as a resource for spouses suggests that the direct effects of FSSB are likely only observable for employee outcomes, and their relationship to spouse outcomes are likely more distal and indirect. Specifically, models that examine behavior changes that occur as result of resource gain may better explain the way FSSB can promote resource replenishment. Specifically, FSSB may promote more positive behaviors from employees at home, which is a more direct and meaningful 
resource for spouses (Ilies et al., 2007; van Steenbergen et al., 2014). Future research should include employee mood and subsequent behaviors as predictors when considering the effects of employee FSSB resource gain on spouse affective resources.

\section{Practical implications}

The finding that daily WTFC is associated with not only, employee but spouse mood on a daily basis suggests an important practical implication for organizations to consider. Evidence indicates that WFC represents a significant cost for organizations (e.g., turnover intentions; Nohe \& Sonntag, 2014), which tends to result from work interfering with family (e.g. Amstad et al., 2011), and work-role stressors (Michel et al., 2011). Importantly, previous work has demonstrated that WFC is associated with employee turnover intentions via spousal resentment and commitment of an employees' job (e.g. Ferguson et al., 2016). Thus, previous work suggests organizations should consider the effects of WTFC originating from the workplace that has important effects that impact employee job outcomes via the impact it has on spouses. This study expands the above implications by demonstrating that even daily increases in WFC are associated with poorer day-to-day mood for spouses. Thus, organizations should take steps to reduce even daily occurrences of WTFC. Since WTFC is most often associated with work-role stressors such as work-load (Michel et al., 2011), one avenue for consideration is prevention through reduced work-load, and other detrimental work-place stressors.

Previous work has demonstrated that FSSB is associated with a host of positive work and non-work outcomes (Crain \& Stevens, 2018), and that interventions targeting increases in work and non-work support are effective at improving employee work and 
non-work outcomes (e.g., health, turnover intentions; Hammer et al., 2011). The finding that daily FSSB protects against daily WTFC associated declines in employee positive mood suggests that FSSB is also an important daily resource that organizations should focus on promoting in order to promote more positive outcomes among employees with higher WTFC. There are days in which organizations are not able to effectively or sufficiently manage the prevention of WTFC all together (e.g., on days with deadline associated temporary increases in workload). Thus, on days when WTFC is not able to be completely prevented against, FSSB provides a useful tool to mitigate detrimental effects on employee positive mood.

\section{Limitations and Future Directions}

While this study made several contributions, there are also limitations to be discussed and avenues for future research. The first limitations surround the data and methodological and analytical designs. First, employees were not nested within their respective organizations due to $<0$ variances attributed at the organization level, an approach used in similar previous research (Lee et al., 2017). Still, there were a small number of employees per organization, which can lead to difficulty in understanding the impact of working in an organization and between-person effects. Future research should target disentangling organization-level versus between-person effects. Additionally, data were collected at only one time per day in order to decrease participant burden associated with a 32-day diary design. While this can lead to increases in common method bias, it is not expected that this was an issue in the current study considering within-person fluctuations were examined, and spouse outcomes relied on both employee and spouse 
reports. Further, we were interested in the micro-processes, or the immediate affective effects associated with WTFC, therefore capturing the relative experience of WTFC in close proximity to mood was necessary. Additionally, there was also missing data, or days that employees and/or spouses did not provide responses to measures. This is a known difficulty with daily data collection, yet requesting even more responses could have led to more participant burnout and less compliance (Iida, Shrout, Laurenceau, \& Bolger, 2012). Unfortunately, individuals who did not complete as many surveys were also those who reported more WTFC and negative mood, and thus, may have benefited most from FSSB. Still, the current study drew on a 32-day design, which is a substantially longer time-period than is typically employed in occupational psychology designs. Future research should aim to identify methods to increase participation among those facing the greatest amount of stressors.

Another limitation of this study was that the employee sample was primarily male, while the spouse sample was primarily female. Although this is potentially problematic, it also reflects the reality of some occupations, which are heavily gendered (e.g., construction, blue-collar occupations being male dominated), and is representative of veterans who made up the sample for this study. Although initial research suggested there are gender differences in the prevalence of WFC (Byron, 2005), more recent evidence suggests this is not as straight forward as originally hypothesized (Shockley, Shen, DeNunzio, Arvan, \& Knudsen, 2017). For instance, men tend to work longer hours, and longer hours are associated with greater work interference with family (Shockley et al., 2017). Despite, this potential issue, the relation between gender and WTFC was not 
significant in the current sample. Therefore, it is unlikely that the experience of the stressor WTFC would differ should the sample be reversed. Future research should examine either a more female-dominated employee sample, a gender heterogeneous sample, or incorporate dyadic analyses to uncover the relative gender, WTFC, and affective well-being links among employees and spouses.

Affective well-being is an important outcome in and of itself, but also due to its power to shape behaviors, and long-term health outcomes. Yet, because the goal of the current study was to examine micro-processes, the focus here was not on distal outcomes. Given that that affective well-being is indeed associated with WTFC for both employees and spouses, future research should examine both positive and negative mood specifically as mediators to distal family and dyadic outcomes. While previous research has examined positivity as a mediator in the relationship between WTFC and relationship quality (van Steenbergen et al., 2014), and mood as a mediator between WTFC and individual outcomes, more research is needed to shed light on the subsequent link between affective well-being and workplace outcomes and dyadic non-work outcomes (e.g. positivity towards a relationship and subsequent relationship quality).

\section{Conclusion}

The current study has shed light on important daily associations between WTFC on spillover and crossover to employee and spouse positive and negative mood. Findings support both spillover and crossover effects from WTFC to declines in positive mood, and spillover effects to negative mood at the daily within-person levels. Despite the important negative effect that WTFC has on daily within-person shifts in mood, FSSB 
serves as resource replenishing under conditions of higher WTFC to reduce the negative effects it has on employee positive mood. However, this relationship was not observed for employee negative mood, suggesting that the unique affective pathways should be further examined and considered when conducting WTFC research. Together, this study suggests that WTFC has important day-to-day effects on employees and spouses that steps should be taken to reduce. Further, it is recommended that supervisors and organizations should increase FSSB on a daily level to counteract the effects of WTFC on reduced positive mood for employees. 
Table 3.1

Within and Between-person Means, Standard Deviations, and Correlations of Study Variables.

\begin{tabular}{lcccccccccc}
\hline & $N$ & $M$ & $S D_{B}$ & $S D_{w}$ & 1 & 2 & 3 & 4 & 5 & 6 \\
\hline Employee & & & & & & & & & & \\
1. WTFC & 2885 & 1.84 & .68 & .73 & - & $.20^{*}$ & $-.24^{*}$ & $.29 * *$ & -.05 & $.37^{* * *}$ \\
2. FSSB & 982 & 3.55 & .78 & .49 & $.08^{*}$ & - & .12 & $-.16 \dagger$ & .13 & -.03 \\
3. Positive Mood & 2897 & 2.49 & .53 & .42 & $-.07^{* * *}$ & $.08^{*}$ & - & $-.27^{* *}$ & $.36^{* * *}$ & -.15 \\
4. Negative Mood & 2897 & 1.16 & .20 & .25 & $.08^{* * *}$ & $-.06 \dagger$ & $-.21^{* * *}$ & - & -.15 & $.43^{* * *}$ \\
Spouse & & & & & & & & & & \\
5. Positive Mood & 2920 & 2.54 & .60 & .43 & $-.06^{* *}$ & -.01 & $.12^{* * *}$ & $-.10^{* * *}$ & - & $-.31^{* *}$ \\
6. Negative Mood & 2920 & 1.21 & .37 & .32 & $.04^{*}$ & .04 & $-.09^{* * *}$ & $.17^{* * *}$ & $-.29^{* * *}$ & - \\
7. Weekends & $34.6 \%$ & - & - & - & $-.16^{* * *}$ & .02 & $.07^{* * *}$ & -.03 & $.07^{* *}$ & $-.05^{* *}$ \\
\hline
\end{tabular}

Note. $M$ and $S D_{B}$ represent aggregated means and standard deviation. $N$ is total observations for variable. $S D_{w}$ represents within-person standard deviation based on person mean centered values. Weekend includes Friday, Saturday, and Sunday $(0=$ weekday, 1 = weekend $)$. Correlations above diagonal are betweenperson level correlations (person means aggregated over repeated daily observations; $N=111$ ), diagonal is indicated by -. Correlations below diagonal are within-person (day level) correlations. $* * * p<.001$, ** $p<$ $.01, * p<.05, \dagger<.10$. 
Table 3.2

General Linear Mixed Model Results for Daily Employee Positive and Negative Mood

\begin{tabular}{|c|c|c|c|c|c|c|c|c|c|c|c|c|}
\hline & \multicolumn{3}{|c|}{ Model 1} & \multicolumn{3}{|c|}{ Model 2} & \multicolumn{3}{|c|}{ Model 3} & \multicolumn{3}{|c|}{ Model 4} \\
\hline & Est & $S E$ & $T$ & Est & $S E$ & $T$ & Est & $S E$ & $T$ & Est & $S E$ & $T$ \\
\hline \multicolumn{13}{|l|}{ Positive Mood } \\
\hline Intercept & 2.50 & .05 & 49.17 & 2.66 & .04 & 66.35 & 2.56 & .06 & 42.71 & 2.55 & .06 & 41.97 \\
\hline Weekend & & & & .01 & .01 & .84 & .01 & .03 & .28 & .02 & .03 & .58 \\
\hline \multicolumn{13}{|l|}{ Work to family conflic } \\
\hline Within-person $\left(B_{w}\right)$ & & & & $-.04^{* *}$ & .01 & -5.00 & $-.04^{*}$ & .02 & -2.37 & $-.04 *$ & .02 & -2.07 \\
\hline $\begin{array}{l}\text { Between-person } \\
\left(B_{b}\right)\end{array}$ & & & & $-.20^{* *}$ & .06 & -3.48 & $-.18^{*}$ & .08 & -2.36 & $-.19^{* *}$ & .08 & -2.39 \\
\hline \multicolumn{13}{|l|}{ FSSB } \\
\hline Within-person $\left(B_{w}\right)$ & & & & & & & $.14^{* * *}$ & .03 & 4.37 & $-.10^{* *}$ & .03 & 3.01 \\
\hline $\begin{array}{l}\text { Between-person } \\
\left(B_{b}\right)\end{array}$ & & & & & & & .07 & .08 & .96 & .09 & .07 & 1.38 \\
\hline \multicolumn{13}{|l|}{ WTFC*FSSB } \\
\hline Within-person $\left(B_{w}\right)$ & & & & & & & & & & $.15^{* * *}$ & .03 & 4.68 \\
\hline $\begin{array}{l}\text { Between-person } \\
\left(B_{b}\right)\end{array}$ & & & & & & & & & & -.13 & .09 & -1.44 \\
\hline \multicolumn{13}{|l|}{ Negative Mood } \\
\hline Intercept & 1.16 & .02 & 61.39 & 1.17 & .02 & 56.09 & 1.16 & .03 & 44.65 & 1.17 & .03 & 44.63 \\
\hline Weekend & & & & -.004 & .01 & -.42 & .01 & .02 & -.28 & .01 & .02 & .30 \\
\hline \multicolumn{13}{|l|}{ Work to family conflic } \\
\hline Within-person $\left(B_{w}\right)$ & & & & $.03^{* * *}$ & .01 & 4.09 & $.02^{*}$ & .01 & 2.12 & $.02 *$ & .01 & 2.07 \\
\hline $\begin{array}{l}\text { Between-person } \\
\left(B_{b}\right)\end{array}$ & & & & $.09^{* *}$ & .03 & 3.32 & $.07^{*}$ & .03 & 2.39 & $.07^{*}$ & .03 & 2.47 \\
\hline \multicolumn{13}{|l|}{ FSSB } \\
\hline Within-person $\left(B_{w}\right)$ & & & & & & & $-.03 *$ & .02 & -1.96 & $-.03^{*}$ & .02 & -1.90 \\
\hline $\begin{array}{l}\text { Between-person } \\
\left(B_{b}\right)\end{array}$ & & & & & & & -.03 & .03 & -1.20 & -.04 & .03 & -1.64 \\
\hline \multicolumn{13}{|l|}{ WTFC $* F S S B$} \\
\hline Within-person $\left(B_{w}\right)$ & & & & & & & & & & -.001 & .02 & -.05 \\
\hline $\begin{array}{l}\text { Between-person } \\
\left(B_{b}\right)\end{array}$ & & & & & & & & & & $.06 \dagger$ & .03 & 1.79 \\
\hline
\end{tabular}

Note. Models control for weekend (Friday, Saturday, Sunday). Within = variables are person-mean centered; between = variables are aggregated across employees over time. Number of observations for Model $2=2,884$ (111 dyads) and Model 3 and Model $4=$ 979 (111 dyads) $* * * p<.001, * * p<.01, * p<.05, \dagger<.10$. 
Table 3.3

General Linear Mixed Model Results for Daily Spouse Positive and Negative Mood

\begin{tabular}{|c|c|c|c|c|c|c|c|c|c|c|c|c|}
\hline & \multicolumn{3}{|c|}{ Model 1} & \multicolumn{3}{|c|}{ Model 2} & \multicolumn{3}{|c|}{ Model 3} & \multicolumn{3}{|c|}{ Model 4} \\
\hline & Est & $S E$ & $T$ & Est & $S E$ & $T$ & Est & $S E$ & $T$ & Est & $S E$ & $T$ \\
\hline \multicolumn{13}{|l|}{ Positive Mood } \\
\hline Intercept & 2.54 & .06 & 44.70 & 2.61 & .06 & 44.7 & 2.60 & .06 & 41.45 & 2.59 & .06 & 40.62 \\
\hline Weekend & & & & $.05 * *$ & .02 & 3.11 & .01 & .04 & .26 & .03 & .04 & .22 \\
\hline \multicolumn{13}{|l|}{ Work to family conflict } \\
\hline Within-person $\left(B_{w}\right)$ & & & & $-.04^{* *}$ & .01 & -3.04 & -.03 & .02 & -1.58 & $-.04 \dagger$ & .02 & -1.65 \\
\hline Between-person $\left(B_{b}\right)$ & & & & -.09 & .08 & -1.11 & .07 & .09 & -.74 & -.07 & .09 & -.78 \\
\hline \multicolumn{13}{|l|}{ FSSB } \\
\hline Within-person $\left(B_{w}\right)$ & & & & & & & -.02 & .03 & -.87 & -.02 & .03 & -.54 \\
\hline Between-person $\left(B_{b}\right)$ & & & & & & & .09 & .07 & 1.24 & .11 & .08 & 1.29 \\
\hline \multicolumn{13}{|l|}{ WTFC*FSSB } \\
\hline Within-person $\left(B_{w}\right)$ & & & & & & & & & & -.03 & .04 & -.90 \\
\hline Between-person $\left(B_{b}\right)$ & & & & & & & & & & -.04 & .10 & -.41 \\
\hline \multicolumn{13}{|l|}{ Negative Mood } \\
\hline Intercept & 1.21 & .03 & 36.02 & 1.22 & .04 & 32.7 & 1.18 & .04 & 30.54 & 1.18 & .04 & 30.11 \\
\hline Weekend & & & & $-.03 *$ & .01 & -2.62 & -.02 & .03 & -.59 & -.02 & .03 & -.59 \\
\hline \multicolumn{13}{|l|}{ Work to family conflict } \\
\hline Within-person $\left(B_{w}\right)$ & & & & .01 & .01 & 1.24 & .03 & .02 & 1.62 & .03 & .02 & 1.63 \\
\hline Between-person $\left(B_{b}\right)$ & & & & $.19^{* * * *}$ & .05 & 4.04 & $.20^{* *}$ & .05 & 4.20 & $.20^{* * *}$ & .05 & 4.15 \\
\hline \multicolumn{13}{|l|}{ FSSB } \\
\hline Within-person $\left(B_{w}\right)$ & & & & & & & .03 & .02 & 1.23 & .03 & .02 & 1.17 \\
\hline Between-person $\left(B_{b}\right)$ & & & & & & & .02 & .04 & .55 & .03 & .04 & .61 \\
\hline \multicolumn{13}{|l|}{ WTFC*FSSB } \\
\hline Within-person $\left(B_{w}\right)$ & & & & & & & & & & .0004 & .03 & .01 \\
\hline Between-person $\left(B_{b}\right)$ & & & & & & & & & & .02 & .06 & -.35 \\
\hline
\end{tabular}

Note. Predictors are employee values. Models control for weekend (Friday, Saturday, Sunday). Within = variables are person-mean centered; between = variables are aggregated across employees over time. Number of observations for Model $2=2,549$ (111 dyads) and Model 3 and Model $4=864$ (109 dyads) $* * * p<.001, * * p<.01, * p<$ $.05, \dagger<.10$ 
Table 3.4

Summary of Hypothesis Test Results

\begin{tabular}{|c|c|c|c|c|}
\hline & \multicolumn{2}{|c|}{ WTFC } & \multicolumn{2}{|c|}{ WTFC*FSSB } \\
\hline Within-person & Positive Mood & Negative Mood & Positive Affect & Negative Mood \\
\hline Employee & Supported & Supported & Supported & Not Supported \\
\hline Spouse & Supported & Not Supported & Not supported & Not Supported \\
\hline Between-person & Positive Mood & Negative Mood & Positive Mood & Negative Mood \\
\hline Employee & Supported & Supported & Supported & Supported \\
\hline Spouse & Not Supported & Not Supported & Not Supported & Not Supported \\
\hline
\end{tabular}

Note: Supported <.05. Hypothesizes are for within-person effects. Research Questions were for between-person effects. WTFC $=$ Work to Family Conflict; FSSB = Family Supportive Supervisor Behaviors. 


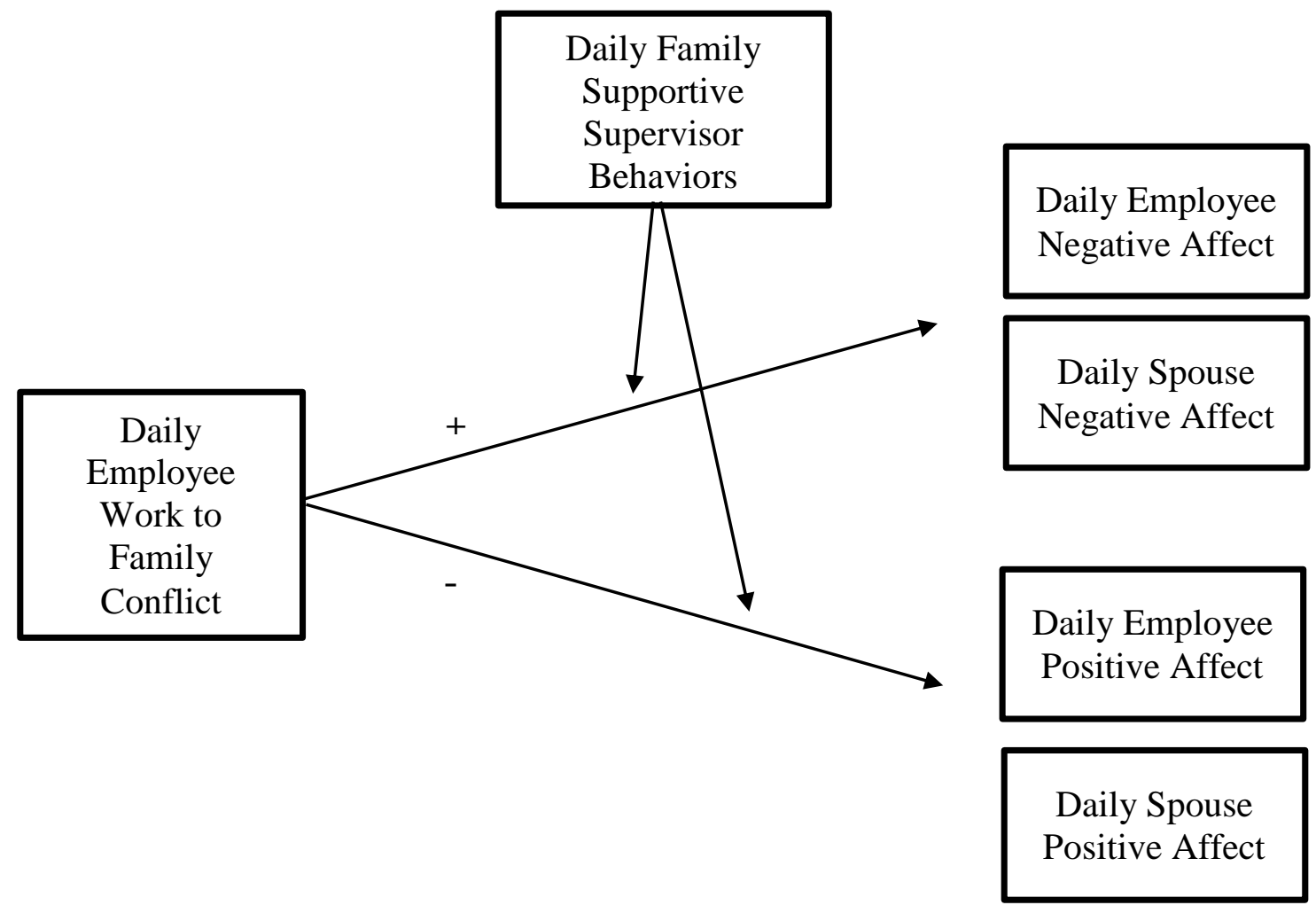

Figure 3.1. Study conceptual model. 


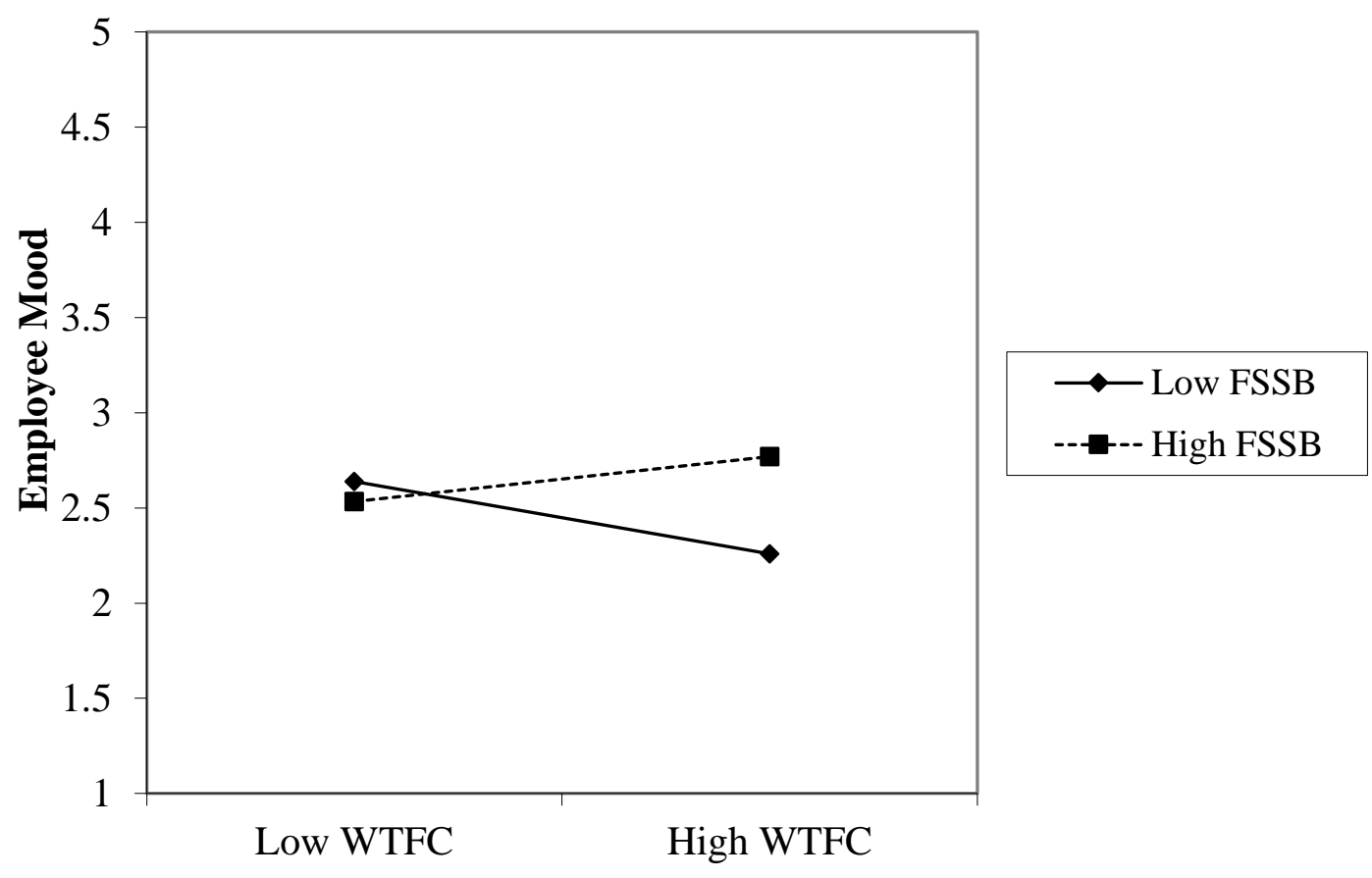

Figure 3.2. Moderating effect of family supportive supervisor behaviors (FSSB) on the association between work-to-family conflict (WTFC) and employee positive mood. 


\section{References}

Allen, T. D., Herst, D. E., Bruck, C. S., \& Sutton, M. (2000). Consequences associated with work-to-family conflict: a review and agenda for future research. Journal of Occupational Health Psychology, 5(2), 278-308.

Almeida, D. M., Davis, K. D., Lee, S., Lawson, K. M., Walter, K. N., \& Moen, P. (2016). Supervisor support buffers daily psychological and physiological reactivity to work-to-family conflict. Journal of Marriage and Family, 78(1), 165-179.

Amstad, F. T., Meier, L. L., Fasel, U., Elfering, A., \& Semmer, N. K. (2011). A metaanalysis of work-family conflict and various outcomes with a special emphasis on cross-domain versus matching-domain relations. Journal of Occupational Health Psychology, 16(2), 151-169.

Aumann K, Galinsky E. (2009). The state of health in the American workforce: Does having an effective workplace matter? Families and Work Institute. New York, NY

Bakker, A. B., Demerouti, E., \& Burke, R. (2009). Workaholism and relationship quality: A spillover-crossover perspective. Journal of Occupational Health Psychology, 14(1), 23-33.

Bakker, A. B., Demerouti, E., \& Schaufeli, W. B. (2005). The crossover of burnout and work engagement among working couples. Human Relations, 58(5), 661-689.

Byron, K. (2005). A meta-analytic review of work-family conflict and its antecedents. Journal of Vocational Behavior, 67, 169-198. 
Crain T.L., Stevens S.C. (2018) Family-supportive supervisor behaviors: A review and recommendations for research and practice. Journal of Organizational Behavior Annual Review, 39, 869-888.

Davis, K. D., Lawson, K. M., Almeida, D. M., Kelly, E. L., King, R. B., Hammer, L., \& McHale, S. M. (2015). Parents' daily time with their children: A workplace intervention. Pediatrics, 135(5), 875-882.

DeSteno, D., Gross, J. J., \& Kubzansky, L. (2013). Affective science and health: The importance of emotion and emotion regulation. Health Psychology, 32(5), 474486.

Diener, E., \& Chan, M. Y. (2011). Happy people live longer: Subjective well-being contributes to health and longevity. Applied Psychology: Health and WellBeing, 3(1), 1-43.

Diener, E., \& Emmons, R. A. (1984). The independence of positive and negative affect. Journal of Personality and Social Psychology, 47(5), 1105.

Ekman, P. (1994). All emotions are basic. The nature of emotion: Fundamental questions, 15-19.

Estrada, C. A., Isen, A. M., \& Young, M. J. (1994). Positive affect improves creative problem solving and influences reported source of practice satisfaction in physicians. Motivation and Emotion, 18(4), 285-299.

Ferguson, M., Carlson, D., Boswell, W., Whitten, D., Butts, M. M., \& Kacmar, K. M. (2016). Tethered to work: A family systems approach linking mobile device use to turnover intentions. Journal of Applied Psychology, 101(4), 520-534. 
Fredrickson, B. L. (2001). The role of positive emotions in positive psychology: The broaden-and-build theory of positive emotions. American Psychologist, 56(3), 218-226.

Frone, M. R., Yardley, J. K., \& Markel, K. S. (1997). Developing and testing an integrative model of the work-family interface. Journal of Vocational Behavior, 50(2), 145-167.

Goh, Z., Ilies, R., \& Wilson, K. S. (2015). Supportive supervisors improve employees' daily lives: The role supervisors play in the impact of daily workload on life satisfaction via work-family conflict. Journal of Vocational Behavior, 89, 65-73.

Grant-Vallone, E. J., \& Donaldson, S. I. (2001). Consequences of work-family conflict on employee well-being over time. Work \& Stress, 15(3), 214-226.

Greenhaus, J. H., \& Beutell, N. J. (1985). Sources of conflict between work and family roles. Academy of Management Review, 10(1), 76-88.

Hammer, L. B., Allen, E., \& Grigsby, T. D. (1997). Work-family conflict in dual-earner couples: Within-individual and crossover effects of work and family. Journal of Vocational Behavior, 50(2), 185-203.

Hammer, L. B., Neal, M. B., Newsom, J. T., Brockwood, K. J., \& Colton, C. L. (2005). A longitudinal study of the effects of dual-earner couples' utilization of familyfriendly workplace supports on work and family outcomes. Journal of Applied Psychology, 90(4), 799-810. 
Hammer, L. B., Kossek, E. E., Yragui, N. L., Bodner, T. E., \& Hanson, G. C. (2009). Development and validation of a multidimensional measure of family supportive supervisor behaviors (FSSB). Journal of Management, 35(4), 837-856.

Hammer, L. B., Kossek, E. E., Bodner, T. E., \& Crain, T. L. (2013). Measurement development and validation of the Family Supportive Supervisor Behavior ShortForm (FSSB-SF). Journal of Occupational Health Psychology, 18(3), 285-296.

Hammer, L. B., Kossek, E. E., Anger, W. K., Bodner, T., \& Zimmerman, K. L. (2011). Clarifying work-family intervention processes: The roles of work-family conflict and family-supportive supervisor behaviors. Journal of Applied Psychology, 96(1), 134-150.

Hammer, L. B., \& Sauter, S. (2013). Total worker health and work-life stress. Journal of Occupational and Environmental Medicine, 55, 25-29.

Hammer, L. B., Wan, W. H., Brockwood, K. J., Mohr, C. D., \& Carlson, K. F. (2017). Military, work, and health characteristics of veterans and reservists from the Study for Employment Retention of Veterans (SERVe). Military Psychology. 29(6), 491-512.

Hobfoll, S. E. (1989). Conservation of resources: A new attempt at conceptualizing stress. American Psychologist, 44(3), 513-524.

Hobfoll, S. E., Halbesleben, J., Neveu, J. P., \& Westman, M. (2018). Conservation of resources in the organizational context: The reality of resources and their consequences. Annual Review of Organizational Psychology and Organizational Behavior, 5, 103-128. 
Iida, M., Shrout, P. E., Laurenceau, J.-P., \& Bolger, N. (2012). Using diary methods in psychological research. In H. Cooper, P. M. Camic, D. L. Long, A. T. Panter, D. Rindskopf, \& K. J. Sher (Eds.), APA handbook of research methods in psychology, Vol. 1. Foundations, planning, measures, and psychometrics (pp. 277-305). Washington, DC, US: American Psychological Association.

Ilies, R., Schwind, K. M., Wagner, D. T., Johnson, M. D., DeRue, D. S., \& Ilgen, D. R. (2007). When can employees have a family life? The effects of daily workload and affect on work-family conflict and social behaviors at home. Journal of Applied Psychology, 92(5), 1368-1379.

Judge, T.A., R. Illies, and B.A. Scott. (2006). Work-family conflict and emotions: Effects at work and at home. Personnel Psychology 59(4): 779-814.

Kafetsios, K. (2007). Work-family conflict and its relationship with job satisfaction and psychological distress: The role of affect at work and gender. Hellenic Journal of Psychology, 4(1), 15-35.

Kiecolt-Glaser, J. K., \& Wilson, S. J. (2017). Lovesick: How couples’ relationships influence health. Annual Review of Clinical Psychology, 13, 421-443.

Kossek, E. E., Pichler, S., Bodner, T., \& Hammer, L. B. (2011). Workplace social support and work-family conflict: A meta-analysis clarifying the influence of general and work-family-specific supervisor and organizational support. Personnel Psychology, 64(2), 289-313.

Larsen, R. J., \& Diener, E. (1992). Promises and problems with the circumplex model of emotion. In M. S. Clark (Ed.), Emotion (pp.25-59). Newbury Park, CA: Sage 
Lee, S., McHale, S. M., Crouter, A. C., Kelly, E. L., Buxton, O. M., \& Almeida, D. M. (2017). Perceived time adequacy improves daily well-being: day-to-day linkages and the effects of a workplace intervention. Community, Work \& Family, 20(5), $500-522$

Lyubomirsky, S., King, L., \& Diener, E. (2005). The benefits of frequent positive affect: Does happiness lead to success? Psychological Bulletin, 131(6), 803-855.

Michel, J. S., Kotrba, L. M., Mitchelson, J. K., Clark, M. A., \& Baltes, B. B. (2011). Antecedents of work-family conflict: A meta-analytic review. Journal of Organizational Behavior, 32(5), 689-725.

Netemeyer, R. G., Boles, J. S., \& McMurrian, R. (1996). Development and validation of work-family conflict and family-work conflict scales. Journal of Applied Psychology, 81(4), 400-410.

Nohe, C., \& Sonntag, K. (2014). Work-family conflict, social support, and turnover intentions: A longitudinal study. Journal of Vocational Behavior, 85(1), 1-12.

Ohly, S., Sonnentag, S., Niessen, C., \& Zapf, D. (2010). Diary studies in organizational research. Journal of Personnel Psychology, 9(2), 9-93.

Pinheiro, J., \& Bates, D. (2000). Mixed-effects models in S and S-PLUS. Berlin: Springer. Repetti, R., \& Wang, S. W. (2017). Effects of job stress on family relationships. Current Opinion in Psychology, 13, 15-18.

Repetti, R. L., \& Wood, J. (1997). Effects of daily stress at work on mothers' interactions with preschoolers. Journal of Family Psychology, 11(1), 90-108. 
Rosenberg, E. L. (1998). Levels of analysis and the organization of affect. Review of General Psychology, 2(3), 247-270.

Russell, J. A., \& Barrett, L. F. (1999). Core affect, prototypical emotional episodes, and other things called emotion: Dissecting the elephant. Journal of Personality and Social Psychology, 76(5), 805-819.

Scott, B. A., \& Barnes, C. M. (2011). A multilevel field investigation of emotional labor, affect, work withdrawal, and gender. Academy of management journal, 54(1), 116-136.

Shockley, K. M., \& Allen, T. D. (2015). Deciding between work and family: An episodic approach. Personnel Psychology, 68(2), 283-318.

Shockley, K. M., Shen, W., DeNunzio, M. M., Arvan, M. L., \& Knudsen, E. A. (2017). Disentangling the relationship between gender and work-family conflict: An integration of theoretical perspectives using meta-analytic methods. Journal of Applied Psychology, 102(12), 1601-1635.

Staw, B. M., Sutton, R. I., \& Pelled, L. H. (1994). Employee positive emotion and favorable outcomes at the workplace. Organization Science, 5(1), 51-71.

Vancouver, J. B., \& Kendall, L. N. (2006). When self-efficacy negatively relates to motivation and performance in a learning context. Journal of Applied Psychology, 91(5), 1146.

Van Hoof, M. L. M., Geurts, S. A. E., Taris, T. W., Kompier, M. A. J., Dikkers, J. S. E., Houtman, I. L. D., \& Van Den Heufel, F. M. M. (2005). Disentangling the causal 
relationships between work- home interference and employee health. Scandinavian Journal of Work \& Environmental Health, 31, 15-29.

van Steenbergen, E. F., Kluwer, E. S., \& Karney, B. R. (2014). Work-family enrichment, work-family conflict, and marital satisfaction: A dyadic analysis. Journal of Occupational Health Psychology, 19(2), 182-194.

Watson, D. \& Clark, L.A. (1994). The PANAS-X: Manual for the Positive and Negative Affect Schedule - Expanded Form. University of Iowa.

Westman, M. (2001). Stress and strain crossover. Human Relations, 54(6), 717-751.

Westman, M. (2016). Old and new trends in crossover research. In Allen, T. D., \& Eby, L. T. (Eds.). The Oxford Handbook of Work and Family (pp.140-150). New York, NY: Oxford University Press.

Williams, K. J., \& Alliger, G. M. (1994). Role stressors, mood spillover, and perceptions of work-family conflict in employed parents. Academy of Management Journal, 37(4), 837-868. 
Chapter 4. A Multi-level Model of Supervisors Perceptions Shaping Unit Work-Family Resources and Subsequent Psychological and Job Well-being

Jacquelyn M. Brady, Leslie B. Hammer, and Jennifer K. Dimoff

Portland State University

Author Note

Jacquelyn M. Brady and Leslie B. Hammer, Department of Psychology, Portland State University and Oregon Institute of Occupational Health Sciences, Oregon Health \& Science University. Jennifer K. Dimoff, Department of Psychology, Portland State University. This research was conducted as part of the Work, Family and Health Network (www.WorkFamilyHealthNetwork.org), which is funded by a cooperative agreement through the National Institutes of Health and the Centers for Disease Control and Prevention: Eunice Kennedy Shriver National Institute of Child Health and Human Development (Grant \# U01HD051217, U01HD051218, U01HD051256, U01HD051276), National Institute on Aging (Grant \# U01AG027669), the National Heart, Lung and Blood Institute (R01HL107240), Office of Behavioral and Science Sciences Research, and National Institute for Occupational Safety and Health (Grant \# U01OH008788, U01HD059773). Grants from the William T. Grant Foundation, Alfred P Sloan Foundation, and the Administration for Children and Families have provided additional funding. The contents of this publication are solely the responsibility of the authors and do not necessarily represent the official views of these institutes and offices. Special acknowledgement goes to Extramural Staff Science Collaborator, Rosalind Berkowitz King, Ph.D. and Lynne Casper, Ph.D. for design of the original Workplace, Family, 
Health and Well-Being Network Initiative. Portions of this research were supported by the Grant \# T03OH008435 awarded to Portland State University, funded by the Centers for Disease Control and Prevention, National Institute for Occupational Safety and Health. Its contents are solely the responsibility of the authors and do not necessarily represent the official views of NIOSH, CDC or HHS

Correspondence concerning this article should be addressed to Jacquelyn M. Brady, Department of Psychology, Portland State University, 1721 SW Broadway St., Portland, OR 97207. Contact: bradja@ohsu.edu. 


\begin{abstract}
Supervisors play an important role in determining employee well-being (Mullen \& Kelloway, 2011), and are in a unique position to influence workplace climate (Zohar \& Luria, 2005), which can be more highly predictive of outcomes than individual perceptions (Christian, 2009). Recent evidence suggests that work-family resources may emerge as a unit-level variable (Hill, Matthews, \& Walsh, 2015). However, there is no known research that establishes predictors of unit-level work-family resources, nor the impact such shared resources have on individual psychological distress, and job burnout. The current study builds on current theoretical perspectives of COR theory with climate frameworks, and work-family literature, and examines the role of supervisor views about flexible work arrangements (FWA) and workplace climate for family sacrifices (WCFS). Consistent with this perspective, supervisor views are considered as predictors of unitlevel work-family resources including schedule control (SC) and family supportive supervisor behaviors (FSSB), and subsequent individual psychological distress and job burnout in a sample of healthcare workers. Findings support an indirect effect of supervisor views toward FWA on job-burnout via unit-level work-family resources. Further, work-family resources were consistently and strongly related to job burnout, and unit-level SC was also related to psychological distress. The present study represents novel contributions in theory and work-family literature, and in addition provides important practical implications.
\end{abstract}


A Multi-level Model of Supervisors Perceptions Shaping Unit Work-Family Resources and Subsequent Employee Psychological and Job Well-being Work-family research has focused on the role of supervisors in improving employee work-family outcomes (e.g. Hammer Kossek, Yragui, Bodner, \& Hanson, 2009), viewing them as linking pins that control the allocation of important resources for employees. Indeed, supervisors influence employees across a wide range of work and health-related outcomes (for an overview on supervision and well-being see Mullen \& Kelloway, 2011), including job satisfaction, (Baruch-Feldman, Brondolo, Ben-Dayan, \& Schwartz, 2002), work-family conflict (Kossek, Pilcher, Bodner \& Hammer, 2011), safety (Zohar, 2002), emotional exhaustion (Lieter \& Maslach, 1988), and burnout (Nahrgang, Morgeson, \& Hoffman, 2010). In addition to influencing many aspects of employees' lives, there are seemingly limitless ways in which supervisors can influence employee work-life outcomes. For instance, supervisors can impact employees by allocating resources (e.g. offering scheduling flexibility, providing support, or by making recommendations for promotions and raises; Dimoff \& Kelloway, 2019) or via crossover (e.g. supervisor work-family enrichment impacts employee work-family enrichment and job satisfaction; Carlson Kacmar, Zivnuska, Ferguson, \& Whitten, 2011).

Resources are viewed as having a positive influence on the work-family interface (Kossek et al., 2011; Siu et al., 2010), employee well-being, and job outcomes (e.g. Bakker \& Demerouti, 2007; Hobfoll, 1989). Specific to reducing work-life stress, tangible resources, such as flexibility and schedule control (SC; Thomas \& Ganster, 1995), as well as emotional resources such as family-specific supervisor social support 
(Kossek, et al., 2011), have been shown to improve work-life outcomes. Resources that are thought to be beneficial for employee family needs, such as control over work hours (Lyness, Gornick, Stone, \& Grotto, 2012), and family supportive supervisor behaviors (FSSB; Hammer et al., 2009; for review see Crain \& Stevens, 2018) are consistently linked to important work, work-family, and health outcomes. Further, work-family resources are thought to contribute to family supportive organizational perceptions (FSOP), which are defined as the extent to which employees view their organization as supportive of family life (Allen, 2000). Yet, despite working for the same organization and supervisor, researchers have observed that group-level perceptions of work-family climate can vary substantially among group members (e.g. Hammer et al., 2016), and variation in attitudes is thought to be a primary cause of work-life policy backlash (Perrigino, et al, 2018). In order to help understand why weak versus stronger workfamily climate perceptions emerge, there must be further specification of factors that are indicative of a positive work-family climate, by examining specific resources important to the work-family domain.

Despite the demonstrated importance of supervisors, resources, and work-family climate perceptions for worker well-being, there are several important gaps in the literature. First, much of the work-family literature has been criticized for being crosssectional and having common method bias (Greenhaus \& Allen, 2011), suggesting that work-family research ought to utilize data collected across multiple time-points, and from multiple sources when possible. Second, although research has demonstrated that supervisors are key to employee well-being and resource allocation, and resources 
promote employee well-being, the underlying causes of supervisor work-family behaviors (e.g., their own views and attitudes) in influencing employee well-being remains understudied, despite evidence that attitudes and behavior are consistently linked (for review of attitude to behavior theories see Montano \& Kasprzyk, 2015). Third, the evidence of work-family climate as strong enough to represent a group-level variable has been mixed (Hammer, et al., 2016; Moen et al., 2015). This suggests that to further explore work-family resources at the group-level, these resources should depart from traditional work-family climate measures. The current study aims to fill these gaps using a time-series design with multi-level data (i.e., supervisor, aggregate employee group, and individual), while drawing on COR theory (Hobfoll, 1989), and the work-family and safety climate literature, with data from healthcare facilities in the Northeastern United States. By doing so, this study furthers our understanding of how supervisor views and views about the work-family interface influence group-level resources, and ultimately employee-level psychological distress and job burnout. See Figure 4.1 for the study model.

\section{Healthcare Professionals and Poor Psychological Well-being}

Job burnout and emotional distress are psychological strain outcomes that result from long-term chronic exposure to stress (Kossek et al., 2019; Maslach, Schuefeli, \& Lieter, 2001). Strain outcomes, such as burnout, pose problems for society and organizations (e.g., turnover, Alarcon, 2011; health complications; Roy-Byrne et al., 2008; Shirom, \& Melamed, 2005). The consequences of burnout in the healthcare industry, however, can be particularly severe. For instance, burnout among healthcare 
professionals is associated with suicidal ideation (Dyrby et al., 2008), lower quality patient care (Le Blanc, Hox, Schaufeli, \& Taris, 2007), and medical mistakes (Shanafelt et al, 2010). Importantly, healthcare professionals are known to have high rates of burnout, which may be partially explained by the emotionally draining job demands (e.g., surface acting and emotional labor; Brotheridge \& Grandey, 2002; Horschild, 1983), health risks and hazards, and job complexity (Nahrgang et al., 2010) in the healthcare industry. Similarly, face-to-face interactions with patients and family members in challenging situations exposes healthcare staff to psychologically distressing events (e.g., upset patient families, terminal illnesses), and this is thought to be one reason for poor psychological outcomes, such as compassion fatigue and burnout (Grandey, Foo, Groth, \& Goodwin, 2012; Le Blanc, Hox, Schaufeli, Taris, \& Peeters, 2007; Maslach, 1982). Unfortunately, burnout also appears to be contagious within members working in the same intensive healthcare units (Bakker, LeBlanc, \& Schaufeli, 2005). Fortunately, studies have shown that interventions targeting the well-being of healthcare professionals via increased resources such as SC and family supportiveness can improve psychological well-being of healthcare workers who also provide care at home (Kossek et al., 2019; Le Blanc et al., 2007).

\section{Conservation of Resources Theory and Climate}

COR theory states that individuals seek to obtain, protect, and maintain resources (Hobfoll, 1989). Resources are personal, material, energies, and conditions that are important for major goal attainment, and share value across large groups of individuals. A major tenant of COR is that when resources are gained, individuals are able to invest in 
obtaining new or maintaining already obtained resources, which leads to "resource caravans." Resource gains also help individuals cope with stress because resources can offset resource loss, and act as a protector against poor outcomes associated with resource loss. On the other hand, COR theory posits that resource loss begets more resource loss, such that, when there is a general lack of resources, individuals will resort to a resource defensive state which prevents obtaining additional resources, and leads to further resource loss, or "loss spirals." Without intervention, a resource depleted state leads to stress and when experienced for prolong period of time can result in burnout and poor physical and psychological health (Hobfoll, 2002; Hobfoll \& Freedy, 1993).

Since COR theory was conceptualized, Hobfoll (1989) has maintained the importance of universally shared values as having higher priority than individual evaluations. Some examples of culturally shared values are health, well-being, and family (Hobfoll, et al., 2018). Because resources are objects, states, and conditions (Hobfoll, 1989), work-family resources can be thought of as resources that help individuals invest into building and maintaining their values in their work and home life as needed. Resources are meaningful to examine on the individual level, but to further examine COR, establishing work-family resources as a group-level predictor of psychological and job well-being would also be a test to determine the shared value of these resources. Very few studies have utilized COR theory to link shared climate variables to psychological well-being (for an exception see; climate of authenticity, Grandey, Foo, Groth, \& Goodwin; 2011), despite the importance of shared values in COR as well as a focus on shared perceptions in climate. 
Climates are defined as employees' within a given unit or groups' shared perceptions about the procedures, practices, and behaviors that are supported or rewarded (Schneider, 1990). Climates are assessed by aggregating to the unit of analysis of theoretical interest, which can include an entire organization, subunits, or workgroups (Kozlowski \& Klein, 2000). Climate variables, can be characterized as strong or weak in terms of agreement, and positive or negative in terms of direction (e.g. Zohar, 1980; Zohar, 2014). Climate research has been investigated in regard to various workplace phenomenon (e.g. safety climate; Zohar, 1980). Climate research has established that shared perceptions develop from the top-down (e.g. top management) and bottom-up (individual attitudes; Neal \& Griffin, 2006). From a top-down perspective, shared perceptions are shaped by top management and supervisors' values and enactments (Zohar \& Luria, 2005), and group interactions. Zohar and Luria (2005) found that group climate is predicted by organizational climate, but leaders who have enough discretion can influence their own unit's climate. Group interactions lead to shared climate perceptions because of symbolic social interaction between workers (Schneider \& Reichers, 1983). Thus, group members employ a sense making process following symbolic interactions, in which they approach agreement by discussing and comparing experiences and interpretations of them (e.g. "our supervisor expects us to take time off work to meet important family needs"), and thus developing a shared sense of their climate.

\section{Establishing Aggregate Work-Family Resources}


The current study examines unit-level perceptions of individuals who work in the same healthcare facility. In healthcare terminology, units typically refer to a specific type of care (e.g. pediatric, oncology, intensive care). Units can be further broken down into smaller increments when looking at specific within-unit managers. In the current study, units are defined by a group of two or more employees who share the same supervisor. Unit-level perceptions of resources can yield important information about why phenomena and outcomes occur, and this can be conceptually distinct from individual perceptions in that it tells us more about the organization or unit as a whole. For example, meta-analytic evidence suggests that shared group perceptions of safety climate have stronger relationships with safety outcomes than individual perceptions of climate (Christian, Bradley, Wallace, \& Burke 2009). However, in order for researchers to examine group-level variables, at least two conditions must be met. First, there must be a theoretical justification for aggregating to unit perceptions (e.g. workers should generally share an environment or have some interaction; Huang, Lee, McFadden, Rineer, \& Robertson, 2017). Second, there must be sufficient evidence of within group agreement (Bliese, 2000).

Research examining work-family climate as a group-level phenomenon has generally been scarcer than safety climate research, likely in part due to finding unacceptably low within-group agreement of individual perceptions of work-family climate (Hammer et al., 2016), a necessary requirement for aggregation (Bliese, 2000). Some scholars argue that such findings should be expected due to varied views about work-life policies (Perrigino et al., 2018), yet existing climate research suggests that if 
policies and procedures are administered consistently, a general climate for work-family resources should develop. Thus, there are challenges in establishing emergent workfamily climate, despite the theoretical and practical value work-family climates hold. Therefore, there exists a need to establish what factors influence the emergence of shared within work group agreement in the work-family interface, and looking towards more specific work-family resources that are indicative of a positive work-family climate should further understanding.

Several scales exist for measuring perceptions of work-family climate and culture (e.g. Allen, 2001; Kossek et al., 2001; Thompson, Beuvais, \& Lyness, 1999). For instance, Allen's (2001) family supportive organizational perceptions (FSOP) measure examines the extent to which organizations and supervisors are family supportive. What these scales have in common is that they tap into how supportive employees perceive their supervisor and organization to be in terms of facilitating their ability to meet their family needs. Individual level findings suggest that work-family climates a) mediate the relationship between individual perceptions of family supportive supervisors and affective commitment, turnover, and WFC (Allen, 2001), b) facilitate the effects of an FSSB intervention on safety compliance and organizational citizenship behaviors (Hammer et al., 2016), and c) are predictive of benefit usage (Thompson et al., 1999). Similarly, positive associations between employees' perceptions of FSSBs and work engagement are moderated by family supportive organizational culture (Rofcanin, Las Heras, \& Bakker, 2017). However, all of the above findings draw on individual perceptions of supportive climates, and while individual perceptions of supportive 
climates remains important, they do not sufficiently capture "climate." Several studies demonstrate the importance of unit-level perceptions of work-family climates. For instance, unit work-family perceptions of managerial support (including organizational support) significantly impacts employee commitment and turnover (O'Niell et al., 2009), work-to-family conflict (WTFC; Moen et al., 2015), and supervisor spoken guidance and work-interference with family (WIF; Paustian-Underdahl \& Halbesleben, 2013).

Given the relative inconsistency with which WF climates appear to form, investigating specific resources that may represent or contribute to a positive work-family climate will help to elucidate more precise aspects of what employees do agree on in regard to work-family related resources. That is, by investigating specific work-family resources using more narrow constructs, there may be less variability within units, and thus more within unit agreement on availability of such resources, and therefore, workfamily resources should be generally agreed upon within units. As established above, SC and FSSB are two such resources. Although these resources have been scarcely examined at the aggregate level in the work-family literature (see Crain \& Stevens, 2018 for review of FSSB), recent work has demonstrated that FSSBs can emerge as a group-level construct that predicts individual perceptions, such as WFC and turnover intentions (Hill, Matthews, \& Walsh, 2015), suggesting that unit-level work-family resources are important to consider in the work-family interface.

\section{Supervisors as Shapers of Unit Work-Family Resources.}

Safety climate researchers have shown that supervisors play an important role in shaping group climates (Hofmann \& Morgeson, 2003; Zohar, 2010, Zohar, 2014). Work- 
family researchers have honed in on these findings, leading many interventions to target supervisors to promote positive employee outcomes, which has been widely argued for (Kelloway \& Barling, 2010) and often supported (e.g. Hammer, 2011; Hammer, 2016). Indeed, supervisor behaviors have been empirically linked to employee well-being outcomes in numerous studies (Mullen \& Kelloway, 2011 for a review). However, there is little research examining the antecedents of supervisor behaviors. A long line of research and theory suggests there are strong links between attitudes, normative beliefs and behavior (Montano \& Kasprzyk, 2015).

Based on COR theory, if individuals perceive a potential threat to resources, they should move to a defensive state to protect remaining resources (Hobfoll, 2002). Providing work-family-related resources, such as flexible schedule accommodations, or allocating their own emotional resources to provide FSSB for employees may be viewed as a source of resource loss on the part of supervisors (e.g., hassles associated with the behavior such as difficulty scheduling employees), and thus lead to supervisors to offer less support and control over one's work schedule. On the other hand, if supervisors anticipate positive outcomes from providing employees with resources, such as more satisfied, committed, and engaged employees, they may view the provision of resources and expenditures of their own resources more positively, and ultimately as resource replenishing.

Indeed, Straub's (2012) multi-level conceptual framework surrounding the antecedents and outcomes of FSSB proposed that family supportive organizational culture would be linked to improved perceptions of FSSB. This framework was based on 
research showing that supervisors who work in a workplace with a family supportive culture are more often engaged in family supportive supervision (Foley et al., 2006). Further, researchers have argued that unit-level work-family cultures emerge via contextual influences, such as immediate supervisors and coworkers, which are important for predicting employee outcomes (Kossek et al., 2017). However, in the work-family literature, there are very few studies utilizing multi-level modeling to examine how supervisors shape resource perceptions, with one recent exception by Kossek et al., (2018). Kossek et al., (2018) found that supervisor ratings of their own transformational leadership is associated with individual level FSSB. These findings suggest that supervisors' perceptions are an important component in understanding the development of FSSB.

Supervisor perceptions of workplace climate for family sacrifices. Workplace climate for family sacrifices (WCFS) has been described as perceptions that one's workplace encourages employees to make family-related sacrifices to support their workplace (Kossek, Colquitt \& Noe, 2001). Organizational expectations and norms exert influence on employee outcomes. For instance, work-time is related to subsequent workinterference with family (Major, Klein, \& Ehrhart, 2002), and WCFS has been linked to WFC (Kossek et al., 2001). Given that supervisor values are embedded within organizational values (Grojean, Resick, Dickson, \& Smith, 2004), and that supervisors likely enact organizational procedures and values due to organizational norms (Montano \& Kasprzyk, 2015), employees often see supervisors as a representative of organizational values (Chen, Tsui, \& Farh, 2002). Thus, if supervisors perceive that their organization 
endorses a WCFS, then they will feel compelled to act in line with these norms, and therefore lead to lower unit work-family resources. Indeed, when workplaces have family supportive cultures, supervisors are more likely to provide family support (Foley et al., 2006). Drawing on COR theory, this suggests that supervisors with high perceptions of WCFS will view resource expenditure on their own part (e.g., providing FSSBs) or the allocation of schedule control to employees as potential threats to organizational resources, and thus provide lower levels of FSSBs and SC to the work group they supervise. As a result, employees will develop shared perceptions of the work-family resource climate.

H1: Supervisor perceptions of WCFS will be negatively related to unit-level perceptions of a) FSSBs and b) SC.

Supervisor views of flexible work arrangements. In addition to WCFS, supervisors also hold their own views regarding work-family resources (i.e., flexible work arrangements), and associated consequences. Such supervisor views may vary substantially across supervisors, both within and outside of an organization. Flexible work arrangements (FWA) refer to a practice or job characteristic in which employees have some job flexibility about when, where, or how they work (Kossek \& Michel, 2011; Kossek \& Thompson, 2016). Studies have shown that FWA can improve employee performance (Kelly et al., 2008), health, and well-being (Kossek \& Michel, 2011; Kossek \& Thompson, 2016). Despite the pronounced benefits of FWA, they can also be associated with costs for employees and employers including concerns about productivity (Kossek \& Thompson, 2016), generate increased demands for coworkers, and subsequent 
discrimination and career consequences for those utilizing FWA (Chung, 2018). To this end, perceptions of FWA can impact employees via FWA policy usage (Kossek et al., 1999). In terms of supervisors, their own views and behavioral beliefs about FWA will likely shape the unit-level climate because of the signals these views give to employees. Specifically, supervisors who hold less positive views, are less likely to exhibit behaviors that promote a positive work-family resource climate. This is in line with COR, in that if supervisors view FWA as a drain on resources they are likely to move to a defensive state, where supervisors provide lower levels of flexible work arrangements. In doing so, the climate of work-family resources should be lower. Thus:

H2: Supervisor views of FWA will be positively related to unit-level perceptions of FSSBs and SC.

\section{Aggregate Work-Family Resources and Psychological Distress and Job Burnout}

Psychological distress represents a poor psychological state that is characterized broadly by cognitive, behavioral, emotional, and psychophysiological symptoms related to mental health disorders, such as depression (Kessler et al., 2002), and results from long-term exposure to stressors (Kossek et al., 2019). Similarly, job burnout is “a prolonged response to chronic emotional and interpersonal stressors on the job, and is defined by the three dimensions of exhaustion, cynicism, and inefficacy" (Maslach, Schaufelli, \& Lieter, 2001, pp. 397). Both job burnout and psychological distress are thus the long-term consequences of stressors and have been linked to health outcomes (RoyByrne et al., 2008; Shirom, \& Melamed, 2005). Although often caused by similar antecedents, distress is more focused on individual well-being, whereas job burnout is 
more centered on the work context, both of which are important to consider in workfamily research. Work-family resources such as FSSB have been linked to improved employee well-being in many studies (Crain \& Stevens, 2018) including improvements in mental health (Kossek et al., 2018), and interventions targeting improvements in FSSB have been linked to improved psychological well-being (Hammer et al., 2011), and reduced psychological distress (Kossek et al., 2017). Similarly, SC has been linked to lower levels of burnout (Almer \& Kaplan, 2002), and the effects of a workplace intervention to reduce negative spillover were mediated by SC (Moen, Kelly, Tranby \& Huang, 2011). Although these relationships have been supported in previous research, they have almost entirely focused on individual perceptions of FSSBs and SC.

As described above, shared perceptions can have a stronger influence on employee outcomes than individual perceptions (Christian et al., 2009), and authors have shown that unit-level job factors such as job strain can influence individual level perceptions of work-family resources (FSSB) and subsequent mental health (Kossek et al., 2018). Given what we know about FSSBs and SC as important resources in the workfamily interface, shared perceptions of these resources may be particularly meaningful for employee well-being. Yet, the work that exists on unit-level work-family resources is almost non-existent. Shared perceptions of FSSB and SC as resources may be particularly meaningful for individuals trying to balance work and family demands by solidifying the work environment as unambiguously supportive. That is, while individual perceptions of FSSB and SC are important, if those perceptions are shared among group members, the 
availability of the resources may feel more certain, and therefore reduce psychological distress and job burnout further. Thus, I hypothesize that:

H3: Unit-level perceptions of FSSBs will be negatively related to psychological distress and job burnout.

H4: Unit-level perceptions of SC will be negatively related to psychological distress and job burnout.

\section{Mediated Model of Supervisors, Aggregate Resources, and Employee Outcomes}

The current study has drawn on COR theory to hypothesize that supervisor views about FWA and views of the WCFS will shape unit-level perceptions of work-family resources (FSSB and SC) of the employees they supervise. Further, I have hypothesized that unit-level perceptions of work-family resources will be negatively related to psychological distress and job burnout. Research has also linked perceptions of WFCS and FWA to decreased well-being in employees (Kossek et al., 2011), and reductions in work interference with family (Byron, 2005) respectively. Thus, in light of the aforementioned body of evidence, supervisor perceptions of WCFS and FWA should be negatively related to psychological distress and job burnout, indirectly, through the unitlevel resources of SC and FSSB. The following hypotheses are reflective of the hypothesized mediation models (see Figure 4.1).

H5: Unit-level FSSBs will mediate the indirect effects of supervisor WCFS on a) job burnout and b) psychological distress, such that WCFS will be negatively related to unit-level FSSBs, which will in turn be associated with greater employee burnout and distress. 
H6: Unit-level FSSB will mediate the indirect effects of supervisor views of FWA on a) job burnout and b) psychological distress, such that FWA will be positively related to unit-level FSSBs, which will in turn be associated with lower burnout and distress.

H7: Unit-level SC will mediate the indirect effects of supervisor WCFS on a) job burnout and b) psychological distress such that WCFS will be negatively related to unit-level SC, which will in turn be negatively associated with employee burnout and distress.

H8: Unit-level SC will mediate the indirect effects of supervisor views of FWA on a) job burnout and b) psychological distress, such that FWA will be positively related to unit-level $S C$, which in turn will be negatively associated with burnout and distress.

\section{Methods}

\section{Sample}

Data for the current study were collected from a component of the Work, Family, \& Health Network (WFHN Bray et al, 2013), a large-scale, trans-disciplinary research program funded by the Centers for Disease Control and National Institutes of Health. The overall purpose of the studies was to determine if a training among cluster randomized locations could improve employee scheduling and manager support. The overall research study included employees, multiple individuals connected to employees (e.g., supervisors, spouses, and children) and multiple modes of data collection (e.g., diary, four time-lagged surveys, and physiological measures such as cortisol and blood 
pressure). The study also included data collection efforts that followed a multi-faceted intervention at 6,12 and 18 months post intervention. The intervention targeted improved supervisor and coworker work-family support, as well as increased perceptions of employee control over work time (Bray et al., 2013). The current study draws on baseline, 6, and 12 month data from participating healthcare facilities in the WFHN studies. Given that the intervention itself is not central to the present study, the analyses for the present study control for condition.

\section{Procedure}

Participating supervisors and employees were recruited from 30 extended healthcare facilities throughout the Northeastern United States. Recruitment involved both site- and individual-level efforts to gain management buy-in and identify interested employees. Data were collected via in-person scripted and computer-assisted personal interviews (CAPI). Each participant completed and was given a copy of an informed consent or assent. Following participation at each wave, respondents received a $\$ 20$ incentive. Data used in the current study were collected from supervisors at baseline (Time 1), and employees at 6-months (Time 2), and 12-months (Time 3). Waves of data were merged based on a manager-employee linked ID that was given to employees and their respective supervisors who completed surveys.

Current study sample. The current study draws on the sample of healthcare facility workers, who were employed at one of the participating 30 extended care facilities in the Northeastern United States. Each healthcare facility was led by qualified nurses, and had several within-facility supervisors with various job titles across sub-units 
(e.g., unit manager, director of nursing). Inclusion requirements in the current study slightly differed from the larger study and included working $\geq 20$ hours in a typical week, having a medical staff job (e.g. direct patient care job as opposed to a non-healthcare specific job such as laundry aide, dietary staff), and working under a manager who had at least two employees who completed the surveys. Individuals not meeting these requirements were excluded from the analyses. Both the weekly hour requirement and medical staff requirement were put in place in order to minimize differences among working conditions and maintain theoretical integrity. For example, if a manager supervised a laundry aide and a registered nurse $(\mathrm{RN})$, they could conceivably employ different requirements and management styles towards employees as a function of employee and manager job roles, leading to lower within unit agreement. Alternatively, if employees worked relatively few hours, the opportunities to contribute to and be affected by shared climate would be more minimal. The requirement of two or more participating employees was for quantitative and climate theoretical concerns, that is, with only one employee this study would simply be investigating individual perceptions.

Facility and wave sample descriptions. The above combination of participation requirements resulted in stronger Time $2 \mathrm{ICC} 1$ values for $\mathrm{FSSB}=.13$ and $\mathrm{SC}=.16$ (as opposed to .10 and .12). However, these restrictions also limited our Time 1 and Time 2 sample. For instance, at Time 1 there were only $(n=101)$ supervisors who supervised two or more matched employees at Time 2, and these managers were spread across 30 medical care facilities $(M=3.37$ managers per facility, $\operatorname{Min}=1, \operatorname{Max}=6)$. At Time 2, there were 118 teams across 30 facilities $(M=3.93$ teams across facilities, $\min =1$, $\max$ 
=6). Finally, at Time 3, there were 977 to 978 employees across the 30 facilities who responded to the outcome variables, and had corresponding units at time 2 that were made up of 2 or more individuals $(M=32.6$ employees per facility, $\min =11, \max =61)$.

Supervisors. Supervisors' data was aggregated to the manager level in order to provide sample descriptive statistics. Supervisors in the current study were $(n=101)$ individuals who provided responses to the CAPI at Time 1 (baseline), and managed at least two participating employees working $\geq 20$ or more hours per week, and held a medical job (described below). Overall, supervisors were primarily white (90\%) females $(93 \%)$, were on average $47.30($ S.D. $=10.51)$ years of age, mostly married or living with a romantic partner (70\%) and about half (47.5\%) had children living at home at least 4 days a week. Supervisors had an average of $9.24(S D=7.79)$ years of tenure with the company, worked on average $48.55(S D=8.40)$ hours per week, and typically worked regular day shift (64\%). Supervisors held various titles including Registered Nurse (RN) or Licensed Practical Nurse (LPN) unit manager $(n=64)$, RN director or administrator $(n$ $=26)$, or RN/LPN supervisor or charge nurse $(n=10)$. On average, supervisors had 8.14 employees in their respective units who participated at Time 2.

Employees. Eligible employees $(N=978)$ in the current sample were primarily female $(92 \%)$, with an average age of $39.39(\mathrm{SD}=12.31)$ years, white $(64.6 \%)$, African American (14.7\%) or Hispanic (14.1\%). Over half (61.4\%) were married or living with a partner, had children (58.4\%), and worked either day (56.6\%) or evening (31.3\%) shift. Employees worked approximately $37.42(S D=7.58)$ hours per week, had $7.63(S D=$ 7.58) years tenure at the company, and were primarily certified nurse assistants $(70.2 \%)$ 
or licensed practical unit nurses (19.4\%). Employees who were matched to a respective manager held various titles, but were primarily Certified Nurse Assistants (CNA; $n=$ $687), \mathrm{RN} / \mathrm{LPN}(n=170)$, or supervising or managing RN/LPN $(n=107)$. Nurses who held supervising positions had more senior supervisors (e.g., charge nurse could have supervising or unit nurse as their manager). On average, teams were made up of 8.29 individuals who also completed Time 3 surveys. See Table 4.1 for descriptive sample statistics.

\section{Measures}

Each scale was computed by creating a composite score of responses to items in the scale with the exception of distress, which is utilized as a sum score. For scales with more than three items, mean imputation was possible and performed because it allows for calculation of missing values and results in unbiased estimates of study associations (Donders, Van Der Heijden, Stijnen, \& Moons, 2006). Supervisor views of WCFS and FWA were measured at T1, while aggregate unit-level variables were measured at T2, and job burnout and psychological distress were measured at T3 (12 months). Table 4.2 provides the means, standard deviations, reliability and correlations between the measures used in the current study.

\section{Supervisor views of organizational climate for making family sacrifices.}

Supervisor views of workplace climate for making family sacrifices (WCFS) was measured with a three-item scale developed by Kossek and colleagues (2001). Items include "In your workplace, employees are expected to take time away from their family or personal lives to get their work done," "In your workplace, employees are expected to 
put their families or personal lives second to their jobs," and "In your workplace, employees are expected to make work their top priority." Respondents answered on a 1 (strongly disagree) - 5 (strongly agree) scale, with higher scores indicating higher perceived expectations of making family sacrifices for the organization. WCFS demonstrated acceptable consistency at $\alpha=73$.

Supervisor views towards flexible work arrangements. Supervisor views of flexible work arrangements was measured with a 6-item scale adapted from Kossek et al., 1999). Respondents responded to items such as "You worry that allowing more flexibility around flexible hours would..... cause staffing headaches" on a 1 (strongly agree) - 5 (strongly disagree) scale. This scale was coded so that higher scores indicated more positive views towards FWA.

Unit-level resources. Two scales were used to capture perceptions of a family supportive resources climate for employees: FSSB short-form (Hammer, Kossek, Bodner, \& Crain, 2013) and SC (Thomas \& Ganster, 1995).

FSSB was measured with 4 items representing 4 constructs: emotional support, creative win-win management, role-modeling, and instrumental support. An example item is "your supervisor works effectively with employees to creatively solve conflicts between work and non-work." Respondent answers are recorded on a 1 (strongly disagree) to 5 (strongly agree) scale, with higher scores indicating higher perceptions of FSSB. The FSSB scale demonstrated good reliability at $\alpha=.89$.

SC was measured with an 8-item scale adapted from Thomas and Ganster (1995). Respondents answered on a 1 (very little) to 5 (very much) scale to items such as "how 
much choice do you have over when you can take off a few hours?" and "How much choice do you have over when you begin and end each work day?" Higher scores indicate higher perceptions of SC. SC demonstrated acceptable consistency at $\alpha=.71$.

\section{Outcomes}

Psychological distress. Psychological distress was measured with a 6-item scale adapted from Kessler and colleagues (2003). Respondents answered on a 1 (all of the time) to 5 (none of the time) scale to items such as "During the past 30 days, how much of the time did you feel that everything was an effort?" This scale is coded so that higher scores indicate increased levels of psychological distress. Scores were then summed to create an overall distress score that ranged from $6-30$. The psychological distress scale demonstrated good internal consistency at $\alpha=.86$.

Burnout. Burnout was measured using a subset of items form the Maslach Burnout Inventory (Maslach \& Jackson, 1986). Respondents were instructed to respond to 3 items on a 1 (everyday) to 7 (never) scale. Participants were prompted that they should respond based on how their work makes them feel to items such as "You feel emotionally drained from your work. How often do you feel this way?" Higher scores indicate greater levels of burnout. Job burnout demonstrated good consistency at $\alpha=.89$.

\section{Analytic Strategy}

In order to test the above hypotheses, data first needed to pass several checks in order to justify aggregation. The first step to establishing between group differences was to perform a basic ANOVA assessing whether group differences existed for the proposed unit-level variables, FSSB and SC. The ANOVA revealed there were significant group 
differences in terms of both FSSB $F(117,854)=2.25, \mathrm{p}<.001$ and $\operatorname{SC} F(117,858)=$ $2.73, p<.001$. Next, an assessment of whether group membership explained scores was performed by evaluating the ICCs, which were reported above. Both FSSB and SC surpassed expected and acceptable ICC1 (e.g., > .10). ICC2 values, which demonstrate reliability within group means, were found to be less strong. A consistent suggested cutoff in the literature for sufficient reliability of group means ranges from $\geq .60$ or $\geq .70$ (Huang et al., 2013). However, the ICC2 values fell just around those values, where FSSB ICC2 fell just below (= .56), and SC ICC2 was just above (.63), which may be reflective of differences in distance for some supervisors and employees within groups. That is, some supervisors supervised employees at different levels (e.g., Lead RN and CNA), which may have led to different types of relationships among the supervisors and their employees. Still, with ICC1 values explaining differences in scores based on group membership, significant between group differences in scores, and moderate reliability of group means, unit-level resources were aggregated across employees to create a level 2 variable (see Table 4.3 for a summary of the above statistics).

Following aggregation, correlations and sample descriptive statistics were assessed (see Table 4.2). For all of the following analyses condition was controlled for. A series of regressions were performed to assess Hypotheses 1 - 4. For Hypothesis 1 and 2, the data were aggregated to the unit-level (individual employee observations were removed), to not overly bias the results (e.g., values repeated across all 978 employees). The regressions included clustering on the unit-level. For Hypotheses 3 and 4, multilevel regressions were ran with unit resources at the between level, and groups clustered based 
on unit. Following the regression analyses, a series of multi-level structural equation model (SEM) path analyses were run following recommendations from Preacher, Zyphur, and Zhang (2010). The SEM path analyses utilized observed manifest variables rather than individual indicators due to power and theoretical concerns (e.g., no justification to aggregate each indicator to group-level). Confidence intervals for indirect effects were computed utilizing the Monte Carlo method with 20,000 repetitions as described by Preacher and Selig (2012).

\section{Results}

\section{Descriptive Statistics and Correlations}

Level 2 variables (FWA, WCFS, FSSB, and SC) were aggregated to the unit-level (to calculate level 2 means, standard deviations, and correlations between supervisor predictors ( $n=101$; Time 1$)$ and unit-level resources ( $n=118$ units; Time 2$)$. Level 2 variables were also aggregated across employees $(n=978)$ to calculate correlations between level 2 and level 1 variables at level 1, as well as the means and standard deviations of level 1 variables. Table 4.2 displays the means, standard deviations and correlations described below. Overall, supervisors had slightly positive views toward FWA $(M=2.91, S D=.77)$, perceived a slightly higher WCFS $(M=3.21, S D=.87)$. Employees reported higher levels of FSSB $(M=3.70, S D=.41)$, and moderate amounts of SC $(M=2.73, S D=.45)$. Employees also reported moderately high levels of burnout $(M=4.34, S D=1.64)$, and relatively low levels of distress $(M=11.44, S D=2.98)$ at the between-person level, supervisor FWA was moderately correlated with FSSB $(r=.20, p$ $=.002)$. Unit-level FSSB was moderately to strongly and positively correlated with SC ( $r$ 
$=.41, \mathrm{p}<.001)$, suggesting these resources share similar properties but represent different constructs. There were no other significant level 2 correlations between study variables. To calculate cross level correlations, unit-level resources and supervisor views were aggregated across the $n=978$ employees. When supervisor views and unit resources were aggregated across employees, FWA and WCFS demonstrated a moderate correlation $(r=-.25, p<.001)$. FWA and WCFS both had small - moderate correlations with FSSB $(r s=.17$, and -.12 respectively, $p \mathrm{~s}<.001)$ in the expected directions, and supervisor views of FWA were also associated higher levels of unit SC $(r=.10 p=.005)$. SC and FSSB again displayed moderate associations $(r=.32 p<.001)$. Both FSSB and $\mathrm{SC}$ had correlations with job burnout $(r \mathrm{~s}=-.12$ and $-.14, p s<.001)$, while SC was associated with lower distress as well $(r=-.11, p=.001)$. Finally, burnout and SC were moderately to highly correlated $(r=.43, p<.001)$.

\section{Supervisor Views and Unit-level Resources}

Figure 4.2 displays the hypothesized results for the main effects paths (hypotheses $1-4$ ) which includes 4 path a relationships (e.g., FWA and WCFS to FSSB and SC), and 4 path $\mathrm{b}$ relationships (FSSB and SC to burnout and distress). This figure is included to display all main effects results, but caution should be used for interpretation of the figure since each path was run separately (e.g., only one predictor at a time). Hypothesis 1 was that WCFS would be associated with aggregated employee FSSB and SC. Although the effects of supervisor WCFS on unit-level resources were in the expected directions, there was no main effect of WCFC on FSSB $(b=-.08$, S.E. $=.05, p=.073)$ or SC $(b=-.04$, S.E. $=.05, p=.74)$. Therefore, Hypothesis 1 was not supported (see Table 4.4). 
Hypothesis 2 was that supervisor FWA would be associated with aggregated employee FSSB and SC. Although the effects of supervisor FWA on unit-level resources were in the expected direction, there was no statistically significant evidence that FWA was associated with unit-level resources. Specifically, FWA was only marginally associated with unit reports of $\operatorname{FSSB}(b=.12, S . E .=.06 p=.03)$, and not significantly related to $\mathrm{SC}(b=.08, S . E .=.05, p=.146)$. Therefore, Hypothesis 2 was partially supported, supervisor views of FWA were related to higher levels of unit FSSB (see Table 4.4).

\section{Unit Resources and Employee Psychological Outcomes}

Figure 4.2 and Table 4.5 displays all path coefficients for the following regressions. Hypothesis 3 was that unit FSSB would be related to individual burnout and psychological distress. Unit-level FSSB was associated with lower employee burnout ( $b$ $=-.50$, S.E. $=.14, p<.001)$, but not psychological distress $(b=-.29$, S.E. $=.35, p=.403)$. Therefore, we found partial support for Hypothesis 3. Hypothesis 4 was that unit SC would be related to individual burnout and psychological distress. Unit SC was strongly associated with lower burnout $(b=-.65$, S.E. $=.14, p<.001)$ and psychological distress $(b=-1.31$, S.E. $=.34, p<.001)$, therefore Hypothesis 4 was supported .

\section{Multi-level Mixed Path Analyses}

In the following path analyses the direct and indirect effects are reported, but not the main effect paths. This was done to minimize redundancy since there are no discrepancies in conclusions when including the predictor and mediator in the model. 
Hypothesis 5 was that unit-level FSSBs would mediate the indirect effects of supervisor WCFS on a) job burnout and b) psychological distress. Results revealed there was no direct effect of WCFS on burnout $(b=.01$, S.E. $=.07, p=.90)$, or indirect effect of WCFS on burnout via FSSB $(b=.04$, S.E. $=.02, p=.09,[\mathrm{CI}=-.004, .10])$. Similarly, there was no direct effect of WCFS on distress $(b=-.18$, S.E. $=.19, p=.33)$ or indirect effect of WCFS on distress via FSSB $(b=.03$, S.E. $=.03, p=.374$, [CI $-.03, .12])$. Thus, as expected given the results of the initial regressions, there was no evidence to support the hypothesis that WCFS would have an indirect effect on burnout and distress via FSSB, and therefore Hypothesis 5 was not supported.

Figure 4.4 displays the results for the following path analyses for Hypothesis 6 . Hypothesis 6 was that unit-level FSSBs would mediate the effects of supervisor FWA on a) job burnout and b) psychological distress. Results revealed there was no direct effect of FWA on psychological distress $(b=.23$, S.E. $=.18, p=.203)$, or indirect effect of FWA on psychological distress via FSSB $(b=-.05$, S.E. $=.05, p=.357,[\mathrm{CI}=-.04, .17])$. Similarly, there was no direct effect of FWA on burnout $(b=-.09$, S.E. $=.07, p=.230)$, however, there was a significant indirect effect of FWA on burnout via FSSB as indicated by the $95 \%$ Monte Carlo confidence intervals $(b=-.06$, S.E. $=.03, p=.06,[\mathrm{CI}=.004$, .14]). Therefore, Hypothesis 6 was partially supported.

Figure 4.5 for results of path analysis for Hypothesis 7 . Hypothesis 7 was that unit-level SC would mediate the indirect effects of supervisor WCFS on a) job burnout and b) psychological distress. There was no direct effect of WCFS on burnout ( $b=.02$, S.E. $=.07, p=.755)$, or indirect effect of WCFS on burnout via SC $(b=.03$, S.E. $=.04, p$ 
$=.484,[\mathrm{CI}=-.04, .09])$. Additionally, there was no direct effect of WCFS on distress $(b$ $=-.18$, S.E. $=.18, p=.302$ ), or indirect effect of WCFS on psychological distress via SC $(b=.05$, S.E. $=.07, p=.464,[\mathrm{CI}=-.08, .18])$. Thus, Hypothesis 7 was not supported

See Figure 4.6 for path analysis results for hypothesis 8 . Hypothesis 8 was that unit-level SC would mediate the effects of supervisor FWA on a) job burnout and b) psychological distress. There was no direct effect of FWA on burnout $(b=-.10$, S.E. $=$ $.08, p=.229)$, nor was there an indirect effect of FWA on burnout via SC $(b=-.05, S . E$. $=.04, p=.188,[\mathrm{CI}=-.02, .13])$. Additionally, there was no direct effect of FWA on distress $(b=-.27$, S.E. $=.19, p=.144)$ or indirect effect of FWA on distress via SC $(b=-$ .11$, S.E. $=.08, p=.169,[\mathrm{CI}=-.04, .28])$. Thus, there was no support for Hypothesis 8.

\section{Discussion}

The present study uses a novel approach to understand the factors that predict unit-level resources that are particularly relevant as work-family resources. Additionally, this model was extended by examining important individual job and psychological outcomes associated with unit-level resources. Among a sample of healthcare professionals, the current study demonstrated that there is a nuanced relationship between supervisor views and unit-level resources. Specifically, there was an association between higher levels of FWA and unit-level FSSB. However, there were no other main effects of supervisor views on unit-level resources. Additionally, unit-level resource were generally strongly related to improved employee well-being. Specifically, both unit-level FSSB and SC were related to lower burnout, and unit-level SC was related to lower distress. Finally, this study demonstrated that supervisor views indirectly influence employee burnout via 
FSSB. However, there were no other direct or indirect effects of supervisor views on individual outcomes via unit-level resources.

\section{Supervisor Views and Unit-level Resources}

The current study expands previous work and suggests that specific supervisor views about FWA can predict unit FSSB. However, there was otherwise little evidence that supervisor views were associated with unit-level resources. Specifically there were no significant associations between WCFS or FWA and SC, nor was WCFS associated with FSSB, however FWA had a small but meaningful relationship with FSSB. Initial reflections on results from the current study may lead one to conclude that supervisor's own beliefs (FWA) and their normative beliefs (WCFS) may not be generally associated with unit-level FSSB and SC. However, supervisors have been shown to strengthen climate in organizations with weak organizational values (Zohar \& Luria, 2010), and attitudes are consistently related to behaviors (Montano \& Kasprzyk, 2015). Therefore, it seems unlikely that supervisor views about the allocation of resources do not contribute to resources more broadly than demonstrated in the current study. Rather, the relationships between supervisor views (FWA and WCFS) and unit-level resources (FSSB and SC) may be better illuminated by examining certain moderating factors. For example, examining the role of organizational policy or supervisor discretion, which have both been demonstrated as predictors or boundary conditions of safety climate (Christian et al, 2009; Zohar \& Luria, 2005), may help to uncover important boundary conditions. Both SC and facets of FSSB (instrumental support) tap scheduling accommodations. To this end we suggest that boundary conditions (e.g. supervisor discretion) may be 
meaningful in establishing the conditions in which supervisor views will shape unit resources. Some individuals participating in the study were schedulers, who were excluded from the current employee sample. This suggests that scheduling was not consistently or solely a supervisory decision. Further, supervisors were of different ranks (e.g. charge RN, unit manager RN), which also may suggest different amounts of influence across supervisors in terms of scheduling accommodations and decisions. Thus, it is possible, perhaps likely even, that in some cases supervisors had some scheduling decision discretion, while in others they had extremely minimal amounts, effectively weakening the link between supervisor views and both SC and FSSB (due to the instrumental facet). Thus, information about supervisor discretion may help to support and expand upon this relationship in ways the current study could not.

We found that FWA had a small but meaningful relationship with FSSB, suggesting that supervisor views about FWA are still related to FSSB, irrespective of their ability to provide scheduling accommodations. Thus, when supervisors have higher levels of negative views of FWA, unit perceptions of FSSB are also subsequently lower, suggesting that supervisors' views do shape climate. This is quite important considering very little research has established the antecedents FSSB (Crain \& Stevens, 2018). This finding is generally in line with COR (Hobfoll, 1989), if supervisors perceive more difficulties (resource drains) with accommodating FWA, they would less be less likely to disperse FSSB resources. However, WCFS was not related to FSSB. This finding is curious considering that previous research has demonstrated moderate associations between individual perceptions of WCFS and FSSB (e.g., $r=.21, p<.01$; Hammer et al., 
2016). It is possible that supervisor views of WCFS do not meaningfully predict unit FSSB strongly enough without again considering the role of supervisory discretion to make accommodations. Alternatively the current findings may reflect that supervisor individually held beliefs about (FWA) may be more important for predicting unit-level FSSB than their views about the organizational norms (WCFS), suggesting an interesting avenue for future research.

\section{Unit-level Resources and Job Burnout and Psychological Distress}

The literature is clear that FSSB and SC are linked to a host of individual outcomes (Crain \& Stevens, 2018; Thomas \& Ganster, 1995). Both FSSB and SC have shown associations with burnout (Yragui et al., 2016; Thomas \& Ganster, 1995) and psychological distress (Huffman \& Olson, 2017; and Moen et al., 2016). The present study extends upon this research by demonstrating strong associations between unit-level perceptions of FSSB and SC and lower individual burnout over time. However, although there was a relationship between SC and lower distress, there was no demonstrated relationship between unit-level FSSB and psychological distress. It is worth noting that our sample had low levels of distress in general (slightly skewed).Therefore FSSB may not be as meaningful of a resource to those who are already experiencing low levels of distress, or meaningful differences may have been difficult to detect due to a floor effect.

With regard to the expected theoretical link based on COR theory, it is generally expected that greater levels of resources lead to lower levels of distress. While SC was significantly associated with declines in psychological distress, FSSB was not. COR theory suggests that resource gains are less salient than resource losses (Hobfoll, 2002). It 
is possible that better aligning resources to outcomes within a COR framework may further our understanding of why SC, but not FSSB, was related to lower levels of psychological distress. For instance, it is possible that working in a unit with higher levels of FSSB leads individuals to be more satisfied and less burned out with regards to their job, but not necessarily for their own non-job related well-being. This finding may have important implications for theory development. For instance, it is possible that unit-level FSSB does not necessarily encourage the instrumental use of FSSB to meet family needs, and the benefits of unit-level FSSB stops at the end of one's shift. On the other hand, unit-level SC was strongly and negatively related to both burnout and psychological distress $(p<.001)$. Thus, unit-level SC serves as an important predictor of both job and individual non-work well-being, and perhaps because it provides important instrumental value and resources for individuals to utilize in the resource gain process.

\section{Mediations}

Considering there were minimal observed effects of supervisor views on unitlevel resources, it was relatively unsurprising that most of the indirect paths were nonsignificant. That is, the general lack of main effects between the level-2 variables in the regressions suggested that the path analyses would likely be unsuccessful. In regards to the link between supervisor views and unit-level resources as well as the path analyses, there are certain sample limitations (discussed above and below) that may have made potential effects difficult to detect. In future efforts I suggest researchers utilize a sample of supervisors with more quantifiable discretion over specific resources (e.g., scheduling - which also impacts their ability to demonstrate instrumental portions of FSSB), which 
may allow the relationships between supervisor views and unit-level resources to be further elucidated. Despite these limitations, there was still one observed indirect effect of supervisor negative views of FWA on employee burnout via unit-level FSSB, suggesting that even though there was not stringent controls on the distance and interaction level between supervisor to employees, supervisor views of FWA has important downstream effects that ultimately impact employee job burnout via unit-level FSSB. Future research with more strict sample requirements (e.g. equal distances, quantitatively measurable interactions) may demonstrate this relationship to be even stronger considering our limited ability to control the distance between supervisors and employees as well as the amount of interaction across levels of supervisors and employees likely contributed to weaker within unit agreement.

\section{Contributions}

This study makes several contributions to both theory and practice. This is the first known study to utilize conceptualizations from COR theory and climate frameworks together, and while these frameworks are useful both by themselves, they allow for a more clarified understanding together. In an effort to clarify the role of resources, Hobfoll and colleagues (2018) reaffirmed that resources that have shared value are resources that are thought to represent important contributors to well-being. Interestingly, this fits nicely with climate research that suggests shared perceptions are instrumental, and can have practical implications for organizations. Thus these frameworks were utilized together to develop hypotheses and conceptualizations of unit-level (climate level) resources. As expected, this study demonstrated that some supervisor views are important for shaping 
perceptions of FSSB, and that shared perceptions of FSSB and SC have important implications for employee well-being. This conceptualization of unit-level resources can help to further identify strong effects that are more consistent with the essence of COR theory, and represents a substantial addition to the theoretical conceptualizations and practices that rely on the COR framework. However, findings were not without nuances. Specifically, there was no link between FSSB and psychological distress. Theoretically, this suggests that lower levels of shared FSSB have implications for job psychological resources (e.g. burnout), but may stop there, whereas unit-level SC is linked to both burnout and distress, suggesting a need to further classify resources in order to uncover how meaningful they are in terms of their effects on multiple well-being indicators. Unitlevel SC may be more useful for meeting resource related needs across domains, and thus, have more positive relations with burnout and distress, whereas FSSB may be limited in its effects to work-related outcomes (e.g., burnout). Thus, shared resources are not necessarily equal, nor do they necessarily serve the same function, and further theoretical development may be necessary to uncover when and why.

The current study also provides some initial theoretical evidence that supervisor WF views can but do not necessarily equate to resource allocation (or lack thereof) from supervisors to employees. Specifically, there may be significant barriers that prevent supervisors from allocating (or restricting) resources to their employees. Thus, while initial findings may seem inconsistent with COR theory, they are not. If supervisors do not have resources to allocate, they cannot allocate them. That is, greater consideration for the extent to which supervisors have discretion over various job-related resources are 
important to consider. Careful consideration of the discretionary power that supervisors hold within a given organization or within an industry may help to clarify which resources are most appropriately aggregated to the unit-level, and thus, advance the applications of unit-level resources within a COR framework.

This study also makes notable practical contributions. Specifically there is practical relevance in findings that demonstrate unit-level FSSB and SC can have important effects on employees' job burnout over time, and unit-level SC is also positively associated with distress. Specifically, organizations are rightfully often concerned with burnout, considering it is consistently associated with poor organizational outcomes such as withdrawal and turnover (Alcaron, 2011). This study suggests that unitlevel resources can help identify whether employees are more burned out within units, as well as an avenue for improvement in order to turn things around for burned out employees. For instance, when organizations are concerned about employee burnout, trainings that promote shared positive resource climates, can improve burnout. Further, considering that FWA was linked to employee burnout via FSSB, both supervisors and employees should be targets. Findings may be even more practically relevant among healthcare organizations and professionals who are known to have high rates of individual job burnout that is shared among workers (Bakker et al., 2005). Further, because burnout has been associated with harsh consequences such as suicidal ideation (Dyrby, et. Al, 2008), medical mistakes (Shanafelt et al, 2010), and poorer quality patient care (Le Blanc et al., 2007), our findings suggest that unit-level resources may be important to consider from multiple perspectives (e.g., workers, organizations, patients, 
patients' family members). Thus, organizations, particularly healthcare organizations, should examine the extent to which units have positive resource climates.

\section{Limitations and Future Research}

The current study is not without limitations. First, the distance between supervisor and employees cannot be considered equal within or between groups, nor the level of influence each supervisor had. Specifically, there were several different jobs that employees could have (e.g. Licensed RN, medical assistant) and that supervisors held (e.g. unit manager, Lead RN). Although we reduced this issue by only including medical staff in our sample (e.g. not including dietary staff), employees could have been more or less proximally connected to their respective manager within groups. For instance, a unit managing RN would likely have more contact with employees closer in the organizational hierarchy (e.g. RN) as opposed to those at lower levels of the organizational structure (e.g. CNA). This is a limitation that potentially influenced the ICC2 (reliability of group means), because arguably, supervisors may be more able to provide support to those with whom they have more interactions with, whereas those employees that have less contact with their supervisor, may have different feelings about the support their supervisor provides. This problem could also partially explain why the effect of FWA on FSSB was only small. Specifically, if the climate had been more reliable within groups, this may have helped to bolster the magnitude of the effects of supervisor FWA on unit FSSB, and potentially the indirect relationships hypothesized. Future research should further explore consistency across work groups, and model the 
power of supervisors, as well as distances between supervisor and employees within a work group in order to further elucidate the role supervisors have in shaping resources. Additionally, there is very little utilizable information about the policies and procedures that governed each individual worksite, rendering a complete model that accounts for organizational nuances, policies, procedures and informal workplace culture impossible with the current data. For instance, workplace policies may be highly important in predicting the climate of sub-units within organizations, but without those policies, this is not easily explored. Alternatively, the interpersonal backlash or support associated with requesting family or scheduling accommodations may be meaningful in their own right for predicting the unit resources in the current study, considering poor views of policy usage are associated with perceptions of increased coworker demands and career consequences (Chung, 2018). Still, our findings that supervisor FWA is associated with FSSB and indirectly job burnout, despite these limitations, suggests a fruitful avenue for future research. Future efforts could examine the link between supervisor discretion, organizational policy around family leave, taking time off, and unit-level resources to understand the unique impact supervisors have on individuals both in and outside of their job.

A final potential limitation of the current study is that it was not gender diverse, the sample instead was largely female. Previous research has demonstrated that workfamily issues can disproportionately impact women, as women continue to take on the majority of household and family responsibilities (Pew, 2015). As such, the impact on outcomes may have been more pronounced in our study than would be observed in a 
more balanced sample. Additionally, women are still considered family care takers, and therefore some interesting effects may be uncovered with a more balanced sample. Specifically, uncovering whether there are gender effects that explain the strength of climate from both a unit perspective, as well as whether supervisor gender would be differentially associated with strength. Still, given that healthcare occupations as well as other service-oriented occupations (e.g., childcare) are gendered and heavily dominated by female employees, our understanding of the impact of unit resources known to help balance work and family needs in this specific population are important. We recommend future researchers evaluate the generalizability of the finding in this study with samples that are more heterogeneous with respect to gender.

\section{Conclusion}

The current study utilized a novel approach to understand the role of supervisor views in shaping unit-level work-family resources, and the role of unit-level work-family resources in shaping individual outcomes. This study demonstrated that when supervisors view FWA more negatively, there was lower levels of FSSB, suggesting initial evidence that supervisors shape work-family resource climates. Additionally, unit-level FSSB and SC were found to have negative associations with poor employee well-being outcomes including burnout, and in the case of SC, psychological distress. This study also demonstrated that when supervisors hold negative views towards FWAs, employees are more burned out via lower levels of FSSB. However, there were no other indirect effects of supervisor views on employee well-being, which is likely in part due to sample limitations. Taken together, these findings suggest that researchers, practitioners, and 
organizations, and particularly healthcare organizations, should consider the important ramifications associated with poor resource climates, and that future research is needed to further elucidate the antecedents and their boundary conditions that shape positive workfamily resource climates. 
Table 4.1

Sample Demographics and Descriptive Characteristics

\begin{tabular}{|c|c|c|}
\hline & $\begin{array}{c}\text { Employee }(n=978) \\
M / N(S D / \%)\end{array}$ & $\begin{array}{c}\text { Manager }(n=101) \\
M / N(S D / \%)\end{array}$ \\
\hline Female & $900(92 \%)$ & $94(93.1 \%)$ \\
\hline Age & $39.14(12.39)$ & $47.30(10.51)$ \\
\hline \multicolumn{3}{|l|}{ Ethnicity } \\
\hline White & $626(64.4 \%)$ & $90(90.1 \%)$ \\
\hline African American/Black & $144(14.7 \%)$ & $2(2 \%)$ \\
\hline Hispanic & $138(14.1 \%)$ & $4(4 \%)$ \\
\hline Married & $605(61.8 \%)$ & $71(70.3 \%)$ \\
\hline Children & $551(56.3 \%)$ & $47(47.5 \%)$ \\
\hline \multicolumn{3}{|l|}{ Schedule } \\
\hline Day & $466(56.6 \%)$ & $65(64.0 \%)$ \\
\hline Evening & $258(31.3 \%)$ & $9(8.9 \%)$ \\
\hline Rotating & $40(4.9 \%)$ & $26(25.7 \%)$ \\
\hline Variable & $26(3.2 \%)$ & $26(25.7 \%)$ \\
\hline Company tenure (years) & $7.08(6.93)$ & $9.24(7.79)$ \\
\hline Hours per week & $37.28(7.17)$ & $48.55(8.40)$ \\
\hline \multicolumn{3}{|l|}{ Job Title } \\
\hline LPN/RN unit manager & & $64(64 \%)$ \\
\hline $\mathrm{RN}$ director/administrator & & $26(26 \%)$ \\
\hline LPN/RN supervisor & & $10(10 \%)$ \\
\hline CAN & $687(70 \%)$ & \\
\hline LPN/RN & $170(17 \%)$ & \\
\hline LPN/RN supervisor & $107(11 \%)$ & \\
\hline Nursing practice educator & $12(2.3 \%)$ & \\
\hline
\end{tabular}

Note: Married is $0=$ no, $1=$ married or living with partner. Children is $0=0$ children living with subject $\geq 4$ days per week, $1=1$ or more children living with subject $\geq 4$ days per week. Day = regular daytime schedule. Evening = regular evening schedules.

Rotating $=$ shift changes regularly from days to evening or nights. Variable $=$ schedule changes day to day. $\mathrm{LPN}=$ licensed practical nurse; $\mathrm{RN}=$ registered nurse; $\mathrm{CNA}=$ certified nurse assistant. 
Table 4.2

Descriptive Statistics, Scale Reliability, and Correlations of Study Variables

\begin{tabular}{lccccccccc}
\hline & $M$ & $S D$ & 1 & 2 & 3 & 4 & 5 & 6 & 7 \\
\hline 1. FWA & 2.91 & .77 & .79 & -.17 & $.20^{*}$ & .14 & & & \\
2. WCFS & 3.21 & .87 & - & .73 & -.14 & -.08 & & & \\
& & & $.25^{* * *}$ & & & & & & \\
3. FSSB & 3.70 & .41 & $.17^{* * *}$ & $-.12^{* * *}$ & .89 & $.41^{* * *}$ & & & \\
4. SC & 2.73 & .45 & $.10^{* *}$ & -.04 & $.32^{* * *}$ & .71 & & & \\
5. Burnout & 4.34 & 1.64 & -.06 & .03 & $.12^{* *}$ & $-.14^{* * *}$ & $\mathbf{8 9}$ & & \\
6. Distress & 11.22 & 2.98 & .03 & .03 & -.02 & $-.11^{* *}$ & $.43^{* * *}$ & $\mathbf{. 8 6}$ & \\
7. Condition & -- & -- & .02 & $-.21^{* * *}$ & -.01 & .03 & $-.09^{* *}$ & -.01 & -- \\
\hline
\end{tabular}

Note: $* * * * p<.001, * * p<.01, * p<.05, \dagger p<.10$. Raw scale reliability is bolded on diagonal. Supervisor variables are Time 1 responses $=$ FWA and WCFS. FWA = supervisor views toward flexible work arrangements; WCFS = supervisor perceptions of workplace climate for family sacrifices. Unit resource variables are Time 2 aggregated across units under a shared supervisor. Unit resource variables $=$ FSSB and SC. FSSB $=$ family supportive supervisor Behaviors; $\mathrm{SC}=$ schedule control. Level 1 variables are Burnout $=$ job burnout and Distress $=$ psychological distress. Level 2 variables aggregated by cluster (supervisor) across $n=118$ groups, $n=101$ supervisors, and $n=$ 978 employees. Level 2 variables 1 - 4; Level 1 variables $5-6$. Correlations above scale reliabilities represent aggregated unit correlations of level 2 variables. Correlations below scale reliabilities represent correlations observed when unit level variables are repeated across $n=978$ employees. Condition is coded as $0=$ control, $1=$ training. 
Table 4.3

Unit-level Resource Variable Means, Standard Deviations, ICCs and F-test.

\begin{tabular}{llllll}
\hline & $M_{1}\left(S D_{1}\right)$ & $M_{2}\left(S D_{2}\right)$ & ICC1 & ICC2 & F \\
\hline FSSB & $3.69(.83)$ & $3.70(.41)$ & .13 & .56 & $2.25^{* * *}$ \\
SC & $2.63(.75)$ & $2.73(.45)$ & .16 & .63 & $2.75^{* * *}$ \\
\hline
\end{tabular}

Note: $* * * p<.001, * * p<.01, * p<.05, \dagger p<.10 . M_{1}\left(S D_{1}\right)$ represents sample mean and standard deviation of for FSSB and SC respectively, prior to aggregation. $M_{2}\left(S D_{2}\right)$ represents mean and standard deviation aggregated across $n=118$ units (clusters) across 978 employees. ICC values and F-test represent group estimates by supervisor prior to aggregation (describe percentage of variance attributable to group membership, reliability of group means, and whether there are group mean differences). 
Table 4.4

Main Effects of Supervisor Views on Unit-level Resources.

\begin{tabular}{lcccccc}
\hline & \multicolumn{3}{c}{ FWA } & \multicolumn{3}{c}{ WCFS } \\
\hline & $\mathrm{B}$ & S.E. & $\mathrm{r}^{2}$ & $\beta$ & S.E. & $\mathrm{r}^{2}$ \\
FSSB & $.12^{*}$ & .06 & .05 & $.08 \dagger$ & .05 & .03 \\
SC & .08 & .05 & .02 & .04 & .05 & .01 \\
\hline
\end{tabular}

Note: Utilizes supervisor attitude and unit resource scores aggregated across all individuals at Time 1 and Time 2; $N=101$ supervisors at time 1, 118 units (clusters) at time 2 ( $n=978$ employees; average cluster size $=8.29)$. Values are unstandardized effects observed from main effects analyses for Hypothesis 1 and 2. Predictors were modeled separately (separate regressions). Supervisor Baseline Variables: Workplace Climate for Family Sacrifices (WCFS) was composite scored, with higher scores indicating stronger supervisor perceptions of workplace climate for family sacrifices. Supervisor views toward Flexible Work Arrangements (FWA) was composite scored, with higher values indicating more positive views toward FWA. Aggregate Unit Resources time 2 variables (6 months): Control over Work Schedule and Work Hours (SC) was composite scored, with higher values representing higher perceptions of schedule control. Family Supportive Supervisor Behaviors (FSSB) was composite scored, with higher scores indicating higher perceptions of FSSB. ${ }^{* * *} p \leq .001, * * p \leq .01, * p \leq .05, \dagger p<.10$. 
Table 4.5

Main Effects of Unit-level Resources on Employee Well-being

\begin{tabular}{lcccccc}
\hline & \multicolumn{3}{c}{ FSSB } & \multicolumn{3}{c}{ SC } \\
\hline & B & S.E. & $\mathrm{r}^{2}$ & $\beta$ & S.E. & $\mathrm{r}^{2}$ \\
Burnout & $-.50 * * *$ & .06 & $.79 *$ & $-.65 * * *$ & .14 & $.89 * * *$ \\
Distress & -.29 & .35 & .15 & $-1.32 * * *$ & .34 & .84 \\
\hline
\end{tabular}

Note: Level 2 variables (FSSB and SC) were aggregated across within unit employees $n$ $=118$ units, with an average cluster size 8.29, and total employee sample of $n=978$. Values represent unstandardized effects observed from main effects analyses for Hypothesis 3 and 4. 2-level regressions were run separately. Aggregate unit resources Time 2 variables (6 months): Control over Work Schedule and Work Hours (SC) was composite scored, with higher values representing higher perceptions of schedule control. Family Supportive Supervisor Behaviors (FSSB) was composite scored, with higher scores indicating higher perceptions of FSSB. Individual outcomes measured at Time 3 (12 months). Job burnout was composite scored, where higher scores indicated greater job burnout. Psychological distress was a 6-item sum score. Final psychological distress scores range from $6-30$ where higher scores indicate higher levels of distress. $* * * p$ $\leq .001, * * p \leq .01, * p \leq .05, \dagger p<.10$ 


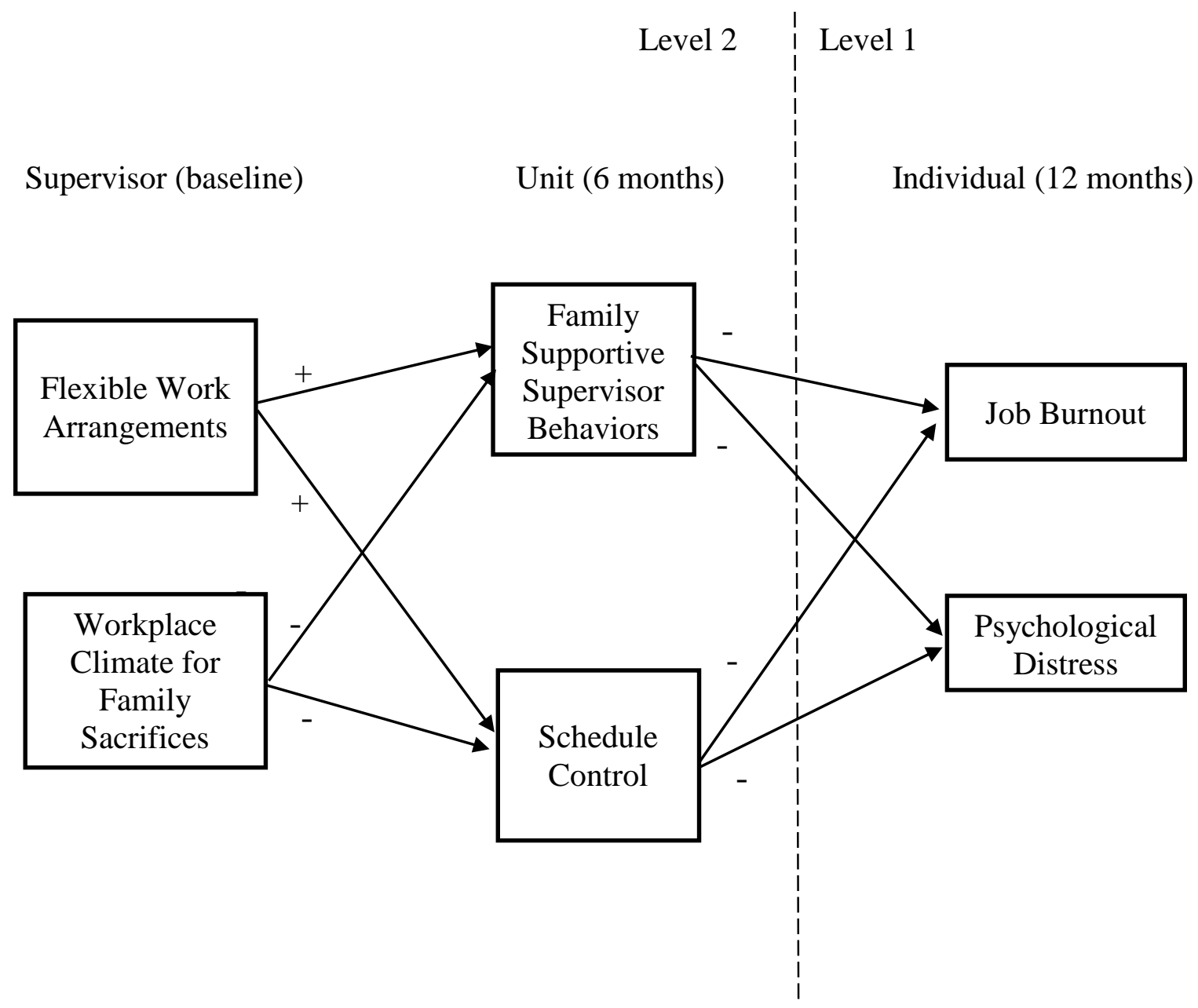

Figure 4.1. Study conceptual model where each relationship is hypothesized with a single predictor. 


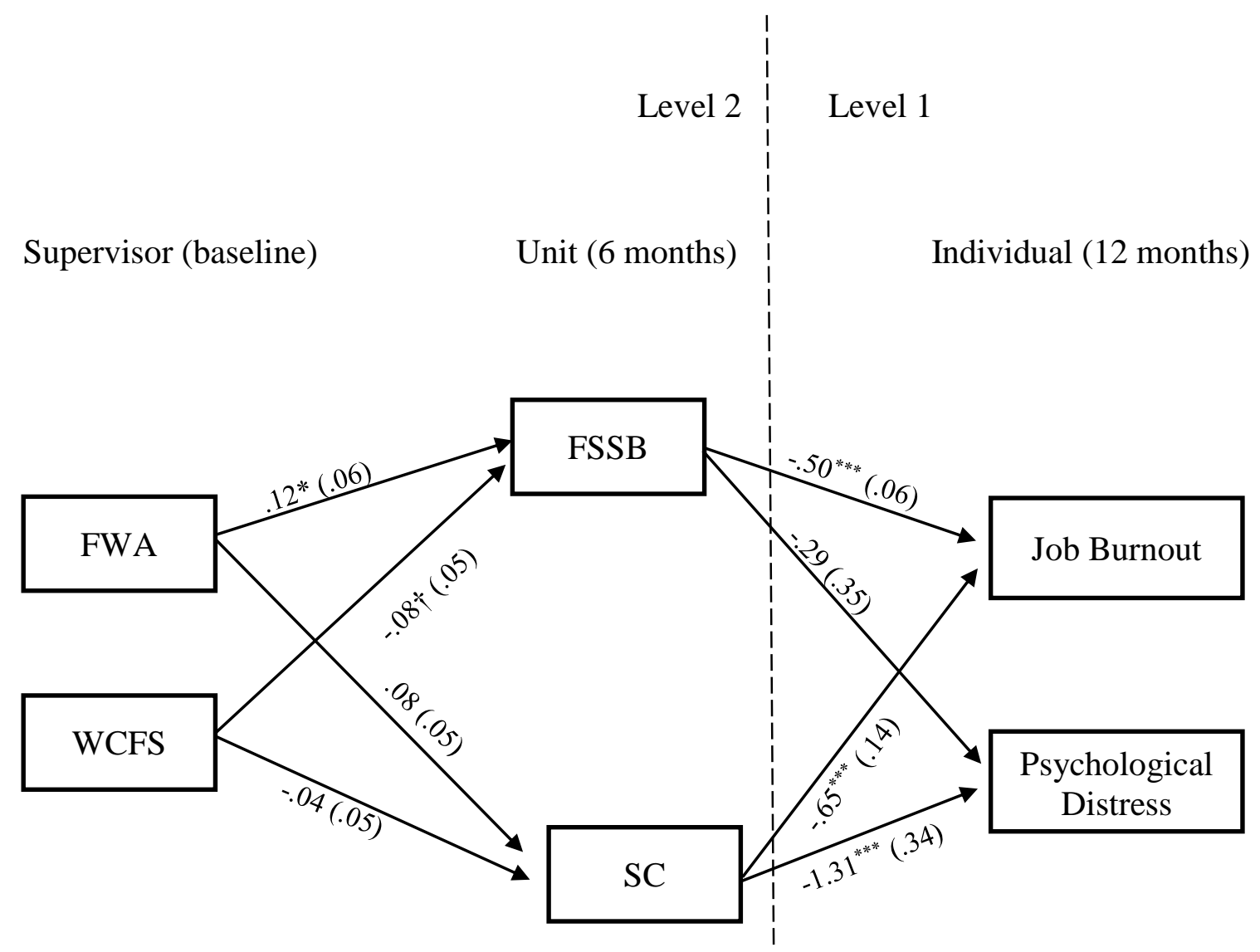

Figure 4.2. Unstandardized effects observed from main effects, single predictor hypotheses (hypothesis 1 - 4), and analyses. 


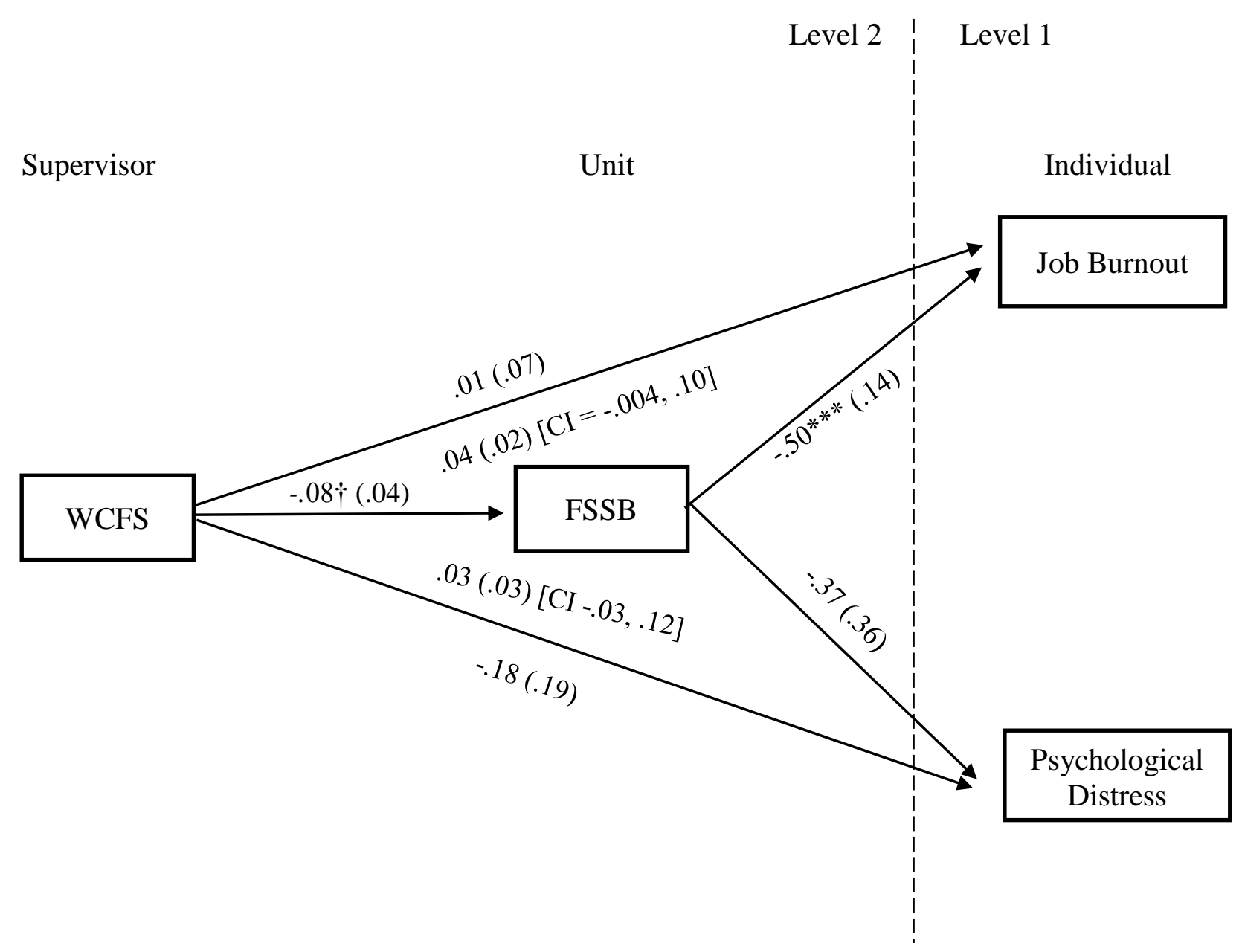

Figure 4.3. Unstandardized path statistics from MSEM mediation path analysis of supervisor perceptions of workplace climate for family sacrifices, unit-level family supportive supervisor behaviors, and individual job burnout and psychological distress. 


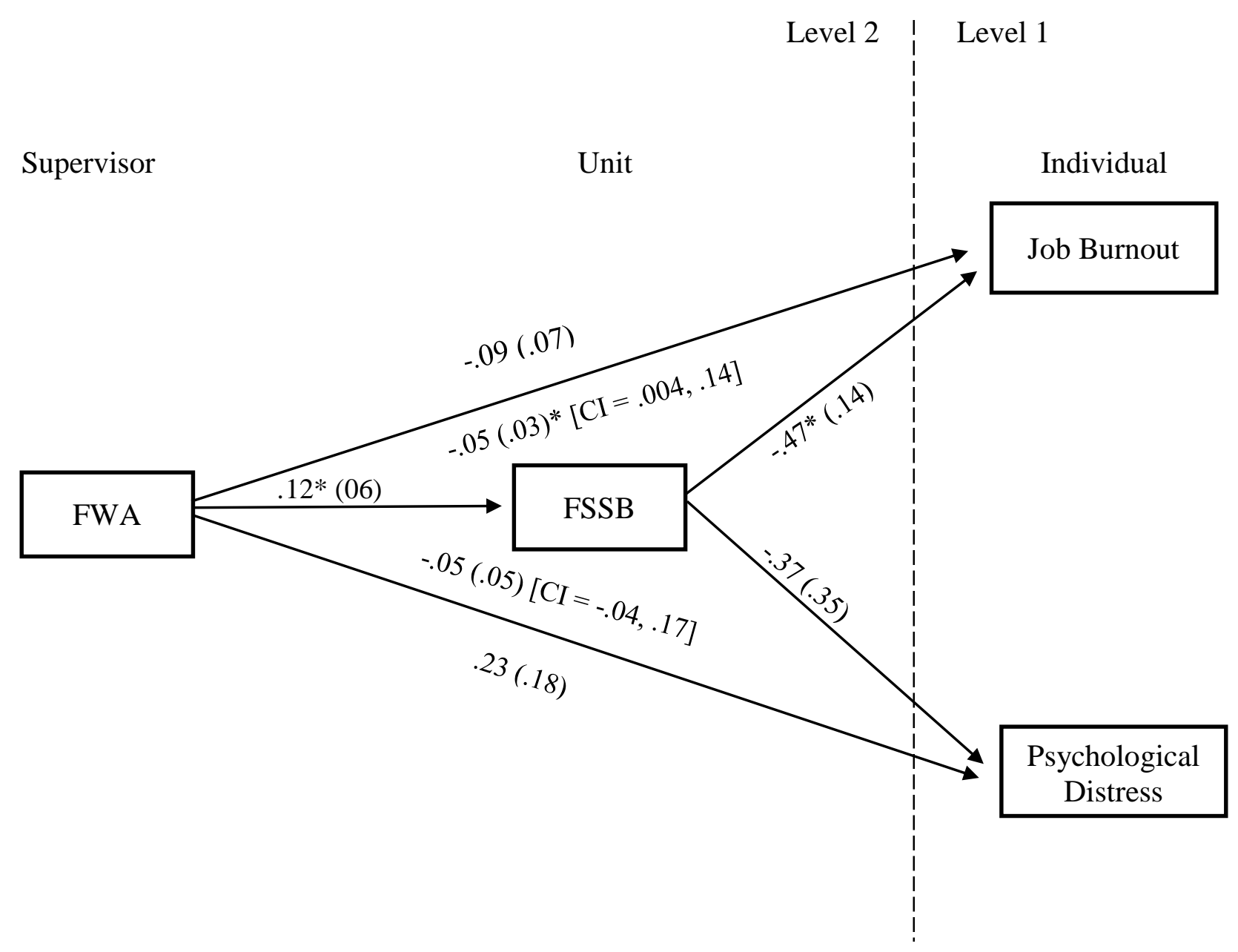

Figure 4.4. Unstandardized path statistics from MSEM mediation path analysis of supervisor views toward flexible work arrangements, unit-level family supportive supervisor behaviors and individual job burnout and psychological distress. 


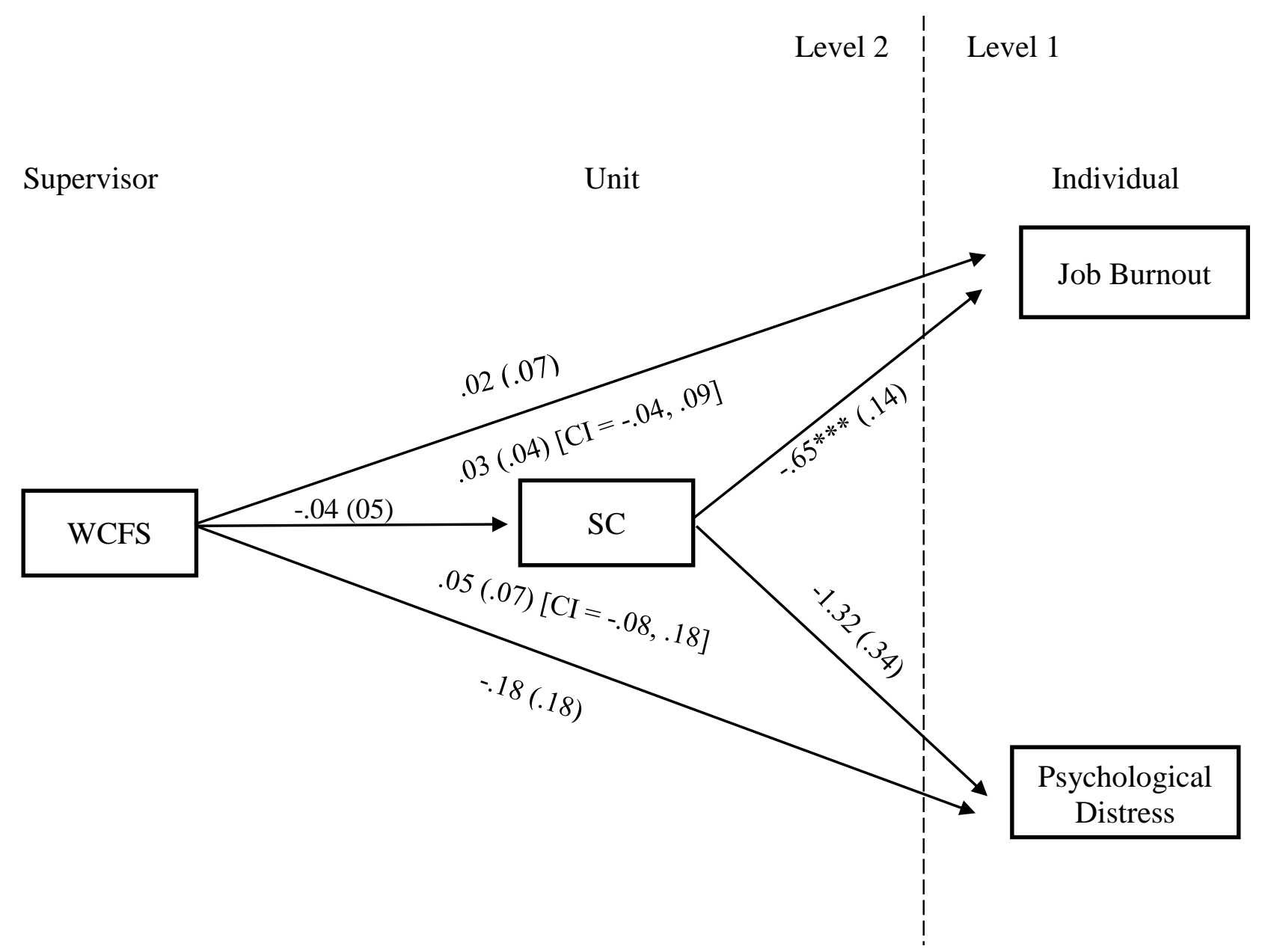

Figure 4.5. Unstandardized path statistics from MSEM mediation path analysis of supervisor perceptions of workplace climate for family sacrifices, unit-level family supportive supervisor behaviors and individual job burnout and psychological distress. 


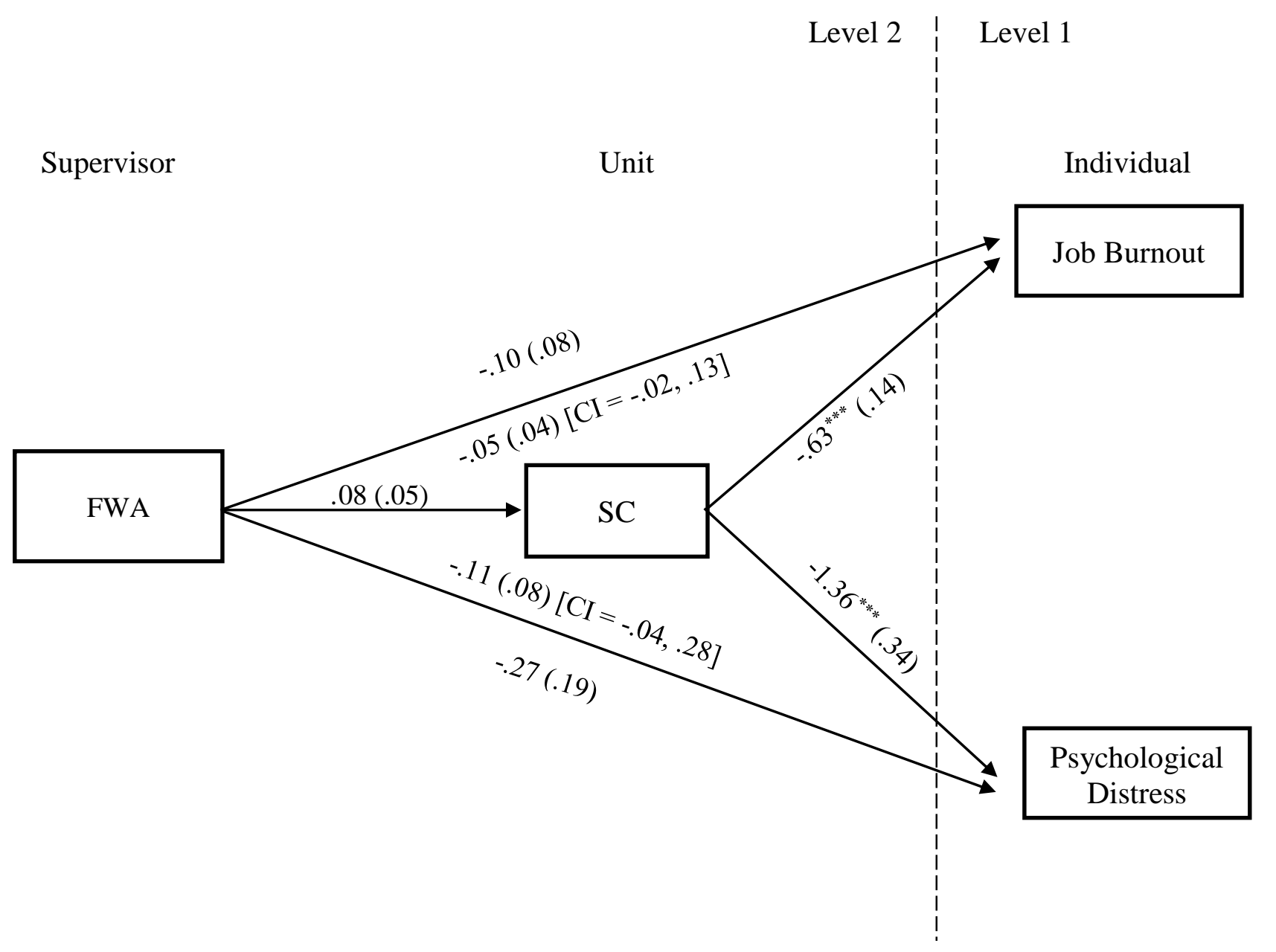

Figure 4.6. Unstandardized path statistics from MSEM mediation path analysis of supervisor views toward flexible work arrangements (FWA), unit-level family schedule control (SC), and individual job burnout and psychological distress. 


\section{References}

Alarcon, G. M. (2011). A meta-analysis of burnout with job demands, resources, and attitudes. Journal of Vocational Behavior, 79(2), 549-562.

Allen, T. D. (2001). Family-supportive work environments: The role of organizational perceptions. Journal of Vocational Behavior, 58(3), 414-435.

Almer, E. D., \& Kaplan, S. E. (2002). The effects of flexible work arrangements on stressors, burnout, and behavioral job outcomes in public accounting. Behavioral Research in Accounting, 14(1), 1-34.

Bakker, A. B., \& Demerouti, E. (2007). The job demands-resources model: State of the art. Journal of Managerial Psychology, 22(3), 309-328.

Bakker, A. B., Le Blanc, P. M., \& Schaufeli, W. B. (2005). Burnout contagion among intensive care nurses. Journal of Advanced Nursing, 51(3), 276-287.

Baruch-Feldman, C., Brondolo, E., Ben-Dayan, D., \& Schwartz, J. (2002). Sources of social support and burnout, job satisfaction, and productivity. Journal of Occupational Health Psychology, 7(1), 84-93.

Bliese, P. D. (2000). Within-group agreement, non-independence, and reliability: Implications for data aggregation and analysis. In K. J. Klein \& S. W. J. Kozlowski (Eds.), Multilevel theory, research, and methods in organizations: Foundations, extensions, and new directions (pp. 349-381). San Francisco, CA, US: Jossey-Bass.

Bray, J. W., Kelly, E. L., Hammer, L. B., Almeida, D. M., Dearing, J. W., King, R. B., \& Buxton, O. M. (2013). An integrative, multilevel, and transdisciplinary research 
approach to challenges of work, family, and health. Methods Report (RTI Press), 1.

Brotheridge, C. M., \& Grandey, A. A. (2002). Emotional labor and burnout: Comparing two perspectives of "people work". Journal of Vocational Behavior, 60(1), 17-39.

Byron, K. (2005). A meta-analytic review of work-family conflict and its antecedents. Journal of Vocational Behavior, 67(2), 169-198.

Carlson, D., Kacmar, K. M., Zivnuska, S., Ferguson, M., \& Whitten, D. (2011). Workfamily enrichment and job performance: A constructive replication of affective events theory. Journal of Occupational Health Psychology, 16(3), 297-312.

Chen, Z. X., Tsui, A. S., \& Farh, J. L. (2002). Loyalty to supervisor vs. organizational commitment: Relationships to employee performance in China. Journal of Occupational and Organizational Psychology, 75(3), 339-356.

Christian, M. S., Bradley, J. C., Wallace, J. C., \& Burke, M. J. (2009). Workplace safety: a meta-analysis of the roles of person and situation factors. Journal of Applied Psychology, 94(5), 1103-1127.

Chung, H. (2018). Gender, Flexibility Stigma and the Perceived Negative Consequences of Flexible Working in the UK. Social Indicators Research, 1-25.

Crain T.L., Stevens S.C. (2018) Family-supportive supervisor behaviors: A review and recommendations for research and practice. Journal of Organizational Behavior Annual Review, 39, 869-888. 
Dimoff, J. K., \& Kelloway, E. K. (2019). With a little help from my boss: The impact of workplace mental health training on leader behaviors and employee resource utilization. Journal of occupational health psychology, 24(1), 4-19.

Donders, A. R. T., Van Der Heijden, G. J., Stijnen, T., \& Moons, K. G. (2006). A gentle introduction to imputation of missing values. Journal of Clinical Epidemiology, 59(10), 1087-1091.

Dyrbye, L. N., Thomas, M. R., Massie, F. S., Power, D. V., Eacker, A., Harper, W., \& Sloan, J. A. (2008). Burnout and suicidal ideation among US medical students. Annals of Internal Medicine, 149(5), 334-341.

Embriaco, N., Papazian, L., Kentish-Barnes, N., Pochard, F., \& Azoulay, E. (2007). Burnout syndrome among critical care healthcare workers. Current opinion in Critical Care, 13(5), 482-488.

Foley, S., Linnehan, F., Greenhaus, J. H., \& Weer, C. H. (2006). The impact of gender similarity, racial similarity, and work culture on family-supportive supervision. Group \& Organization Management, 31(4), 420-441.

Glasberg, A. L., Eriksson, S., \& Norberg, A. (2007). Burnout and 'stress of conscience' among healthcare personnel. Journal of Advanced Nursing, 57(4), 392-403.

Glasman, L. R., \& Albarracin, D. (2006). Forming attitudes that predict future behavior: A meta-analysis of the attitude-behavior relation. Psychological Bulletin, 132(5), 778. 
Grandey, A., Foo, S. C., Groth, M., \& Goodwin, R. E. (2012). Free to be you and me: a climate of authenticity alleviates burnout from emotional labor. Journal of Occupational Health Psychology, 17(1), 1-14.

Greenhaus, J. H., \& Allen, T. D. (2011). Work-family balance: A review and extension of the literature. In J. C. Quick \& L. E. Tetrick (Eds.), Handbook of Occupational Health Psychology $2^{\text {nd }}$ edition (pp. 165-183). Washington, DC, US: American Psychological Association.

Grojean, M. W., Resick, C. J., Dickson, M. W., \& Smith, D. B. (2004). Leaders, values, and organizational climate: Examining leadership strategies for establishing an organizational climate regarding ethics. Journal of Business Ethics, 55(3), 223241.

Hammer, L. B., Johnson, R. C., Crain, T. L., Bodner, T., Kossek, E. E., Davis, K. D., \& Berkman, L. (2016). Intervention effects on safety compliance and citizenship behaviors: Evidence from the work, family, and health study. Journal of Applied Psychology, 101(2), 190-208.

Hammer, L. B., Kossek, E. E., Yragui, N. L., Bodner, T. E., \& Hanson, G. C. (2009). Development and validation of a multidimensional measure of family supportive supervisor behaviors (FSSB). Journal of Management, 35(4), 837-856.

Hill, R. T., Matthews, R. A., \& Walsh, B. M. (2016). The emergence of family-specific support constructs: Cross-level effects of family-supportive supervision and family-supportive organization perceptions on individual outcomes. Stress and Health, 32(5), 472-484. 
Hobfoll, S. E. (1989). Conservation of resources: A new attempt at conceptualizing stress. American Psychologist, 44(3), 513-524.

Hobfoll, S. E. (2002). Social and psychological resources and adaptation. Review of General Psychology, 6(4), 307-324.

Hobfoll, S. E., \& Freedy, J. (1993). Conservation of resources: A general stress theory applied to burnout. In W. B. Schaufeli, C. Maslach, \& T. Marek (Eds.), Series in applied psychology: Social issues and questions. Professional burnout: Recent developments in theory and research (pp. 115-133). Philadelphia, PA, US: Taylor \& Francis.

Hobfoll, S. E., Halbesleben, J., Neveu, J. P., \& Westman, M. (2018). Conservation of resources in the organizational context: The reality of resources and their consequences. Annual Review of Organizational Psychology and Organizational Behavior, 5, 103-128.

Hofmann, D. A., Morgeson, F. P., \& Gerras, S. J. (2003). Climate as a moderator of the relationship between leader-member exchange and content specific citizenship: safety climate as an exemplar. Journal of Applied Psychology, 88(1), 170-178.

Huang, Y. H., Lee, J., McFadden, A. C., Rineer, J., \& Robertson, M. M. (2017). Individual employee's perceptions of “Group-level Safety Climate” (supervisor referenced) versus "Organization-level Safety Climate” (top management referenced): Associations with safety outcomes for lone workers. Accident Analysis \& Prevention, 98, 37-45. 
Huang, Y. H., Zohar, D., Robertson, M. M., Garabet, A., Lee, J., \& Murphy, L. A. (2013). Development and validation of safety climate scales for lone workers using truck drivers as exemplar. Transportation Research Part F: Traffic Psychology and Behaviour, 17, 5-19.

Kelloway, E. K., \& Barling, J. (2010). Leadership development as an intervention in occupational health psychology. Work \& Stress, 24(3), 260-279.

Kessler, R. C., Andrews, G., Colpe, L. J., Hiripi, E., Mroczek, D. K., Normand, S. L., ... \& Zaslavsky, A. M. (2002). Short screening scales to monitor population prevalences and trends in non-specific psychological distress. Psychological Medicine, 32(6), 959-976

Kessler, R.C., Barker, P.R., Colpe, L.J., Epstein, J.F., Gfroerer, J.C., Hiripi, E., Howes, M.J, Normand, S-L.T., Manderscheid, R.W., Walters, E.E., Zaslavsky, A.M. (2003). Screening for serious mental illness in the general population. Archives of General Psychiatry, 60(2), 184-189.

Kossek, E.E., Barber, A. E. \& Winters, D. (1999). Using flexible schedules in the managerial world: The power of peers. Human Resource Management, 38(1), 3346.

Kossek, E. E., Colquitt, J. A., \& Noe, R. A. (2001). Caregiving decisions, well-being, and performance: The effects of place and provider as a function of dependent type and work-family climates. Academy of Management Journal, 44(1), 29-44.

Kossek, E.E \& Michel, J.S. (2011). Flexible work schedules. American Psychological Association, Washington, D.C. 535-572 
Kossek, E. E., Petty, R. A., Bodner, T. E., Perrigino, M. B., Hammer, L. B., Yragui, N. L., \& Michel, J. S. (2018). Lasting Impression: Transformational Leadership and Family Supportive Supervision as Resources for Well-Being and Performance. Occupational Health Science. https://doi.org/10.1007/s41542-018-0012-x'.

Kossek, E. E., Petty, R. A., Michel, J. S., Bodner, T. E., Yragui, N. L., Perrigino, M. B., \& Hammer, L. B. (2017). Work-family subcultures: Workgroup multilevel influences on family supportive supervisor behaviors (FSSB) affecting individual sleep quality and safety performance. In Las Heras, M., Chinchilla, N., \& Grau, M. (Eds.) The work-family balance in light of globalization and technology (pp. 62-85). Cambridge, UK: Cambridge Scholars Publishing.

Kossek, E. E., Pichler, S., Bodner, T., \& Hammer, L. B. (2011). Workplace social support and work-family conflict: A meta-analysis clarifying the influence of general and work-family-specific supervisor and organizational support. Personnel Psychology, 64(2), 289-313.

Kossek, E. E., \& Thompson, R. J. (2016). Workplace flexibility: Integrating employer and employee perspectives to close the research-practice implementation gap. In Allen, T. D., \& Eby, L. T. (Eds.). The Oxford Handbook of Work and Family (pp. 255-270). New York, NY: Oxford University Press.

Kossek, E. E., Thompson, R. J., Lawson, K. M., Bodner, T., Perrigino, M. B., Hammer, L. B., \& Wipfli, B. (2019). Caring for the elderly at work and home: Can a randomized organizational intervention improve psychological health? Journal of Occupational Health Psychology. 
Le Blanc, P. M., Hox, J. J., Schaufeli, W. B., Taris, T. W., \& Peeters, M. C. (2007). Take care! The evaluation of a team-based burnout intervention program for oncology care providers. Journal of Applied Psychology, 92(1), 213-227.

Leiter, M. P., \& Maslach, C. (1988). The impact of interpersonal environment on burnout and organizational commitment. Journal of Organizational Behavior, 9(4), 297308.

Lyness, K. S., Gornick, J. C., Stone, P., \& Grotto, A. R. (2012). It's all about control: Worker control over schedule and hours in cross-national context. American Sociological Review, 77(6), 1023-1049.

MacKinnon, D. P., Fairchild, A. J., \& Fritz, M. S. (2007). Mediation analysis. Annual Review of Psychology, 58, 593-614.

Major, V. S., Klein, K. J., \& Ehrhart, M. G. (2002). Work time, work interference with family, and psychological distress. Journal of Applied Psychology, 87(3), 427436.

Maslach, C., \& Jackson, S. (1986). Maslach Burnout Inventory Manual (2nd ed.) Palo Alto, CA: Consulting Psychologists Press.

Maslach, C., Schaufeli, W. B., \& Leiter, M. P. (2001). Job burnout. Annual Review of Psychology, 52(1), 397-422.

McNall, L. A., Masuda, A. D., \& Nicklin, J. M. (2009). Flexible work arrangements, job satisfaction, and turnover intentions: The mediating role of work-to-family enrichment. The Journal of Psychology, 144(1), 61-81. 
Moen, P., Kaduk, A., Kossek, E. E., Hammer, L., Buxton, O. M., O’Donnell, E., \& Casper, L. (2015). Is work-family conflict a multilevel stressor linking job conditions to mental health? Evidence from the Work, Family and Health Network. In Work and Family in the New Economy (pp. 177-217). Emerald Group Publishing Limited.

Moen, P., Kelly, E.L., Tranby, E. \& Huang, Q. (2011). Changing work, changing health: Can real work-time flexibility promote health behaviors and well-being? Journal of Health and Social Behavior 52(4), 404-429.

Montano, D. E., \& Kasprzyk, D. (2015). Theory of reasoned action, theory of planned behavior, and the integrated behavioral model. Health behavior: Theory, Research and Practice, 95-124.

Mullen, J. \& Kelloway, E.K. 2011. Occupational health and safety leadership. In J. Campbell Quick L.E. Tetrick Handbook of Occupational Health Psychology, 2nd Edition. (pp. 357- 372). Washington, DC: American Psychological Association. Nahrgang, J. D., Morgeson, F. P., \& Hofmann, D. A. (2011). Safety at work: a metaanalytic investigation of the link between job demands, job resources, burnout, engagement, and safety outcomes. Journal of Applied Psychology, 96(1), 71-95.

Neal, A., \& Griffin, M. A. (2006). A study of the lagged relationships among safety climate, safety motivation, safety behavior, and accidents at the individual and group levels. Journal of Applied Psychology, 91(4), 946-953.

O’Neill, J. W., Harrison, M. M., Cleveland, J., Almeida, D., Stawski, R., \& Crouter, A. C. (2009). Work-family climate, organizational commitment, and turnover: 
Multilevel contagion effects of leaders. Journal of Vocational Behavior, 74(1), 18-29.

Perrigino, M. B., Dunford, B. B., \& Wilson, K. S. (2018). Work-Family Backlash: The "Dark Side" of Work-Life Balance (WLB) Policies. Academy of Management Annals, 12(2), 600-630.

Preacher, K. J., Zyphur, M. J., \& Zhang, Z. (2010). A general multilevel SEM framework for assessing multilevel mediation. Psychological Methods, 15(3), 209.

Rofcanin, Y., Las Heras, M., \& Bakker, A. B. (2017). Family supportive supervisor behaviors and organizational culture: Effects on work engagement and performance. Journal of Occupational Health Psychology, 22(2), 207-217.

Roy-Byrne P. P., Davidson, K. W., Kessler, R. C., Asmundson, G. J., Goodwin, R. D., Kubzansky, L., \& Stein, M. B. (2008). Anxiety disorders and comorbid medical illness. General Hospital Psychiatry, 30(3), 208-225.

Schneider B, ed. 1990. Organizational Climate and Culture. San Francisco: Jossey-Bass

Schneider, B., \& Reichers, A. E. (1983). On the etiology of climates. Personnel Psychology, 36(1), 19-39.

Schultz, P. W., Nolan, J. M., Cialdini, R. B., Goldstein, N. J., \& Griskevicius, V. (2007). The constructive, destructive, and reconstructive power of social norms. Psychological Science, 18(5), 429-434.

Shanafelt, T. D., Balch, C. M., Bechamps, G., Russell, T., Dyrbye, L., Satele, D., \& Freischlag, J. (2010). Burnout and medical errors among American surgeons. Annals of Surgery, 251(6), 995-1000. 
Shirom, A., \& Melamed, S. (2005). 39 Does burnout affect physical health? A review of the evidence. Research Companion to Organizational Health Psychology, 599695.

Siu, O. L., Lu, J. F., Brough, P., Lu, C. Q., Bakker, A. B., Kalliath, T., O’Driscoll, M., Phillips, D. R., Chen, W., Lo, D., Sit, C., \& Shi, K. (2010). Role resources and work-family enrichment: The role of work engagement. Journal of Vocational Behavior, 77(3), 470-480.

Straub, C. (2012). Antecedents and organizational consequences of family supportive supervisor behavior: A multilevel conceptual framework for research. Human Resource Management Review, 22(1), 15-26.

Thomas, L. T., \& Ganster, D. C. (1995). Impact of family-supportive work variables on work-family conflict and strain: A control perspective. Journal of Applied Psychology, 80(1), 6-15.

Thompson, C. A., Beauvais, L. L., \& Lyness, K. S. (1999). When work-family benefits are not enough: The influence of work-family culture on benefit utilization, organizational attachment, and work-family conflict. Journal of Vocational behavior, 54(3), 392-415.

Zohar, D. (1980). Safety climate in industrial organizations: theoretical and applied implications. Journal of Applied Psychology, 65(1), 96-102.

Zohar, D. (2002). The effects of leadership dimensions, safety climate, and assigned priorities on minor injuries in work groups. Journal of Organizational Behavior, 23(1), 75-92. 
Zohar, D. (2010). Thirty years of safety climate research: Reflections and future directions. Accident Analysis \& Prevention, 42(5), 1517-1522.

Zohar, D. (2014). Safety climate: Conceptualization, measurement, and improvement. The Oxford Handbook of Organizational Climate and Culture, 317-334.

Zohar, D., \& Luria, G. (2004). Climate as a social-cognitive construction of supervisory safety practices: scripts as proxy of behavior patterns. Journal of Applied Psychology, 89(2), 322-333.

Zohar, D., \& Luria, G. (2005). A multilevel model of safety climate: cross-level relationships between organization and group-level climates. Journal of Applied Psychology, 90(4), 616-628. 


\section{Chapter 5. Conclusion}

The over-arching aim of this three-study dissertation was to evaluate the role and interplay of work-family resources and employee stress and stressors as they relate to employee and family well-being. This body of work utilized three different methodological approaches with multiple sources of data to demonstrate the important effects of stress, workplace resources and important employee and spouse well-being outcomes. This dissertation has extended understanding of previous research in three overarching ways. Study 1 was the first to examine the role of a supportive supervisor training in promoting both employee and spouse reports of marital and parent-child relationship quality. Study 2 was the first to consider together the association of day-today employee work-family conflict (WFC) and family-supportive supervisor behaviors (FSSB) on both employees and spouses at within and between person-levels. Study 3 utilized a time-lagged design with a novel approach linking together theoretically relevant literatures, COR theory and climate research. Study 3 elucidated the role of supervisor views about work-place policy in shaping resource climates at the unit-level, as well as the effects of resource climates on employee long-term individual and job wellbeing. Together, this dissertation has highlighted that a supervisor work-family training improves family relationships, the effect of day-to-day employee work-family stressors and resources may help to explain important spillover and crossover processes by which work can impact family life, and that supervisor views and work-family resource climates have important implications for employee job and psychological well-being over time.

\section{Recurring Theory, Constructs and Conceptualizations}


Prior to revisiting the initial research questions, and summarizing the theoretical integration and practical contributions resulting from the above set of three studies, recurring theory, constructs, and conceptualizations that were utilized in the studies are reviewed here.

COR theory. Each of these three studies utilized conceptualizations from COR theory (Hobfoll, 1989). COR theory posits that resources are what drive behavior, stress and motivation, because individuals are motivated to seek, obtain, maintain, and protect resources. Resources can be objects, personal characteristics, conditions, or energies that are valued by the individual or that serve as a means for attainment of major goals or universal values such as family and well-being (Hobfoll, 1989). COR theory provides several principles and tenets that are useful for guiding research and practice. Specifically, Hobfoll (1989) posits that resource gains are less salient than resource loss, however, resource gain is more salient in the face of resource loss. In addition, resource gains can lead to gain spirals where individuals invest gained resources into obtaining additional resources, and resource loss can result in loss spirals because resource loss signals individuals to move to a defensive state to protect remaining resources when faced with resource loss, which subsequently prevents them from investing in and gaining new resources. Across the three studies well-being was considered an important outcome that is predicted by specific principles of COR theory. Additionally, consistent with COR theory (Hobfoll, 1989), stress and stressors were considered resource depleting and predictive of poor well-being outcomes, except under the case of higher workfamily-specific resources, which were considered important to promoting well-being. 
Well-being. The conceptualization of well-being is broad, and was likewise so in this dissertation. Specifically, there were 3 conceptualizations of well-being outcomes, which differed dependent on study. First, employee and spouse perceptions of spouse and parent-child relational well-being was considered as a well-being outcome. Indeed, one's family is often a primary source of support, and social relationships are key to health (Cohen, 2004). Further, marital quality has been linked lower blood pressure, stress, and depression (Holt-Lunstad, Brimingham, \& Jones, 2008), while parent-child relationship quality indicators (e.g. parental concern) are linked to both emotional and behavioral health of children (Ackard, et al., 2006). In Study 2, day-to-day affect was considered a primary and immediate indicator of well-being for both employees and spouses. Indeed, affect is associated with health both directly and indirectly, and is considered a subjective indicator of well-being (Diener \& Chan, 2011). In Study 3 the definition of well-being was conceptualized as individual and job psychological strain outcomes (job burnout and psychological distress) resulting from long-term chronic exposure to stress, specifically, job burnout and emotional distress (Kossek et al., 2019; Maslach, Schuefeli, \& Lieter, 2001). Together, these three conceptualizations of well-being paint a picture of the multitude of ways and domains in which work can impact employee and family wellbeing.

Stress and Stressors. Stress has a detrimental effect on individuals as evidenced by decades of research (Thoits, 2010). In this dissertation, the focus on stress was also important because it is considered resource depleting. Each study had separate, but related conceptualizations of employee stress that were considered to influence the above 
well-being outcomes. In Study 1, general employee stress was utilized to understand the conditions by which individuals and spouses would have improved family relationship quality following a supportive supervisor training. This conceptualization of stress was based on work suggesting that individuals who have higher stress are more sensitive to both positive and negative environmental changes, and respond disproportionately to both stressors and resources in the environment (Belsky \& Pluess, 2009). Principles of COR theory that suggests under conditions of high stress, resource gains would be more salient (Hobfoll, 1989). In Study 2, WTFC was conceptualized as a resource draining stressor, that would lead to day-to-day within person shifts in well-being for employees and spouses. This conceptualization was based on work suggesting work-life stress is an occupational health hazard (Hammer \& Sauter, 2013). Third and finally, stress in Study 3 was not measured, but was implied by the context of patient healthcare work. Patient healthcare workers are known to experience poor health and work outcomes associated with the cost of combined high stakes work demands such as high workload, long hours, few to no breaks, and extensive amounts of emotional labor.

Resources. This dissertation emphasized both work-family resources, as well as the role of supervisors as facilitators of work-family resources. This view of resources aligns them with the specific employee needs, and is consistent with Hobfoll's intent in presenting COR theory (1989). Specifically, resources should promote universally shared values such as family and well-being (Hobfoll, 1989; Hobfoll, Halbesleben, Neveu, \& Westman, 2018). Thus, my conceptualization of resources included those that are situated to promote well-being from a work-family perspective. Further, this dissertation 
considered supervisors central to dispersing and promoting resource gains that would improve well-being. In Study 1, the role of a supportive supervisor training that targeted meeting employee work-life needs was conceptualized as a work-family resource that supervisors would facilitate. In Study 2, the role of employee perceptions of day-to-day FSSB was assessed in terms of preventing poor well-being outcomes associated with dayto-day resource draining WFC. In study 3, the role of supervisor views about workfamily issues such as poor views of flexible work arrangement (FWA) were considered important for promoting a positive work-family resource climate that included unit-level perceptions of FSSB, and schedule control (SC), two resources that are often considered critical to meeting work-family needs.

\section{Research Questions and Answers}

In Chapter 1, specific research questions were posed in order to meet the aims of furthering understanding the impact of stressors and work-family resources on employee well-being, and by extension their family's well-being. The goal of this section is to review and answer the initial research questions based on findings from the above body of work.

\section{Research Question 1:}

Can a supportive supervisor training reach beyond a focal employee to their spouse and improve both employee and spousal reports of spousal and parent-child relationship quality? Further, in a test of COR theory, are resource gains in this situation more meaningful when employees are more highly resource depleted? 
Study 1 built on existing knowledge about the potential impact of supportive work-family supervisor training effects, as well as spillover and crossover effects of resources by examining the impact of the training on employee and spouse reports of spouse and parent-child relationship quality. This study drew on multiple time-point data (e.g., baseline, 3 month, and 9 month) two sources of data, employee and spouses. This study demonstrated that main effects of the training improved spouse reports of spouse relationship quality, but there were no other main effects on employee (spillover) and spouse (crossover) indicators of relationship well-being. However, the supportive supervisor training promoted more long-term spouse and parent-child relationship quality for employees (spillover) and spouses (crossover) when employees had higher stress. Thus, Study 1 lends support for COR theory's resource gain saliency principle, that is, resources are more salient when employees are more resource depleted.

\section{Research Question 2:}

Do daily employee reports of WFC impact both positive and negative affect among employees and their spouses, and can receiving FSSB on days with higher WFC counteract the negative effects of WFC on affective well-being for an employee and their spouse?

Whereas Study 1 demonstrated the long-term outcomes associated with improved work-family resources, Study 2 was developed to uncover potential underlying mechanisms that may lead to long-term changes in employee and spouse relationship quality resulting from work. Study 2 drew on a 32-day daily diary sample of participating employees and their matched spouses. Overall, Study 2 supported the link between daily 
within person effects of employee WFC and employee and spouse affect, between person wear-and-tear associations of WFC on employee and spouse affect, and the role of FSSB preventing against within person WFC associated declines in positive affect for employees. This study also highlighted some nuances in these micro-processes. Specifically, in terms of spouse affect, WFC was associated with positive affect declines as a within person phenomena, but negative affect as a between person wear-and-tear phenomena. Further, FSSB appeared to promote within employee positive affect, but did not prevent against increases in negative affect. Further, there were no between person effects of FSSB on employee affect, nor did FSSB crossover to promote spouse wellbeing.

Research Question 3:

Do supervisor views of workplace family policy and family policy usage play a role in shaping aggregate unit-level perceptions of work-family resources as reported by their employees? Further, can these aggregate unit-level perceptions of work-family resources predict individual level job outcomes and employee well-being?

Study 3 built on research and theory building by joining together three frameworks, COR theory (Hobfoll, 1989), climate frameworks and empirical evidence (Christian et al., 2009; Zohar, 2016), and research demonstrating work-family resources such as FSSB are important for employee well-being (Crain \& Stevens, 2018; Hammer et al., 2011). Study 3 drew on multi-level data (supervisor, aggregate employee unit-level, and individual employee), at multiple time points (baseline, 6-months, and 12-months). 
Study 3 demonstrated that supervisor views about flexible work arrangements are indirectly associated with employee well-being via with unit-level shared perceptions of FSSB. Further, aggregate unit-level work-family resources were unequivocally associated with declines in poor job well-being, while the unit resource of SC was also associated with declines in individual distress as well. Together, these findings suggest that supervisor views can shape unit-level resources, and unit-level resources are important for employee well-being.

\section{Integrating findings}

Together, this dissertation has generated several points for integrating knowledge about work-family resources, as well as the contexts and conditions in which they promote employee and family well-being. First, work-family resources are important for employee well-being across the three contexts presented in this dissertation. FSSB, as conceptualized by training, self-reports, and as a unit-level climate was consistently associated with improved outcomes for employees, particularly under the contexts of resource depletion including higher stress, higher WFC, and stressful job context. Second, all three studies add support for the body of literature suggesting supervisors ought to be targets of training strategies to promote employee well-being (Kelloway \& Mullen, 2010). This dissertation demonstrated that supervisors are linked to employee well-being by demonstrating effects on employee well-being following a supportive supervisor training, employee reports of FSSB, unit reports of FSSB, and finally supervisor's own views about flexible workplace arrangements. Third, this dissertation has demonstrated consistent support for spillover outcomes that are associated with 
resources and resource depleting stressors, including marital and parent-child relationship quality, day-to-day affective well-being, and long-term psychological distress. Finally, evidence from this dissertation suggests that the relationship between employee resources and spouse well-being may be more complex than the current set of studies accounted for. Specifically, an examination of direct crossover of resources suggests that resources do crossover to promote spouse relational well-being long-term, particularly under conditions of high employee stress. Further, employee work-family stressors crossover to drain spouses' positive affect on a daily within person level, but only impact spouse negative affect from a wear-and-tear perspective. Further, employee reports of workfamily resources do not appear to crossover and directly protect spouses from employee work-family stressors. Thus, although over time resources crossover to promote wellbeing, the underlying process remains to be uncovered, suggesting there are still exciting avenues for future research.

\section{Theoretical Integration and Implications}

A key criticism of the primary theoretical framework utilized in this dissertation (COR theory; Hobfoll, 1989) is that it is challenging to hypothesize against COR, and that virtually any factor or phenomena can be characterized by resources. Even Hobfoll et al., (2018) has been critical of the indiscriminate categorizing of resources across empirical works, and has maintained that researchers ought to utilize this resource-based framework in line with the way it was conceived, resources are those objects that promote well-being, family, work, and other universally valued resources. This dissertation took heed in those criticisms and thus narrowed the focus of resources to 
include those that should meet universal family needs (e.g., family supportive supervisor training, employee reports of FSSB, and SC), and thus be instrumental in improving employee well-being.

Additionally, unlike most other published research, specific tenets and principles of COR theory were examined. In utilizing COR in this way, these studies demonstrate that work-family resources serve as protective factors against stress related declines in well-being with a couple of important caveats. First, and perhaps most interestingly, FSSB does not appear to buffer against the negative effects of day-to-day WFC on employee negative affect. However, FSSB does protect against declines in employee positive affect. This finding suggests that resources may operate to promote well-being in more nuanced pathways then are proposed by COR theory. For instance, the literature suggests that there are different pathways in which positive and negative affect operate (Fredrickson, 2004). Thus, a potential explanation is that resources must be more powerful to reverse the harmful spillover effects of resource loss on negative affect (which has a narrowing effect on one's thought processes), but not positive affect, because positive affect may be more easily induced, and more resource malleable and impressionable. However, given that this was not tested explicitly, it remains an area ripe for future research.

Another caveat is that the gain saliency principle does not consistently predict crossover effects. Specifically, while Study 1 demonstrated support for the gain saliency principle with crossover effects, Study 2 demonstrated these effects are not necessarily observed on a micro-level. Together, findings from these studies demonstrated that while 
the long-term effects of the gain saliency principle map nicely on to crossover perspectives, they may not operate strongly enough via day-to-day crossover microprocesses in order to produce noticeable effects. It is therefore likely that resource gains must be perceived first-hand in order to serve as a protective factor. Thus, spouse resources may be better measured directly from spouse or objectively.

Perhaps most theoretically notably, this dissertation utilized combined conceptually consistent theory and frameworks to advance work-family research. COR theory, climate framework, and supporting work-family literature were theoretically combined in order to take a novel perspective and approach in understanding workfamily resources from a shared perspective. Specifically, COR theory emphasizes that resource value is in part determined by the universal value of the resource (Hobfoll et al., 2018), and the climate literature takes a shared perspective to assessing phenomena. Climate research suggests that unit-level (shared) variables are important for shaping employee outcomes (Christian, Bradley, Wallace, \& Burke, 2009; Nahrgang, Morgeson, \& Hoffman, 2010), and supports the notion that supervisors are important shapers of employee outcomes via climate (Zohar \& Luria, 2005). The work-family literature generally shares the perspective that supervisors are critical, because they can allocate important work-family resources to promote employee well-being (Hammer et al., 2011; Kossek et al., 2011). While these perspectives are well suited to be integrated, there is no known research unifying them. This dissertation shows that this framework is theoretically relevant to the work-family literature. Namely, supervisors indirectly influence employee well-being through their impact on unit-level work-family resources. 


\section{Practical Implications}

This dissertation has several practical implications. First, individuals should be mindful and considerate of the impact their work and work stressors can have not only on their own well-being, but their spouses' and children's as well. A host of research has demonstrated that work stress can spillover and impact employee behaviors at home (Repetti \& Wang, 2017). However, this dissertation suggests that work-family resources can promote long-term well-being for both employees and spouses in the face of resource loss, that resource climates can promote employee well-being and job outcomes, and that day-to-day work stress has direct associations with employee and spouse affect. Thus, if work represents an overly stressful context without providing the necessary resources to prevent against poor job, and day-to-day and long-term employee and spouse well-being outcomes, individuals may want to consider alternate avenues to replenish resources and promote more positive outcomes.

Work-family resources are also important for organizations to consider. Perhaps the most convincing reason for organizations to be concerned with work-family resources is the evidence that supervisor views and shared work-family resources are important for employee job outcomes. Specifically, as suggested by the results of Study 3, supervisors with poor views towards flexible work arrangements indirectly contribute to employee burnout through a shared unit sense of lower work-family resources (e.g., FSSB). Workfamily resources demonstrated (SC and FSSB) strong direct associations with lower levels of job burnout. These results represent practical value for organizations considering what is known about the association of job-burnout and poor work outcomes 
(e.g., turnover intentions, organizational commitment, job satisfaction; Lee \& Ashforth, 1996). Organizations should consider the many ways of increasing positive work-family resource climates by offering more schedule flexibility when possible, and ensuring that supervisors are as family supportive as possible.

Additionally, organizations ought to be concerned with the impact work-family resources have on employee and spouse outcomes that go beyond the job. Resources were consistently beneficial for well-being. For instance, resources in the form of supervisor training were associated with positive relationship quality for both employees and spouses, FSSB prevented against WFC associated declines in daily positive affect for employees, and SC as a unit-level resource was related to lower employee distress. Taken together, these "non-work" outcomes are likely to have an influence on employees in the workplace as well. Simply put, it would be surprising to find employees who are performing well, engaged with their work, and committed, if they were having relationship troubles with their spouse or were suffering from poor well-being. Considering that spouse resentment towards a focal employees work increases that employees turnover intentions (Ferguson, Carlson, Kacmar, \& Halbesleben, 2016), and well-being is associated with poor performance (Cropanzano \& Wright, 1999). To that end, employers would be wise to consider the interplay between these work and nonwork outcomes to have a more holistic understanding of the positive effects of resources and potential negative effects of workplace stressors.

\section{Sample Specific Implications}


Recently, scholars have called for more research on underserved populations, including veterans (Colella et al., 2017). Both Studies 1 and 2 drew upon a sample of veteran employees and their spouses. Veterans report facing a host of challenges as they re-integrate into the civilian work-force, including sustaining employment and social functioning (Sayer et al., 2010), and to the extent that these transitions are negative, veterans may be at increased risk for remarkably poor outcomes such as suicide (Castro \& Kintzle, 2018). Additionally, there are significant economic costs to society that can be associated with veteran unemployment (Ainspan, Orvis, \& Kelley, 2019). As such, research findings that support the link between improved resources and well-being among veteran populations serves significant practical value to society, organizations, and veterans. Study 3 utilized a sample of healthcare workers and demonstrated practical value of resources for reducing job burnout via work-family resources. Job burnout is considered universally detrimental, but is exceptionally prevalent in the healthcare workers and other industries with high emotional labor (Horschild, 1983). Burnout can spread and appears to be shared among healthcare workers in the same units (Bakker et al., 2005). The effects of burnout in healthcare work are particularly harsh. For instance, healthcare worker burnout is associated with both medical mistakes (Shanafelt et al, 2010), and poorer quality patient care (Le Blanc et al., 2007). As such, these findings are particularly important for healthcare organizations, healthcare professionals, and any society that relies on healthcare. Improving upon unit-level work-family resources may be one key way to stop high levels of burnout from occurring and thus potentially reducing such harmful effects. While the above sample specific implications are 
important and provide value to the respective populations and industries, they are not unique to them. Indeed, I utilized theory to guide the development of hypotheses, and although there are characteristics which make veterans and healthcare workers unique, the strong theoretical foundation of the present research suggest that the findings should generalize well to broader populations.

\section{Overall Limitations}

Study 1 included an examination of the role of supervisor training to promote important well-being outcomes of employees and spouses. Study 2 focused on a process by which such long-term outcomes may occur (i.e. through immediate micro-affective processes). However, these phenomena were not examined together. In light of the mixed findings and above avenues for theoretical development in terms of affect spillover and crossover, this limitation also represents a particularly interesting avenue for future research. Indeed, crossover research provides the potential mechanisms by which phenomena from one individual influence another individual (Westman, 2001), such as emotion contagion. Future research should attempt to understand these phenomena with process oriented dyadic analyses and the incorporation of longer-term outcomes. These analyses will help shed light on the mechanisms by which trainings can promote wellbeing among spouses over time.

This dissertation also considered supervisors as facilitators of resources. However, each study relied on this process from an implied perspective. Specifically, a supportive supervisor training, and individual and unit employee reports of FSSB were utilized to imply supportive supervisor behaviors. In Study 3 this gap was reduced by 
incorporating measures of supervisor views towards flexible work arrangements and workplace climate for family sacrifices. However, the limitations of Study 3, including unequal distances between supervisors and employees, prevented sufficient recovery from this limitation. Additionally, none of these studies incorporated objective supervisor behavior measures. Although strong theoretical work was utilized, the nature and design of the current studies could be elaborated upon in future research by utilizing objective measures that demonstrate the resource facilitation process.

\section{Conclusion}

Taken together this dissertation answers calls to utilize more methodologically advanced techniques to further our understanding of processes in the work-family literature (Kossek \& Lee, 2016), and adds a nuanced understanding of the relationship between supervisors, work-family resources, and employee and spouse well-being. This dissertation made several contributions to the work-family literature by extending knowledge on the implications of work-family resources in terms of trainings on important family relationship outcomes, day-to-day effects on employee and spouse wellbeing, and multi-level associations with individual well-being. Findings from this dissertation have further underscored the intricate links between the work and home domains, made several theoretical and practical contributions. Together these studies should inform researchers, practitioners, and organizations about the value of resources in promoting positive well-being for employees and their families. 


\section{References}

Ackard, D. M., Neumark-Sztainer, D., Story, M., \& Perry, C. (2006). Parent-child connectedness and behavioral and emotional health among adolescents. American Journal of Preventive Medicine, 30(1), 59-66

Amstad, F. T., Meier, L. L., Fasel, U., Elfering, A., \& Semmer, N. K. (2011). A metaanalysis of work-family conflict and various outcomes with a special emphasis on cross-domain versus matching-domain relations. Journal of Occupational Health Psychology, 16(2), $151-169$.

Ainspan, N. D., Orvis, K. A., \& Kelley, L. M. (2019). The military as a source for civilian workforce development. Workforce Readiness and the Future of Work, 92-110.

Belsky, J., \& Pluess, M. (2009). Beyond diathesis stress: differential susceptibility to environmental influences. Psychological Bulletin, 135(6), 885-908.

Crain T.L., Stevens S.C. (2018) Family-supportive supervisor behaviors: A review and recommendations for research and practice. Journal of Organizational Behavior Annual Review, 39, 869-888.

Cropanzano, R., \& Wright, T. A. (1999). A 5-year study of change in the relationship between well-being and job performance. Consulting psychology journal: Practice and Research, 51(4), 252-265.

Fenner, G. H., \& Renn, R. W. (2010). Technology-assisted supplemental work and workto-family conflict: The role of instrumentality beliefs, organizational expectations and time management. Human Relations, 63(1), 63-82. 
Ferguson, M., Carlson, D., Boswell, W., Whitten, D., Butts, M. M., \& Kacmar, K. M. (2016). Tethered to work: A family systems approach linking mobile device use to turnover intentions. Journal of Applied Psychology, 101(4), 520-534.

Ferguson, M., Carlson, D., Kacmar, K. M., \& Halbesleben, J. R. (2016). The supportive spouse at work: Does being work-linked help? Journal of Occupational Health Psychology, 21(1), 37-51.

Hammer, L. B., Kossek, E. E., Anger, W. K., Bodner, T., \& Zimmerman, K. L. (2011). Clarifying work-family intervention processes: The roles of work-family conflict and family-supportive supervisor behaviors. Journal of Applied Psychology, 96(1), 134-150.

Hammer, L. B., \& Sauter, S. (2013). Total worker health and work-life stress. Journal of Occupational and Environmental Medicine, 55, S25-S29.

Hobfoll, S. E. (1989). Conservation of resources: A new attempt at conceptualizing stress. American Psychologist, 44(3), 513-524.

Kossek, E. E., \& Lee, K. (2017). Work-family conflict and work-life conflict. Oxford Research Encyclopedia of Business and Management. http://oxfordre.com/business/view/10.1093/acrefore/9780190224851.001.0001/ac refore-9780190224851-e-52

Kossek, E. E., Petty, R. A., Bodner, T. E., Perrigino, M. B., Hammer, L. B., Yragui, N. L., \& Michel, J. S. (2018). Lasting Impression: Transformational Leadership and Family Supportive Supervision as Resources for Well-Being and Performance. Occupational Health Science. https://doi.org/10.1007/s41542-018-0012-x’. 
Kossek, E. E., Petty, R. A., Michel, J. S., Bodner, T. E., Yragui, N. L., Perrigino, M. B., \& Hammer, L. B. (2017). Work-family subcultures: Workgroup multilevel influences on family supportive supervisor behaviors (FSSB) affecting individual sleep quality and safety performance. In Las Heras, M., Chinchilla, N., \& Grau, M. (Eds.) The work-family balance in light of globalization and technology (pp. 62-85). Cambridge, UK: Cambridge Scholars Publishing.

Lawson, K. M., Davis, K. D., McHale, S. M., Almeida, D. M., Kelly, E. L., \& King, R. B. (2016). Effects of workplace intervention on affective well-being in employees' children. Developmental Psychology, 52(5), 772-777.

Lee, R. T., \& Ashforth, B. E. (1996). A meta-analytic examination of the correlates of the three dimensions of job burnout. Journal of Applied Psychology, 81(2), 123-133.

McHale, S. M., Lawson, K. M., Davis, K. D., Casper, L., Kelly, E. L., \& Buxton, O. (2015). Effects of a workplace intervention on sleep in employees' children. Journal of Adolescent Health, 56(6), 672-677.

Repetti, R., \& Wang, S. W. (2017). Effects of job stress on family relationships. Current Opinion in Psychology, 13, 15-18.

Sayer, N. A., Noorbaloochi, S., Frazier, P., Carlson, K., Gravely, A., \& Murdoch, M. (2010). Reintegration problems and treatment interests among Iraq and Afghanistan combat veterans receiving VA medical care. Psychiatric Services, 61(6), 589-597. 
van Steenbergen, E. F., Kluwer, E. S., \& Karney, B. R. (2014). Work-family enrichment, work-family conflict, and marital satisfaction: A dyadic analysis. Journal of Occupational Health Psychology, 19(2), 182-194.

Westman, M. (2001). Stress and strain crossover. Human Relations, 54(6), 717-751. 
Appendix

\section{Measures}

Some scales may have been reverse coded for specific studies in this dissertation. Please refer to the measures sections of each paper for the specific coding used.

\section{Study 1}

Perceived Stress Scale - Employees. Higher scores indicate higher perceived stress.

Items:

1. In the last month, how often have you felt that you were unable to control the important things in your life?

2. In the last month, how often have you felt confident about your ability to handle your personal problem? (Reverse Coded)

3. In the last month, how often have you felt that things were going your way? (Reverse Coded)

4. In the last month, how often have you felt difficulties were piling up so high that you could not overcome them?

Responses:

$1=$ Never, 2 = Almost never, $3=$ Sometimes, $4=$ Fairly often, $5=$ Very often

Dyadic Adjustment - Employees and Spouses, higher scores indicate higher dyadic adjustment

Items: 
Most people have disagreements in their relationships. Please rate the extent of agreement or disagreement between you and your spouse/partner based on the scale below.

1. Philosophy of life

2. Aims, goals, and things believed important

3. Amount of time spent together

\section{Responses:}

$1=$ Always disagree 2 = Almost always disagree, $3=$ Frequently disagree, $4=$ Occasionally disagree, $5=$ Almost always agree, $6=$ Always agree

How often would you say the following events occur between you and your spouse/partner?

4. Have a stimulating exchange of ideas

5. Calmly discuss something together

6. Work together on a project

\section{Responses:}

$1=$ Never, $2=$ Less than once a month, $3=$ Once or twice a month, $4=$ Once or twice a week, 5 = Once a day, $6=$ More often

7. Please select the place on the scale that best describes the degree of happiness, all things considered, of your relationship.

\section{Responses:}

0 = Extremely unhappy, 1 = Fairly unhappy, 2 = A little unhappy, $3=$ Happy, $4=$ Very happy, $5=$ Extremely happy, $6=$ Perfect 
Positive Parenting - Employee and Spouse. Higher scores indicate higher levels of positive parenting.

Items:

1. You let your child know when he/she is doing a good job with something.

2. You compliment your child after he/she has done something well.

3. You praise your child if he/she behaves well.

Responses:

$1=$ Never, $2=$ Almost never, $3=$ Sometimes, $4=$ Often, $5=$ Always

\section{$\underline{\text { Study } 2}$}

Daily Work-to-Family Conflict - Employees. Higher scores indicate more work-tofamily conflict in the past 24 hours.

1. The demands of my work interfered with my family or personal time

2. The amount of time my job took up made it difficult to fulfill my family responsibilities

3. Things I wanted to do at home did not get done because of the demands my job put on me

4. My job produced strain that made it difficult to fulfill family duties

5. Due to my work-related duties, I had to make changes to my plans for family activities

\section{Responses:}

1 =Strongly Disagree, 2 = Disagree, $3=$ Neither Agree nor Disagree, $4=$ Agree, 5 $=$ Strongly Agree 
Daily Family Supportive Supervisor Behaviors - Employees. Higher scores indicate higher perceptions of family supportive supervisor behaviors in the past 24 hours.

1. Made me feel comfortable talking to him/her about conflicts between work and non-work

2. Worked effectively with employees to creatively solve conflicts between work and non-work

3. Demonstrated effective behaviors in how to juggle work and non-work issues

4. Organized the work in my department or unit to jointly benefit employees and the company

Responses:

$1=$ Strongly disagree, $2=$ Disagree, $3=$ Neutral, $4=$ Agree, $5=$ Strongly Agree

Positive and Negative Affect. Employees and spouses. Higher scores on each subscale are reflective of higher positive and negative affect respectively, right now.

1. Happy

2. Relaxed

3. Focused

4. Active

5. Grateful

6. Sad

7. Angry

8. Lonely

9. Ashamed 
10. Guilty

11. Nervous

Responses:

$1=$ Not at all, $2=$ Slightly, $3=$ Moderately, 4 = Very much, 5 = Extremely.

\section{$\underline{\text { Study } 3}$}

Workplace Climate for Family Sacrifice. Supervisor. Higher scores indicate

supervisors have a lower perception of a workplace climate for family sacrifices.

Items:

1. In your workplace, employees are expected to take time away from their family or personal lives to get their work done

2. In your workplace, employees are expected to put their families or personal lives second to their jobs

3. In your workplace, employees are expected to make work their top priority.

Responses:

$1=$ Strongly agree, 2 = Agree, $3=$ Neither, $4=$ Disagree, $5=$ Strongly Disagree .

Flexible Work Arrangements (FWA) - Supervisors. Higher FWA indicates more

negative views of FWA.

Items:

You worry that allowing more flexibility around hours would....

1. ...increase your workload

2. ...create problems among your subordinates

3. ...cause staffing headaches 
4. ....increase your costs

5. ...make it more difficult for your employees to reach their objectives

6. If you allow my subordinates to use flexible work schedules, you would be understaffed

\section{Responses:}

$5=$ Strongly Agree, 4 = Agree, $3=$ Neither agree nor disagree, $2=$ Disagree, $1=$ Strongly Disagree

Family Supportive Supervisor Behaviors - Employees, aggregated to unit. Higher scores indicate more FSSB

Items:

1. Your supervisor makes you feel comfortable talking to him/her about my conflicts between work and non-work.

2. Your supervisor works effectively with employees to creatively solve conflicts between work and non-work.

3. Your supervisor demonstrates effective behaviors in how to juggle work and non-work issues.

4. Your supervisor organizes the work in your department or unit to jointly benefit employees and the company.

Responses:

$5=$ Strongly agree, $4=$ Agree, $3=$ Niether, $2=$ Disagree, $1=$ Strongly disagree Schedule Control - Employees, aggregated to unit. Higher scores indicate more schedule control 
Items:

1. How much choice do you have over when you take vacations or days off?

2. How much choice do you have over when you can take off a few hours?

3. How much choice do you have over when you begin and end each work day?

4. How much choice do you have over the total number of hours you work each week?

5. How much choice do you have over doing some of your work at home or at another location, instead of [insert company name/location]?

6. How much choice do you have over the number of personal phone calls you make or receive while you work?

7. How much choice do you have over the amount or times you take work home with you?

8. How much choice do you have over shifting to a part-time schedule (or fulltime if currently part-time) while remaining in your current position if you wanted to do so?

Responses:

$1=$ Very little, $2=$ Little, $3=$ A moderate amount, $4=$ Much, $5=$ Very much.

Job Burnout - Employee. Higher scores indicate more burnout.

Items:

1. You feel emotionally drained from your work. How often do you feel this way?

2. You feel burned out by your work. How often do you feel this way? 
3. You feel used up at the end of the workday. How often do you feel this way?

Responses:

$1=$ Never, $2=$ A few times a year or less, $3=$ Once a month or less, $4=\mathrm{A}$ few times a month, $5=$ Once a week, $6=$ A few times a week, $7=$ Every day.

Emotional Distress - Employee. Higher scores indicate more distress.

Items:

1. During the past 30 days, how much of the time did you feel so sad nothing could cheer you up? Was it all of the time, most of the time, some of the time, a little of the time, or none of the time?

2. During the past 30 days, how much of the time did you feel nervous? (Was it all of the time, most of the time, some of the time, a little of the time, or none of the time?)

3. During the past 30 days, how much of the time did you feel restless or fidgety? (Was it all of the time, most of the time, some of the time, a little of the time, or none of the time?)

4. During the past 30 days, how much of the time did you feel hopeless? (Was it all of the time, most of the time, some of the time, a little of the time, or none of the time?)

5. During the past 30 days, how much of the time did you feel that everything was an effort? (Was it all of the time, most of the time, some of the time, a little of the time, or none of the time?) 
6. During the past 30 days, how much of the time did you feel worthless? (Was it all of the time, most of the time, some of the time, a little of the time, or none of the time?)

Responses:

$1=$ None of the time, $2=$ A little of the time, $3=$ Some of the time, $4=$ Most of the time, $5=$ All of the time 